\title{
Is a spatial investigation possible without long-distance refit/conjoin? Application to the MIS 11 lithic assemblage of levels E and J from La Cansaladeta site (Tarragona, Spain)
}

\author{
Görkem Cenk Yeşilova ${ }^{1,2}\left(\mathbb{D} \cdot\right.$ Andreu Ollé $^{1,2}$ (D) Josep Maria Vergès ${ }^{1,2}(\mathbb{D}$
}

Received: 23 March 2021 / Accepted: 21 June 2021 / Published online: 2 September 2021

(c) The Author(s) 2021

\begin{abstract}
In this manuscript, we present the first systematic refitting results of the small-scale Middle Pleistocene (MIS11) rock shelter site of La Cansaladeta. The lithic materials that have been recovered from the archaeological levels $\mathrm{E}$ and $\mathrm{J}$ were the main study materials. These levels were investigated regarding spatial pattern analysis and analyzed with auxiliary methods such as quantitative density mapping demonstration and technological analysis of the lithic clusters. Thus, the spatial patterns of the two levels were compared and discussed, in terms of connections, clusters, and movement of the lithic elements. Undoubtedly, the well preservation of the archaeological levels offered a great opportunity for the interpretation of the spatial patterns in a high-resolution perspective. La Cansaladeta has not been paid attention adequately so far may be due to the small dimension of the excavation surface or to the scarcity of faunal record. Our results show that small-scale sites without long-distance refit/ conjoin connections can provide significant spatial information. Indeed, if the sites have very well-preserved archaeological levels, the absence of long connections can be supported by the auxiliary methods.
\end{abstract}

Keywords Refit $\cdot$ Lithic technology $\cdot$ Conjoin $\cdot$ Spatial analysis $\cdot$ Middle Pleistocene $\cdot$ La Cansaladeta

\section{Introduction}

Lithic industry can be studied with variable methods for the different goals. However, in terms of the technology and spatial analysis, the most common and effective one is refitting. If two pieces belong to each other, undoubtedly, this means they fit. This is the reason why refitting is a very precise method. Refitting is a three-dimensional riddle without guide and has a very long background in the lithic studies (Ashton 2004; Cooper and Qiu 2006; Laughlin and Kelly 2010; Smith 1894, p. 126;

Görkem Cenk Yeşilova

gorkemyesilova90@gmail.com

Andreu Ollé

aolle@iphes.cat

Josep Maria Vergès

jmverges@iphes.cat

1 Institut Català de Paleoecologia Humana i Evolució Social (IPHES-CERCA), Zona educacional 4 (Edifici W3), Campus Sescelades URV, 43007 Tarragona, Spain

2 Universitat Rovira i Virgili, Dept. d'Història i Història de l'Art, Av. Catalunya 35, 43002 Tarragona, Spain
Spurrell 1880). Even though refitting has been used frequently during the 1970s, it was recognized as a systematic method for both technology and spatial activity by "The Big Puzzle International Symposium on Refitting Stone Artifacts" (Cziesla et al. 1990; Schurmans 2007). Especially, this method has been mainly used to identify the technological concept of lithic industry (Larson and Ingbar 1992). Additionally, the using of refitting has been realized in Hofman and Enloe (1992) for the faunal records as a different approach regarding the food sharing and carcass transportation and this has been confirmed by the other researchers (Enloe 2010; Enloe and David 1992; Marean and Kim 1998; O'Brien 2015; Rosell et al. 2019; Vaquero et al. 2017; Waguespack, 2002). Refitting is a very effective approach to identify the intra-site activities and the social organizations of the pre-historic human groups. The importance of refitting analysis has already been tested, in terms of archaeostratigraphy and the site formation studies, as it provides crucial information about the integrity of an assemblage, the types and degree of post-depositional processes affecting it, and in the end, its temporal resolution (Ashton 2004; Bargalló et al. 2016; Deschamps and Zilhão 2018; Hofman 1986; Villa 1982). Undoubtedly, in terms of the social organization of the Paleolithic human groups, spatial interrogation with refitting 

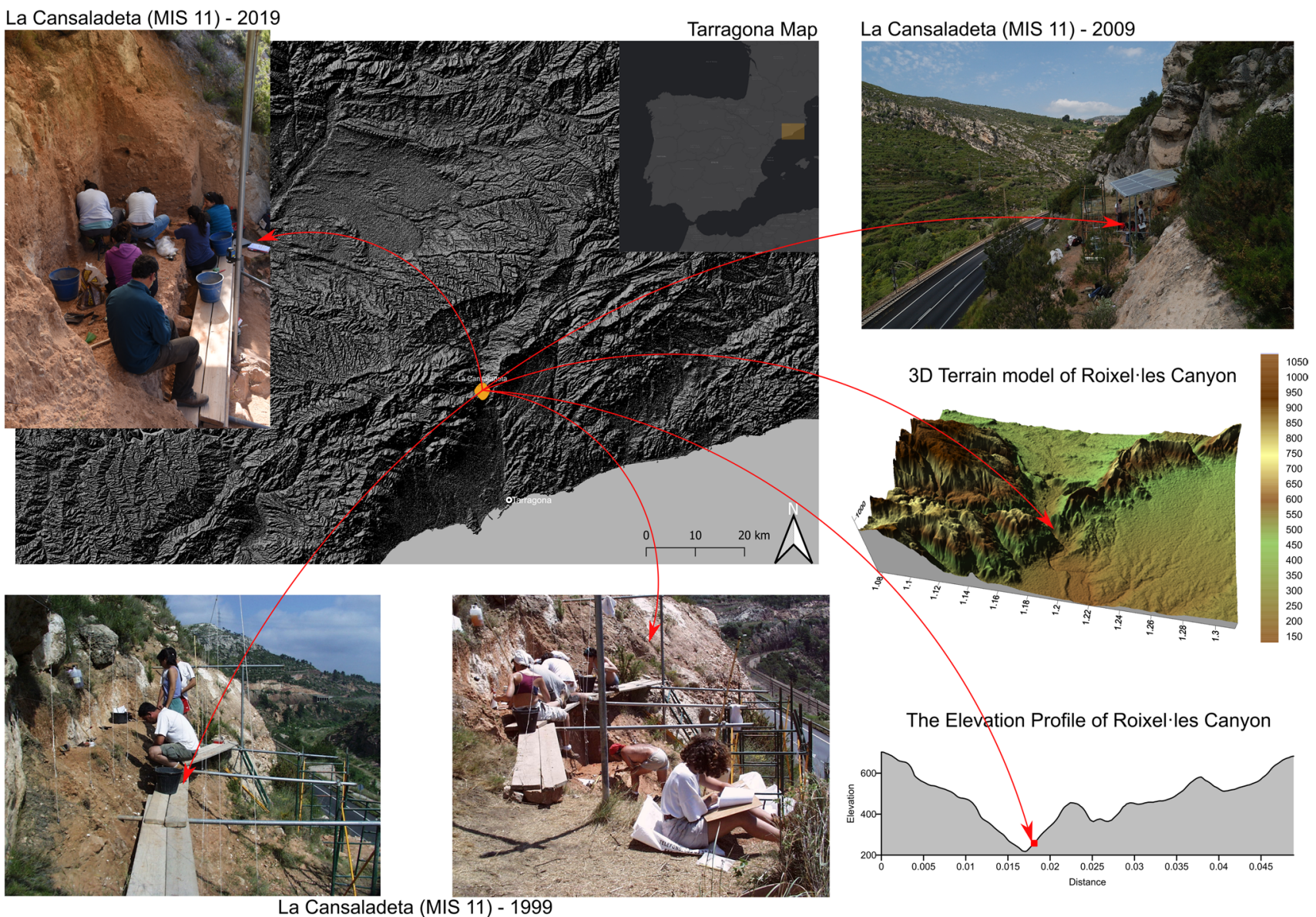

Fig. 1 Tarragona map, pictures of the La Cansaladeta, 3D terrain model of Roixel·les Canyon, elevation of canyon, and the altitude of the La Cansaladeta

method has been applied to several sites, being the most famous some Magdalenian settlements as the well-known sites in the Paris basin such as Verberie (Audouze 1988; Audouze and Enloe 1997; Audouze et al. 1981), Pincevent (Karlin and Julien 2019; Leroi-Gourhan and Brézillon 1966), and Étiolles (CaronLaviolette et al. 2018; Olive 1988; Olive et al. 2019; Pigeot 1987). According to the perception of spatial analysts and refitters, this method and high-resolution sites have always been thought they complete each other. However, this perception has already started to be broken and evolved into the different ways. Several studies have demonstrated how refitting and quantitative methods can elucidate early periods of the Pleistocene in terms of both technological, intra-site, and density analyses. For instance, the refitting study investigation at Gran Dolina TD10.1 was supported with different statistical methods (López-Ortega et al. 2011, 2017, 2019); Omo Kibish has been studied regarding lithic density, refitting, and site formation (Sisk and Shea 2008); the Acheulean site of Boxgrove is shown to have very large in situ flaking debris and represents very intense refitting results (Bergman and Roberts 1988; Pope and Roberts 2005; Pope et al. 2020; Roberts and Parfitt 1999); the Late Acheulean site of Mieso has shown clusters even though they represented low density (de la Torre et al. 2014); and the spatial analysis of Gesher Benot Ya'aqov was reinforced with density analysis and thermoluminescence method for the hearth-related flint samples (Alperson-Afil et al. 2009, 2017).

The archaeological sites with a large dimension and high refit success have always been more attractive to design a logic and acceptable scenario or more realistic interpretations concerning a living area of the human groups (Clark 2017). The long-distance connection is a great indicator in terms of the selection of the specific areas in the settlement (Bodu 1996; Close 2000; Karlin and Julien 2019). However, the long-distance refit or conjoin connections are limited in the small-scale sites. So, this issue makes the small excavations less attractive than larger ones. For an instance if the case area comprised a $5 \mathrm{~m} \times 3 \mathrm{~m}$ space, this would create a problem about the interpretation of the lithic scatters, because the results of the experimental analysis have shown that small debris can scatter $4 \mathrm{~m}$ away from the flaking area (Kvamme 1997; Newcomer and Sieveking 1980), probably scattering distance, and the dimension of the excavation 
Fig. 2 Stratigraphy of the La Cansaladeta (Ollé et al. 2016)

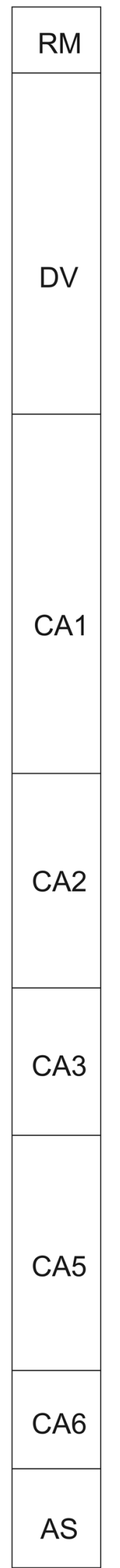

CLSG
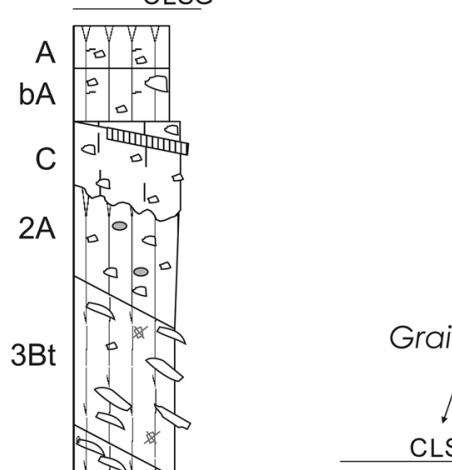

$\mathrm{Ck}$

$\mathrm{Ckm}$
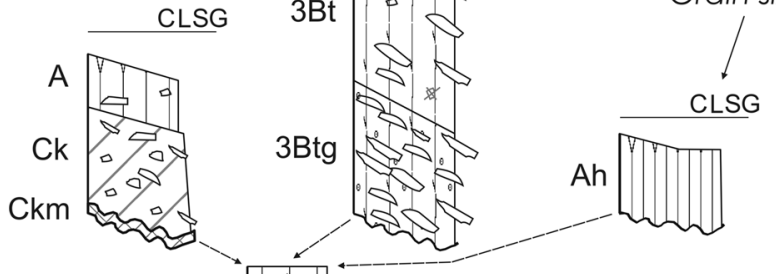

in size

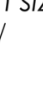

\section{.}

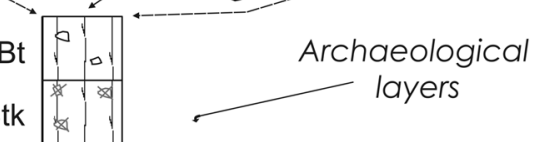

Btk

A

$\mathrm{Btc}$

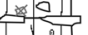

$A$

B

$4 \mathrm{Btk}_{1} \gg \mathrm{B}$

$4 \mathrm{Btk}_{2}$

C

D

$4 \mathrm{Bt}_{2}$

$\mathrm{Bt}_{2}$

$\mathrm{BC}$

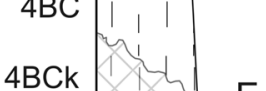

- $372 \pm 34 \mathrm{ka}(\mathrm{TL})$

- $380 \pm 30$ ka (TT-OSL)

$4 \mathrm{BCk}+\mathrm{E}$

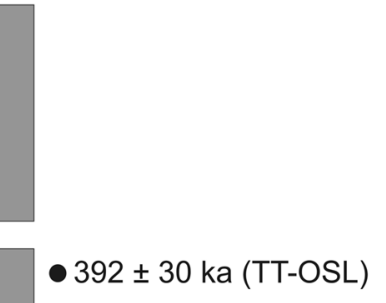

$4 \mathrm{BC}_{2}$

12

$\begin{array}{lll}1 & 1 \\ 1 & 1\end{array}$

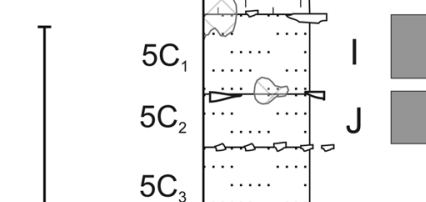

$392 \pm 30 \mathrm{ka}(\mathrm{TT}-\mathrm{OSL})$

$\bullet 393+34$ / -33 ka (ESR-Us)

$5 \mathrm{C}_{3}$

$\varepsilon$
$\check{8}$
$\overleftarrow{\delta}$

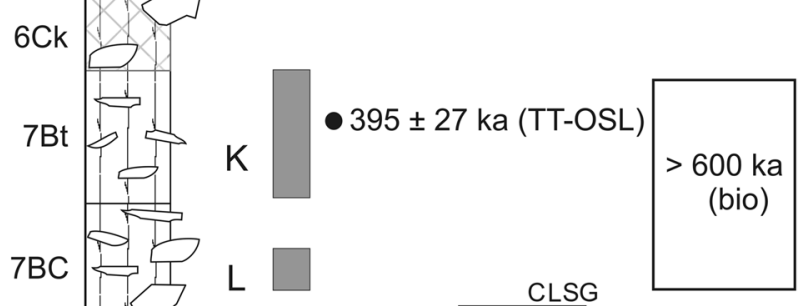

$\mathrm{R}$ 年

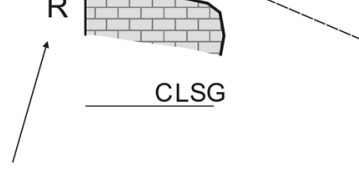

il horizons 
Table 1 Raw materials and technological categories of the level $\mathrm{E}$

\begin{tabular}{|c|c|c|c|c|c|c|c|c|c|c|c|c|c|c|c|}
\hline \multirow[t]{2}{*}{ Raw material } & \multicolumn{4}{|c|}{ Natural bases } & \multicolumn{3}{|l|}{ Cores } & \multicolumn{5}{|l|}{ Products } & \multirow[t]{2}{*}{ Indeterminate } & \multicolumn{2}{|c|}{ Grand total } \\
\hline & $\mathrm{nBa}$ & $\mathrm{nBb}$ & $\mathrm{nBc}$ & $\mathrm{nBd}$ & 1GNBE & 2GNBE & F1GNB & $2 \mathrm{GNBC}$ & PB & Frag. of PB & FPB & Fragment & & & \\
\hline Agate & & & & 1 & & & & & & & & 1 & & 2 & $0 \%$ \\
\hline Schist & 5 & 1 & 1 & 1 & 6 & & & & 67 & 38 & 17 & 26 & 116 & 278 & $17 \%$ \\
\hline Limestone & 2 & & 1 & & & & & & 2 & & & & & 5 & $0 \%$ \\
\hline Quartz & & & 1 & & 4 & 1 & & & 32 & 42 & 24 & 34 & 5 & 143 & $9 \%$ \\
\hline Quartzite & & 2 & & & 3 & 1 & & & 25 & 18 & 12 & 10 & & 71 & $4 \%$ \\
\hline Chert & & & & & 5 & 6 & 4 & 24 & 460 & 428 & 112 & 118 & 19 & 1176 & $70 \%$ \\
\hline Grand total & 7 & 3 & 3 & 2 & 18 & 8 & 4 & 24 & 586 & 526 & 165 & 189 & 140 & 1675 & $100 \%$ \\
\hline & $0 \%$ & $0 \%$ & $0 \%$ & $0 \%$ & $1 \%$ & $0 \%$ & $0 \%$ & $1 \%$ & $35 \%$ & $31 \%$ & $10 \%$ & $11 \%$ & $8 \%$ & $100 \%$ & \\
\hline
\end{tabular}

Equivalency of logic analytic system and universal lithic terminology: without any marks (nBa); with percussion marks (nBb); with fractures, $>75 \%(\mathrm{nBc})$; fragment, $<25 \%(\mathrm{nBd})$; core fragment (F1GNB); cores on block/cobble (1GNBE); cores on flake (2GNBE); retouched tool on cobble (1GNBC); retouched tool on flake (2GNBC); whole flakes (PB); Frag. of PB (flake fragment); FPB (broken flake); fragment (angular fragments)

would be indistinguishable, in terms of the interpretation. Moreover, these scatters also can be the result of displacements which are related to the other unintentional activities such as foot traffic and trampling (Clark 2017, p. 1307; Villa and Courtin 1983). According to the experiments by Nielsen (1991), there were two distributional areas which were related to the height of the ceiling regarding the trampling. In addition, Theunissen et al. (1998) have made more detailed analysis for Petzkes Cave (New South Wales, Australia) and the results of the experiments have shown that larger lithic elements have moved longer distance than smaller ones. Another example is the children activity in the site. Sometimes, large lithic elements can be very attractive for the children (Hammond and Hammond 1981; Langley 2020). Maybe those pieces moved to another place from their original location due to this. This has been defined by Stevenson (1991) as one of the unintentional size sorting processes. Concerning the intentional activity, tossing and dumping (Binford 1978, pp. 345-346) are two major phenomena which are relevant to ethnographic observations or cleaning activity area-secondary refuse disposal (O'Connell et al. 1991, pp. 66-67; Schiffer 1972; Wilson 1994). Animal trampling is also one of the other examples of unintentional activity (Schoville 2019).

So, applying the refitting to the small excavations would be very difficult regarding the creation of a scenario about the activities in the settlement due to the reasons that we mentioned above. However, what if the site has very wellpreserved archaeological levels with a well-clustered lithic assemblage; would results have interpretation problems? The answer to this question depends on some variability. First is the location of the clusters. In other words, where does the assemblage concentrate? If the case area is a cave or rock shelter, probably significant dense areas will be the rear sides, the places very close to the wall, and around the hearth when existing (Fernández-Laso et al. 2020).

Second, the technological categories of the clusters are good indicators regarding the kind of activity carried out in each area. The flake and flake fragment concentration can give very important clues. If the dimension and the cortex analyses of the flakes demonstrate progressively increasing values, this will be one of the proves in terms of the flaking area (Bradbury and Carr 1995; Dibble et al. 2005; Mauldin and Amick 1989; Vaquero 2008). Sometimes the ratio of the entirely cortical flake can be higher than noncortical dominant and noncortical flakes in a cluster while the other clusters can indicate an opposite view. This can be related to the flaking phase carried out in different areas. Cortex removals and production phases might have been done in the different place of the settlement (Roebroeks 1988, pp. 45-46). Technological analyses can help to obtain very effective results concerning the description of the clusters. Especially, if there are more clusters than one, this approach allows us for the comparative analyses between lithic accumulations. Moreover, similar values of the results can be used for the interpretation of the contemporaneity issues between two clusters; however, this contemporaneity phenomenon among the clusters needs a solid evidence such as physical refit or conjoin connections (Vaquero et al. 2012, p. 195).

Third, refitting is the most important method to analyze the clusters in the settlements. The connection lines between two refitted pieces are an exact physical proof of the relation among the clusters. Unidirectional and the bidirectional movements of the connection lines can provide very effective results for the interpretation of temporal issues of the clusters (Bodu 1996; Vaquero 2011). According to Vaquero et al. (2019), the hypothesis of contemporaneity between two areas can be explained by bidirectional movement of the connection lines. In addition, this issue has also been 


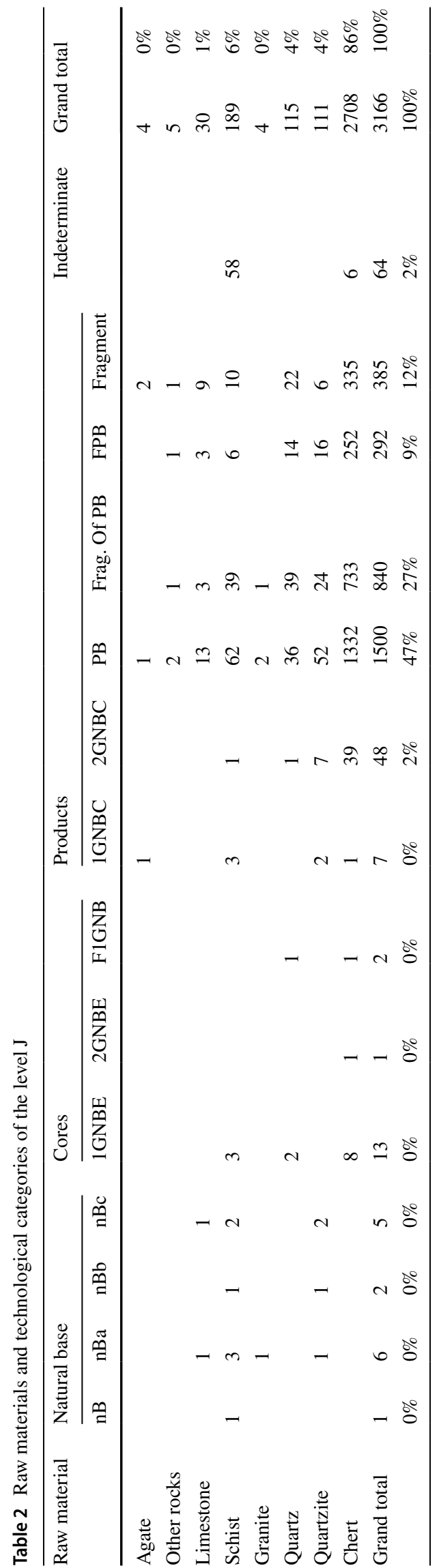

confirmed by Karlin and Julien (2019, p. 4439) for Pincevent, level IV20. This contemporaneity scenario or hypothesis can be explained, for example if there were two hotspots (Ex1-Ex2) that were documented in a Pleistocene site and two core-flake connection sets (set 1-set 2) were analyzed in those clusters. The flakes of set 1 were in Ex1 while the core was in Ex2, and the core of the set 2 was in Ex1 while the flakes were in Ex2. This is a kind of mutual lithic element transfers between clusters. Even though the unidirectional movements cannot provide strong evidence among two areas regarding their contemporaneity, this issue can be supported by the technological analysis of the clusters as we explained above. If the technological similarities can be observed in the areas, this can be used as an auxiliary indication to reinforce the contemporaneity hypothesis. In addition, bone connections are very suitable between the clusters and different activity areas although it is really hard to find the sites that have lithic and bone refits at the same time (O'Brien 2015; Rapson and Todd 1992; Romagnoli and Vaquero 2019; Vaquero et al. 2017). Orientations of the connection lines are one of the other factors, which can help for the relation of the connections between the accumulations. The preferential trends of the connection lines can help for the interpretation of the related clusters. However, the distances of the connection lines play an important role in this analysis (Vaquero et al. 2017). The longer distances of the connections should be considered more than small connections. The connected elements with a short distance can be misleading and related to any kind of different unintentional activities or minimal post-depositional disturbance (LópezOrtega et al. 2019).

Our study focuses on the spatial analysis of levels E and $\mathrm{J}$ with the refitting method. Obtained results from two levels showed very interesting spatial patterns and type of connections between refitted pieces. These results will play a very significant role to explain and interpret the technological and spatial differences among those levels. In this manuscript, we exhibit not only the results, but also, we reinforce the small dimension of La Cansaladeta with different methods: technological, refitting, and cluster-density analyses with quantitative auxiliary demonstration techniques. Our goal here is not to draw a clear picture showing the daily living scenario of the human groups of La Cansaladeta. We are aware that the site has still unexcavated parts very close to the hotspots. In addition, the scarcity of the faunal remains is one of the negative issues of La Cansaladeta to support our spatial data. However, we propose that even smallscale, well-preserved Middle Pleistocene sites can be suitable regarding the spatial approach, if the distribution of the assemblage and their technological analyses can be done and the refitting study can be applied systematically. 


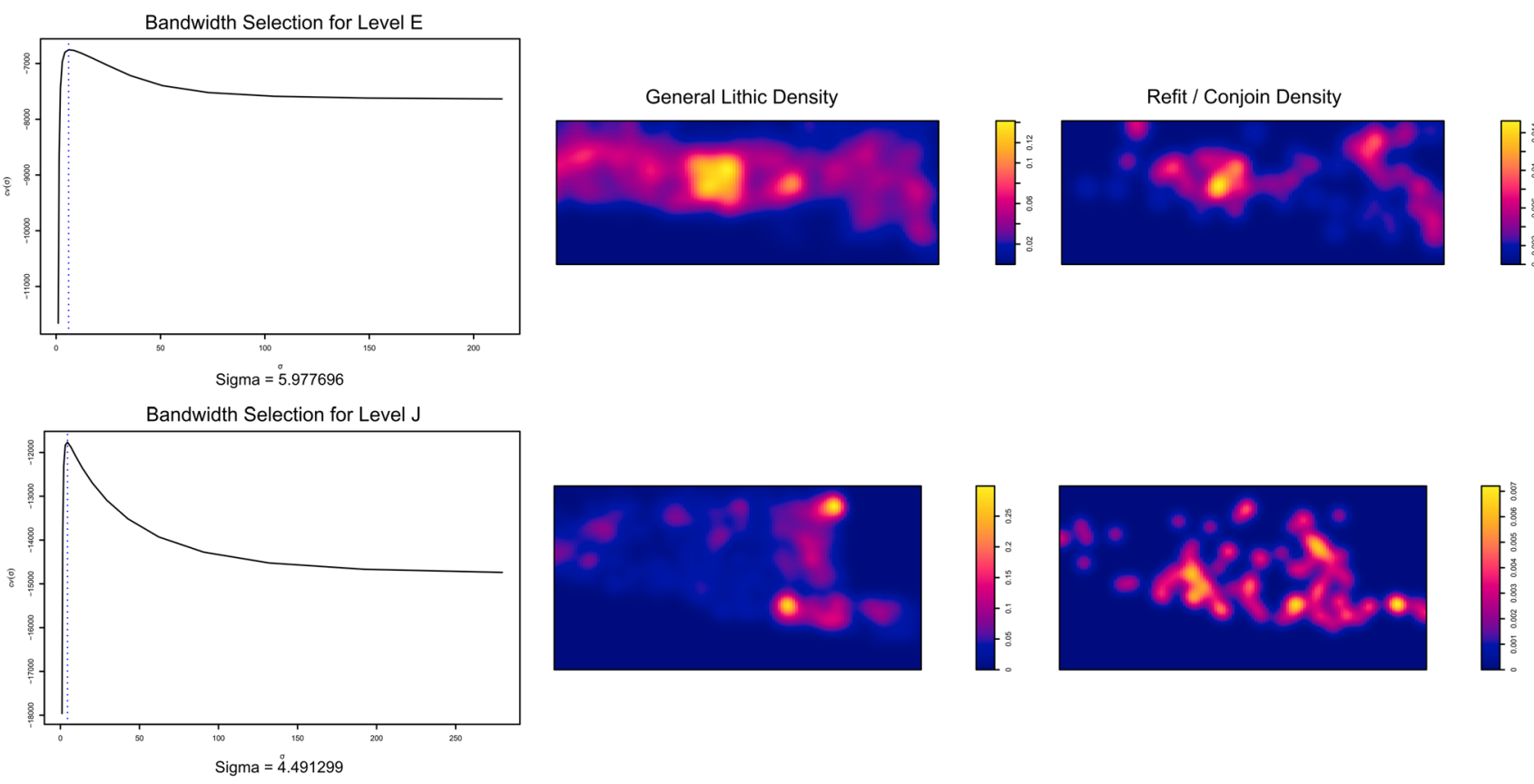

Fig. 3 Bandwidth selection (sigma value) and density maps

\section{Materials and methods}

\section{La Cansaladeta}

La Cansaladeta (La Riba, Tarragona) is a small Middle Pleistocene (MIS11) rock shelter site which was discovered by the researchers of the Universitat Rovira i Virgili in 1998, and the excavation was started in 1999. Geographically, the site is located in the Roixel-les Canyon that forms a kind of natural gate slashed into the Pre-Coastal Catalan mountain range by the Francolí River that connects the Tarragona plain with the inland depression of Conca de Barberà. The

Table $3 \mathrm{X}$ and $\mathrm{Y}$ intervals of the clusters

\begin{tabular}{llll}
\hline Level & Clusters & $\begin{array}{l}\text { X } \\
\text { Between }\end{array}$ & \begin{tabular}{l} 
Between \\
\hline E
\end{tabular} \\
& E1 & $2250-2295$ & $1170-1215$ \\
& E2 & $2400-2460$ & $1200-1245$ \\
& E3 & $2310-2370$ & $1170-1215$ \\
& E4 & $2115-2205$ & $1200-1230$ \\
J & J1 & $2400-2450$ & $1050-1100$ \\
& J2 & $2450-2500$ & $1050-1100$ \\
& J3 & $2450-2500$ & $1200-1250$ \\
& J4 & $2400-2500$ & $1100-1200$ \\
& J5 & $2500-2600$ & $1000-1100$ \\
& J6 & $2250-2375$ & $1175-1250$ \\
& J7 & $2100-2200$ & $1125-1225$ \\
\hline
\end{tabular}

archaeological deposition of the site is part of a thick stratigraphic inheritance that was exposed by a road cut through the left slope of the canyon, at the inner side of a fluvial meander. La Cansaladeta belongs to the Quaternary system sediments that were formed by past sedimentary deposits from the Francolí River (Fig. 1).

Stratigraphy of La Cansaladeta contains three main Pleistocene complexes: DV, CA, and AS. The complex DV contains Pleistocene slope sediments that have been affected by the soil formation. The Middle Pleistocene archaeological levels have been located in the complex CA. This stratigraphic formation was divided into six sub-complexes: CA1 (levels A-D), CA2 (level E), CA3 (levels J-I), CA4 (no archaeological levels), CA5 (levels K-L), and CA6 (level M). The final complex AS includes the fluvial sediments of the Francolí River. No archaeological remains were found in this complex (Angelucci et al. 2004; Mouhoubi 2012) (Fig. 2).

The Middle Pleistocene chronology of La Cansaladeta has already been confirmed by the numerical ages: level $\mathrm{D}, 372 \pm 34$ (TL)/380 \pm 30 (TT-OSL); level I, $392 \pm 30$ (TT-OSL); level J, 393+34/-33 (ESR/Us); and level K, $395 \pm 27$ (TT-OSL). Biochronology analysis has shown there is a disagreement between numerical and tentative dates regarding levels $\mathrm{K}-\mathrm{L}$. The results of the small vertebrate studies have suggested that levels are older than $600 \mathrm{ka}$. However, the reliability of the numerical age of level K has been supported with the agreement between three other numerical dating techniques (Ollé et al. 2016). 
Table 4 Distribution of the general raw material, RMU, and connected elements of the level E

\begin{tabular}{|c|c|c|c|c|c|c|c|c|c|}
\hline \multirow[t]{3}{*}{ Raw material } & \multirow{2}{*}{\multicolumn{2}{|c|}{ General }} & \multirow{2}{*}{\multicolumn{2}{|c|}{ In RMU }} & \multicolumn{5}{|c|}{ Connected elements } \\
\hline & & & & & \multicolumn{2}{|c|}{$\begin{array}{l}\text { In total assem- } \\
\text { blage }\end{array}$} & \multirow{2}{*}{$\begin{array}{l}\mathrm{In}>20 \mathrm{~mm} \\
\%\end{array}$} & \multicolumn{2}{|c|}{$\begin{array}{l}\text { Ele- } \\
\text { ments }>20 \mathrm{~mm}\end{array}$} \\
\hline & $N$ & $\%$ & $N$ & $\%$ & $N$ & $\%$ & & $N$ & $\%$ \\
\hline Agate & 2 & 0 & & & & & & 1 & 0 \\
\hline Limestone & 5 & 0 & & & & & & 4 & 1 \\
\hline Quartzite & 71 & 4 & 47 & 66 & 31 & 44 & 78 & 40 & 7 \\
\hline Quartz & 143 & 9 & 8 & 6 & 12 & 8 & 32 & 37 & 6 \\
\hline Schist & 278 & 17 & 14 & 5 & 15 & 5 & 9 & 170 & 29 \\
\hline Chert & 1176 & 70 & 15 & 1 & 37 & 3 & 11 & 335 & 57 \\
\hline Grand total & 1675 & 100 & 84 & 5 & 95 & 6 & 16 & 587 & 100 \\
\hline
\end{tabular}

The archaeological record from La Cansaladeta is composed by 11,971 remains. Most of them are lithic artifacts $(90 \%)$ and the rest $(5 \%)$ faunal remains. These elements have been recovered from ten archaeological levels, being the fauna more abundant in the basal ones and totally absent for levels $\mathrm{A}$ and $\mathrm{B}$.

Chert $(81.92 \%)$ was the most preferred raw material for flaking activity. In addition, quartz (7.14\%), schist $(6.72 \%)$, and quartzite $(3.03 \%)$ were the other commonly preferred raw materials. Limestone, granite, basanite, and agate represented a very low value (1.18\%). Unfortunately, most of the chert was patinated and altered. Some of the examples can include extensive geodes and fissures. Chert of Eocene formations can be found as irregular blocks slightly rounded by fluvial erosion. Also, the Muschelkalk formation presents chert outcrops included in the Triassic levels of the pre-littoral range. Particularly, Upper Muschelkalk is found in the close town of La Riba (Soto et al. 2014). Schist can be seen mainly as large cobbles. This raw material, which has not been petrologically studied yet, shows an altered and fragile structure because of post-depositional processes. Most of the quartz and quartzite blanks can be found as cobbles and pebbles, often affected by internal fractures. This is related to the original geological formation, the Triassic conglomerates (Buntsandstein). All these materials are locally available, with primary outcrops within a range $10 \mathrm{~km}$, and most of them could be gathered in the fluvial terraces at the feet of the site (Ollé et al. 2016).

In terms of the technology, La Cansaladeta has scarce presence of large cutting tools and bifacially shaped elements. Most of the cores were flaked by unipolar longitudinal, opposed bidirectional, and orthogonal strategies. Centripetal core reduction has also been identified, although it is poorly standardized, so only occasionally discoidal or Levallois methods have been identified. Also, bipolar flaking on an anvil is present. These flaking methods globally lead to small- and medium-sized flakes (Ollé et al. 2016). Regarding the retouched tool component, most of the samples were denticulates and notches, which is common for MIS11 sites (Ashton 2016; Connet et al. 2020; Moncel et al. 2015).

\section{Levels E-J}

The archaeological level E was situated in the CA2 sub-complex. Although no numerical data have been obtained for this level, the overlaying level D has been dated to $372 \pm 34$ (TL,
Table 5 Distribution of the general raw material, RMU, and connected elements of the level J

\begin{tabular}{|c|c|c|c|c|c|c|c|c|c|}
\hline \multirow[t]{3}{*}{ Raw material } & \multirow{2}{*}{\multicolumn{2}{|c|}{ General }} & \multirow{2}{*}{\multicolumn{2}{|c|}{ In RMU }} & \multicolumn{5}{|c|}{ Connected elements } \\
\hline & & & & & \multicolumn{2}{|c|}{$\begin{array}{l}\text { In total assem- } \\
\text { blage }\end{array}$} & \multirow{2}{*}{$\begin{array}{l}\text { In }>20 \mathrm{~mm} \\
\%\end{array}$} & \multicolumn{2}{|c|}{$\begin{array}{l}\text { Ele- } \\
\text { ments }>20 \mathrm{~mm}\end{array}$} \\
\hline & $N$ & $\%$ & $N$ & $\%$ & $N$ & $\%$ & & $N$ & $\%$ \\
\hline Granite & 4 & 0 & & & & & & 3 & 0 \\
\hline Agate & 4 & 0 & & & & & & 4 & 0 \\
\hline Other rocks & 5 & 0 & & & & & & 3 & 0 \\
\hline Limestone & 30 & 1 & & & & & & 25 & 3 \\
\hline Quartzite & 111 & 4 & 61 & 55 & 31 & 28 & 61 & 51 & 6 \\
\hline Quartz & 115 & 4 & & & 2 & 2 & 4 & 45 & 5 \\
\hline Schist & 189 & 6 & & & 4 & 2 & 3 & 135 & 15 \\
\hline Chert & 2708 & 86 & 70 & 3 & 54 & 2 & 9 & 615 & 70 \\
\hline Grand total & 3166 & 100 & 131 & 4 & 91 & 3 & 10 & 881 & 100 \\
\hline
\end{tabular}


on a burnt chert) and $380 \pm 30$ (TT-OSL). Chert represented $(N=1176) 70 \%$ of the assemblage $(N=1675)$. Most of the technological categories were flakes $(35 \%)$ and flake fragments (31\%) (Table 1).

The archaeological level J was situated in the CA3 subcomplex. In terms of chronology, this level has been dated to $393+34 /-33$ (ESR/Us, on a rhino tooth fragment). Chert represented $(N=2708) 86 \%$ of the assemblage $(N=3166)$. Most of the technological categories were flakes (47\%) and flake fragments (27\%) (Table 2).

\section{Refit and conjoin connections}

The refitting method was generated in two sections and different times for each level. First, raw material unit (RMU) analysis was generated. The assemblage was scattered on the table and analyzed according to the macroscopic features. In terms of the determinative criteria, cortical surface color, grain size of the external-internal parts, and geode-fissure formation were considered (Chacón et al. 2015; Roebroeks 1988; Vaquero et al. 2017). Finally, each RMU was identified by the basic code system: RMU-SI01 $(\mathrm{Q}=$ quartzite, $\mathrm{SI}=$ chert, $\mathrm{CO}=$ schist, $\mathrm{QS}=$ quartz). RMU was applied for most of the quartzite and very few well-preserved samples of chert, schist, and quartz of level E. Regarding level J, it was applied only for the most of the quartzite and less patinated chert. Schist and quartz elements of level J were not selected because of the unavailability of their macroscopic criteria.

Second, refitting practice was generated according to the RMU results. Lithic elements less than $20 \mathrm{~mm}$ were excused (Laughlin and Kelly 2010, p. 430), because refitting method is time consuming and it should be limited in order to use the time effectively. Basically, refit and conjoin distinctions were considered to generate the connection sets with a hybrid composition of the different methodologies (Cziesla 1990; López-Ortega et al. 2011, 2017; Sisk and Shea 2008). In terms of the refit, core-flake (the connection between core and flake), dorso-ventral (successive flake removals as dorso-ventral), indirect intentional nonconchoidal fragment (intentional fragments because of flaking accident and unexpectable flaking dynamics), retouch (tool modification), and technological gap (measurable, and reconstructable missing pieces between two successive lithic elements) were identified. Conjoin was classified by Siret (Siret 1933) (accidental detachment of a flake along the flaking axis), longitudinal, transversal, and nonconchoidal fragments (Online Resource 1). Each connection set was identified by the following code system: CAN, site name; (J/E), archaeological level; R/Co, refit/conjoin; QTA-SI-QS-CO, raw material; and $01-02$, etc., identity number. Some sets could include multiple connections. Those were generally represented by flaking sequence (mostly core-flake and dorso-ventral). This kind of multiple connections was related to uncontrolled

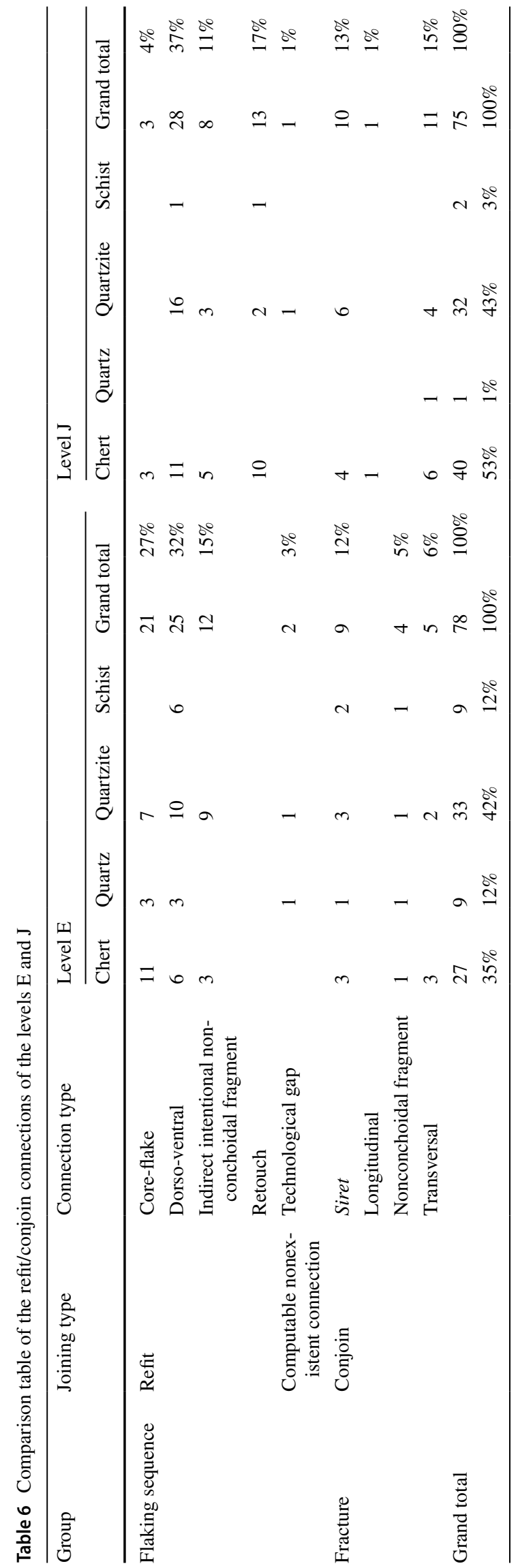




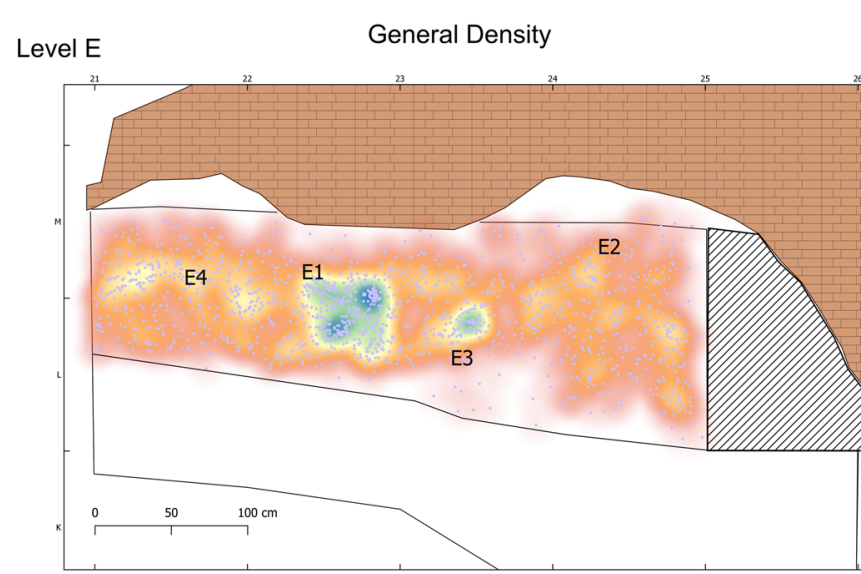

$\lambda$

Level J

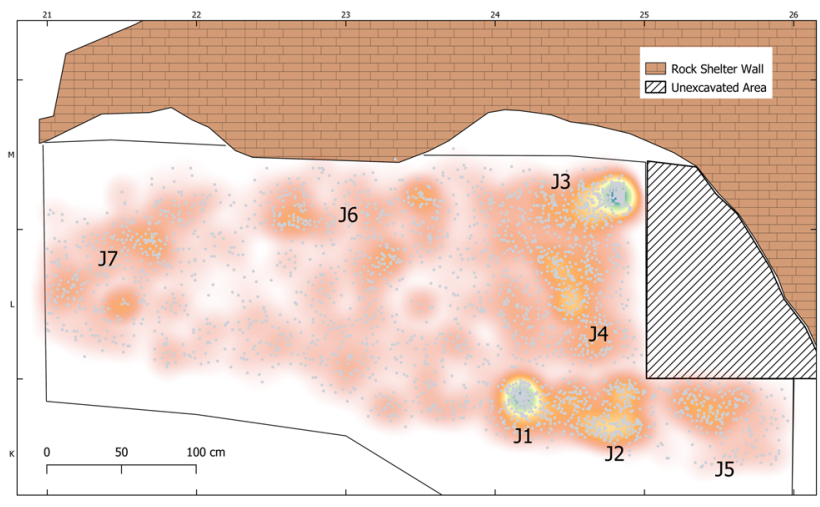

A

Fig. 4 Clusters and refit/conjoin distribution of the levels E and J

flaking dynamics. The criteria of the technological features and dimensions were structured using the following logic analytic system: $\leq 20 \mathrm{~mm}=$ very small, $21-60 \mathrm{~mm}=$ small, 61-100 $\mathrm{mm}=$ medium, and $>100 \mathrm{~mm}=$ large $($ Carbonell et al. 1999; Ollé et al. 2013).

\section{Technological gap}

This term was created during the refitting practice of level $\mathrm{E}$ to describe the missing objects of the almost complete flaking sequence. It means the reconstructable missing element between two lithic objects. Flaking is a continuous activity and has the next and previous notions. These notions can be measurable and computable. The presence of them is a great opportunity to recreate the morphology of the missing element. The reconstruction of these pieces provides a computable nonexistent connection. Several different terms have been used to describe the nonexistent elements of reduction sequence such as ghost (Morrow 1996; Takakura 2018; Vandendriessche and Crombé 2020), void (Delpiano et al. 2019), and widow (Stackelbeck 2010, p. 42). However, the original meanings of these terms do not refer to scientific concepts. Additionally, several recent studies allow reconstructing these gaps with the scientific methods and high-tech virtual equipment (Abel et al. 2011; Delpiano et al. 2017, 2019). Hereafter, we suggest to use the term "technological gap" to describe the invisible connection of the nonexistent element between two pieces sequentially flaked.

\section{Density mapping}

The spatial density demonstration of levels $\mathrm{E}$ and $\mathrm{J}$ was done by kernel density heat map (Alperson-Afil et al. 2009, 2017; Alperson-Afil and Goren-Inbar 2010; Clark 2016, 2017, 2019; de la Torre and Wehr 2018; Lancelotti et al. 2017; Moncel et al. 2021; Sánchez-Romero et al. 2020, 2021). This method was applied to see and show the location of lithic concentration clearer than usual point scatter view. Those analyses were done for both general distribution of the lithic elements and connected elements. The analyses were completed by using 

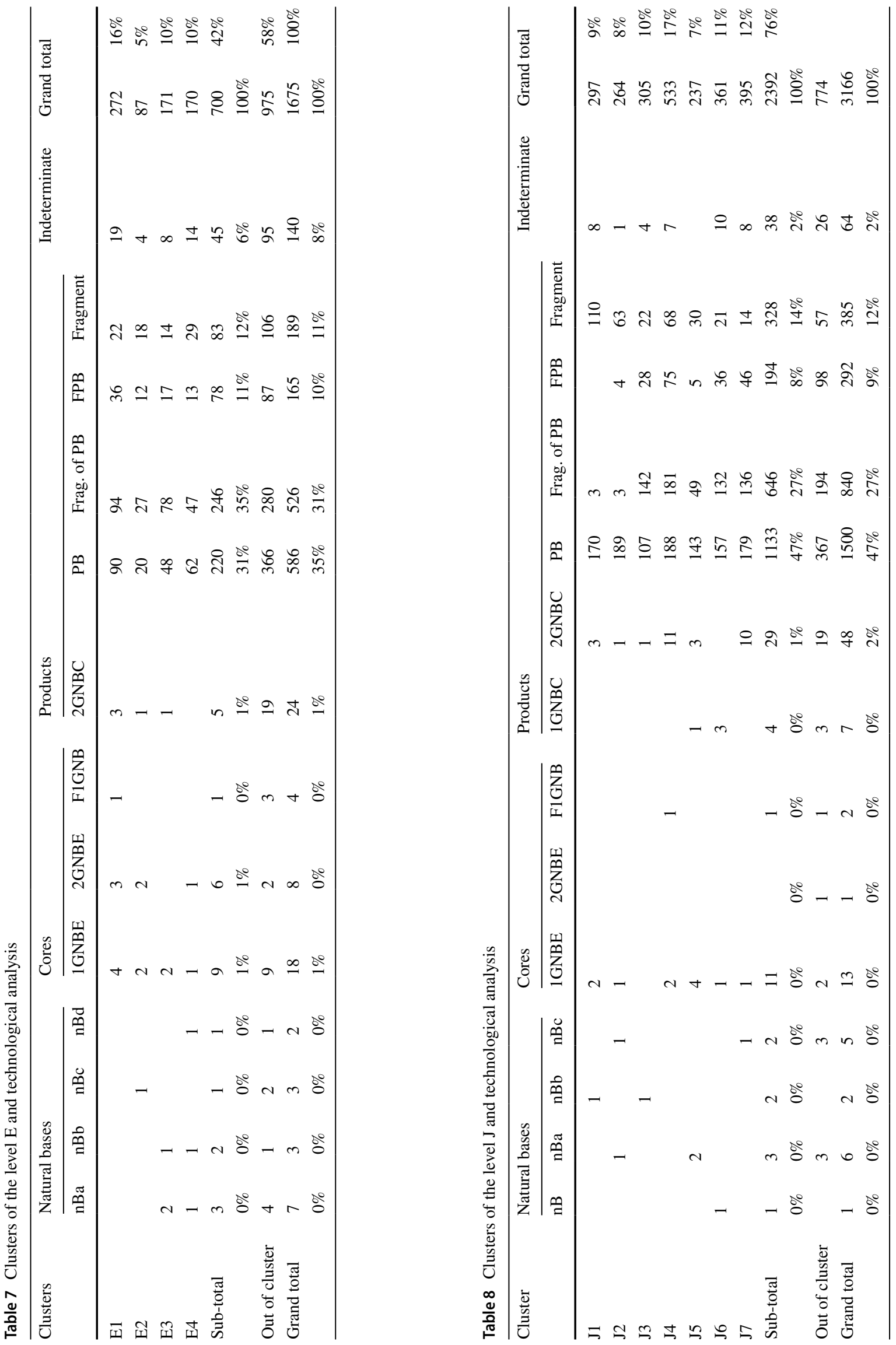

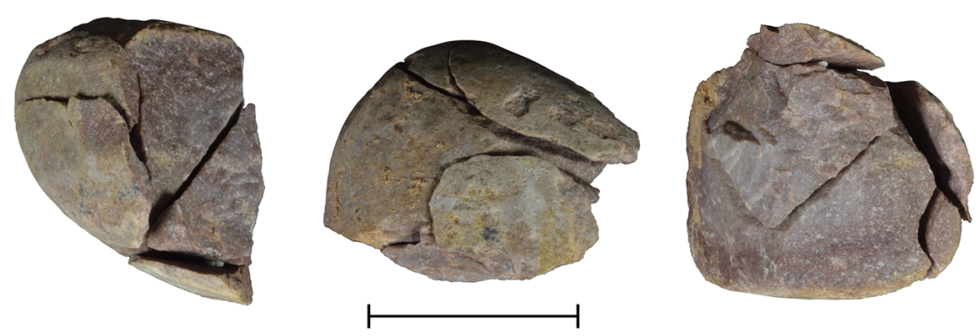

CAN(E)_R_QTA-01

RMU-Q00
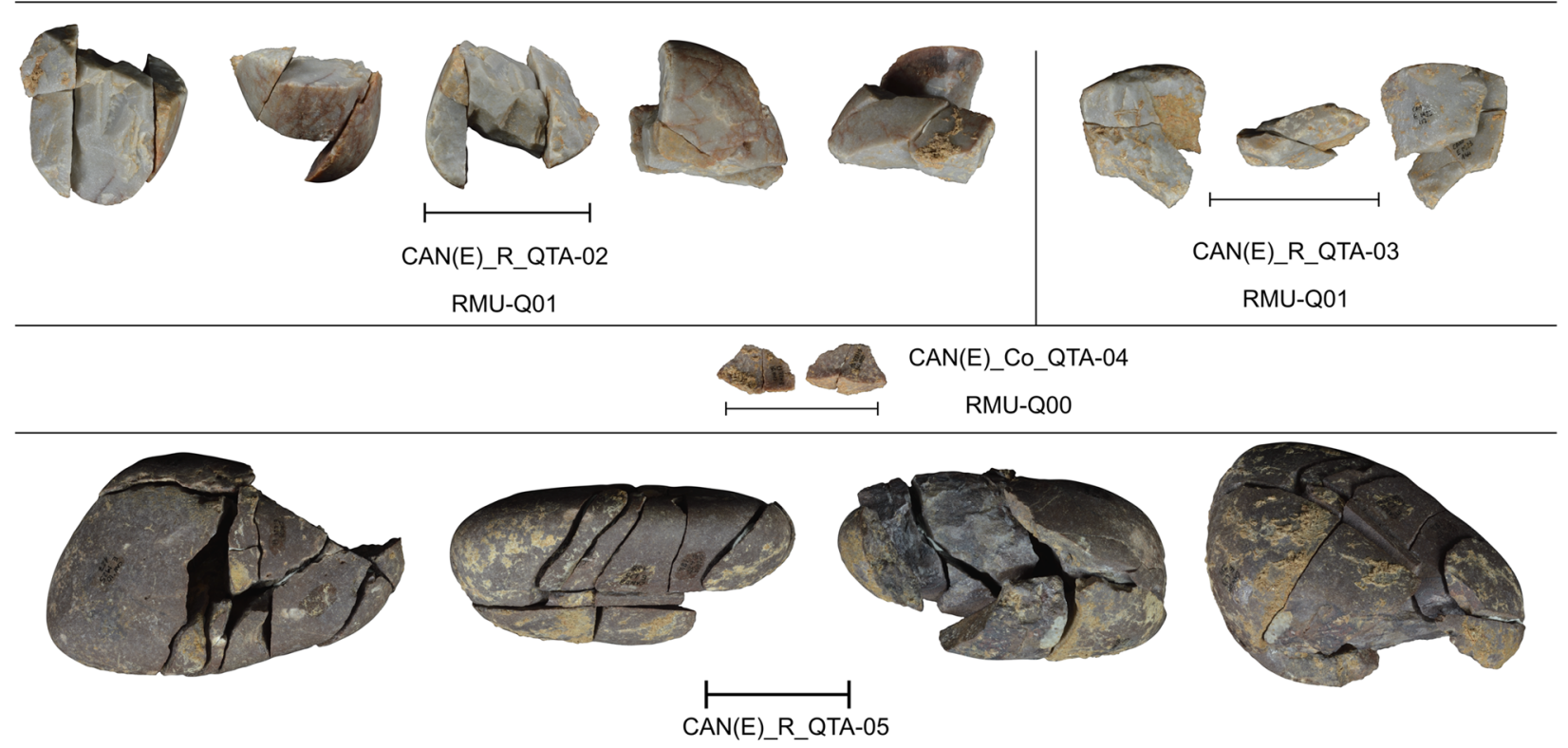

RMU-Q02

Tool bar: $5 \mathrm{~cm}$

Fig. 5 Quartzite connections of level E

the open-source R-R Studio "spatstat" (spatial point pattern analysis) package (Baddeley and Turner 2005) and QGIS-kernel density heat map tool. First, the statistical test was generated for the bandwidth (as known as radius in GIS) selection. The sigma $(\sigma)$ value is an important parameter, regarding controlling the concentration on the map. Small values are appropriate for local densities and create less general view while large values are vice versa. The coordinates of the lithic elements and excavation area of each level were used to obtain the sigma value. The bandwidth can be determined by alternative algorithms such as bw.scott, bw.diggle, bw.frac, and bw.ppl. The sigma of the levels was determined by bw.ppl likelihood cross-validation function (Baddeley et al. 2015, p. 171; Baxter et al. 1997; Domínguez-Rodrigo and Cobo-Sánchez 2017, p. 116; Herzog and Yépez 2013). In occasional instances, the selection of the sigma value does not show compatibility, if the value is obtained by one of those algorithms. The bandwidth selection of levels $\mathrm{E}$ and $\mathbf{J}$ showed different sigma values (level $\mathrm{E}, \sigma=5.977696$; level J, $\sigma=4.491299$ ). This incompatibility was equalized by adjust function. The function "adjust" multiplies the selected sigma with a numeric value (Baddeley et al.
2015, p. 171). The sigma value of levels $E$ and $J$ was multiplied by 1.5 and 2 (Fig. 3).

First, the clusters were named for each level as E1 and E2 (level E), J1 and J2 (level J), etc. The cluster names were preferred to describe the refit and conjoin connections, in terms of the spatial features, if the elements were located in the clusters. Connections or lithic elements out of the clusters were described by using the square names where the elements found. Second, regarding the technological analysis, the excavation area of level $\mathrm{E}$ was divided into $15 \mathrm{~cm}^{2}$. The excavation area of level $\mathbf{J}$ was divided into $25 \mathrm{~cm}^{2}$ (Table 3). Each cluster was analyzed regarding technological categories, flake dimensions, and corticality of the dorsal faces. Technological analysis was based on the clusters of the general distribution of the assemblages of the levels. Clusters of the connected elements were used for the spatial interpretation. Distance and the orientation line between two connected lithic elements were analyzed with the basic trigonometry (López-Ortega et al. 2019; McPherron 2005). Regarding the demonstration of the refit and conjoin connections, chronological demonstration 

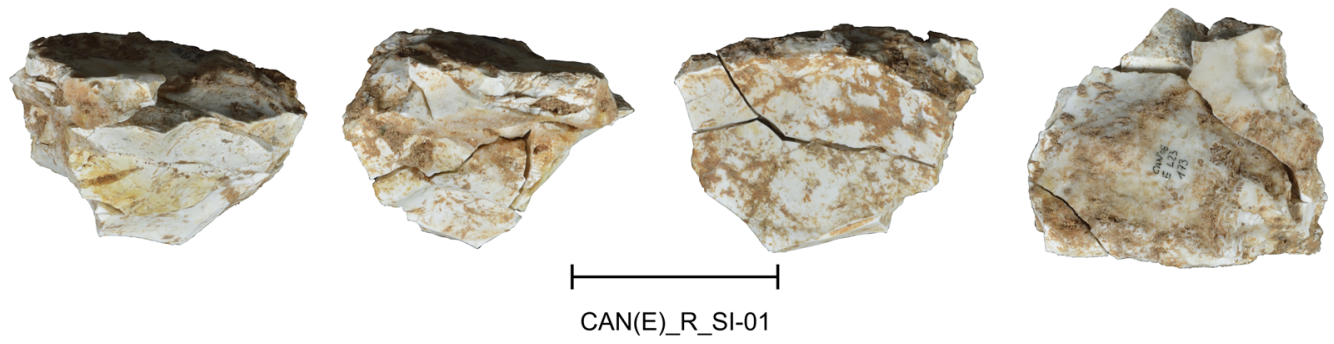

CAN(E)_R_SI-01

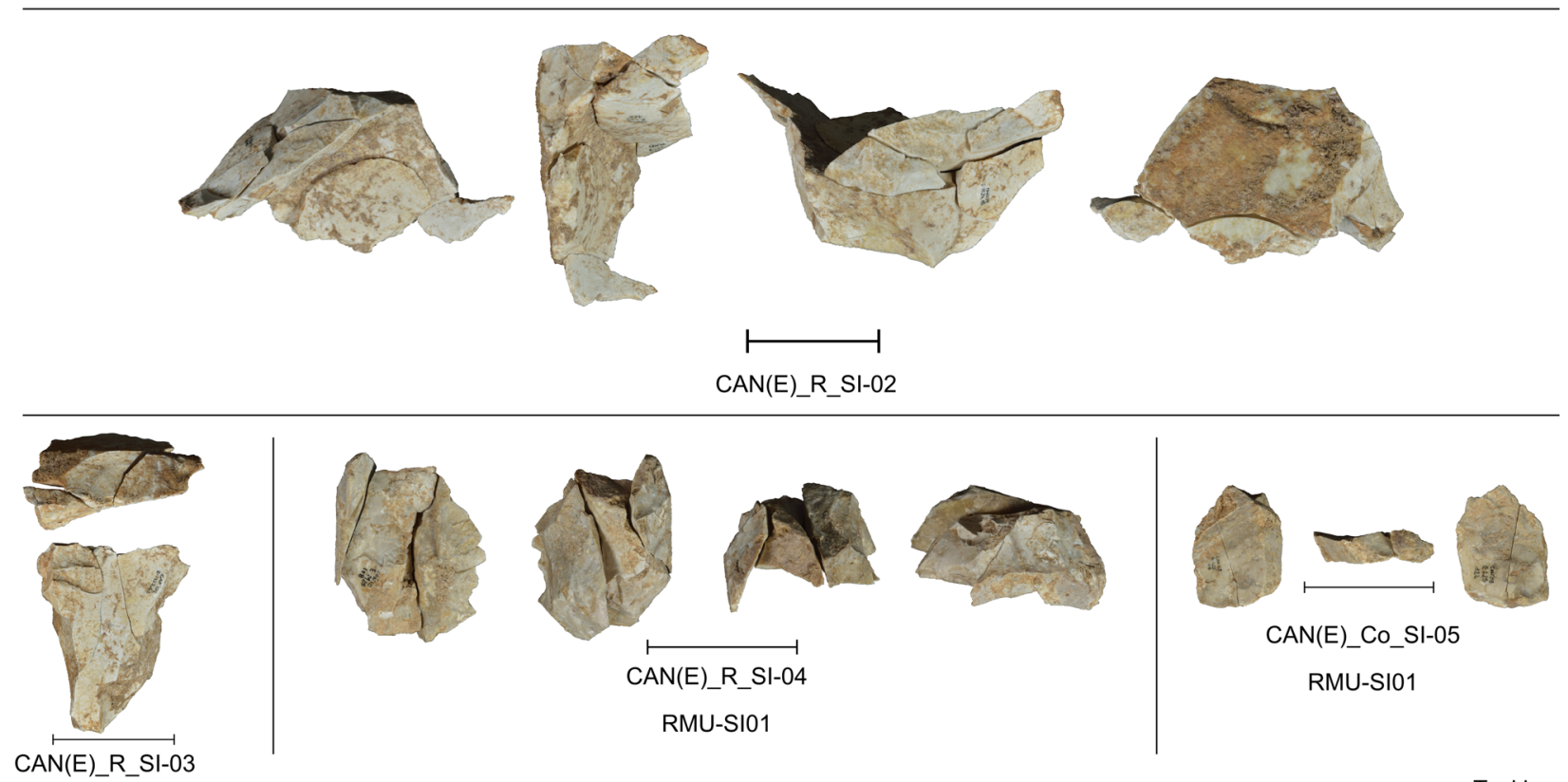

Tool bar: $5 \mathrm{~cm}$

Fig. 6 Chert connections of level E (1)

style was used to identify the reduction order on the surface (Cziesla 1990).

Data visualization and plots were generated in the R-R Studio and the ggplot2 package (Moon 2016; Wickham 2009). Vertical demonstration of the archaeological levels was generated by Voxler® three-dimensional data visualization software (Gallotti et al. 2012). The model of canyon was performed by Surfer®. Some of the lithic elements were illustrated according to the protocol of Stone Tool Illustrations with Vector Art, the STIVA Method in Adobe Illustrator $\AA$ and Inkscape ${ }^{\circledR}$ (Cerasoni 2021). The page design of the online resources was performed in Adobe InDesign $®$.

\section{Results}

This section provides the results of RMU, refit and conjoin, clusters of the levels E and J, and technological examination of the connection sets and their spatial locations. Technological data of the clusters and graphic illustration of the connection sets were provided as Online Resource. Following this section with those documents will be more informative.

\section{RMUs}

\section{Level E}

There were fourteen RMUs generated for quartzite $(N=8)$, chert $(N=2)$, schist $(N=2)$, and quartz $(N=2)$. Sixty-six percent $(N=47)$ of the whole quartzite objects $(N=71)$ was categorized into the RMU. Connected elements represented $44 \%$ $(N=31)$ of the entire quartzite. In terms of chert $(N=1176)$, $1 \%(N=15)$ was categorized into RMU. The elements in the connection sets represented $3 \%(N=37)$ of the whole chert. Five percent $(N=14)$ of the schist was categorized into RMU. The connected pieces represented 5\% $(N=15)$. Six percent $(N=8)$ of the quartz $(N=143)$ was categorized into RMU. The pieces of the connection sets represented $8 \%(N=12)$. If we consider the larger elements than $20 \mathrm{~mm}(N=587)$, this value increased up 16\%. Quartzite and quartz were the best identified raw materials, in terms of the macroscopic criteria. Most of the 


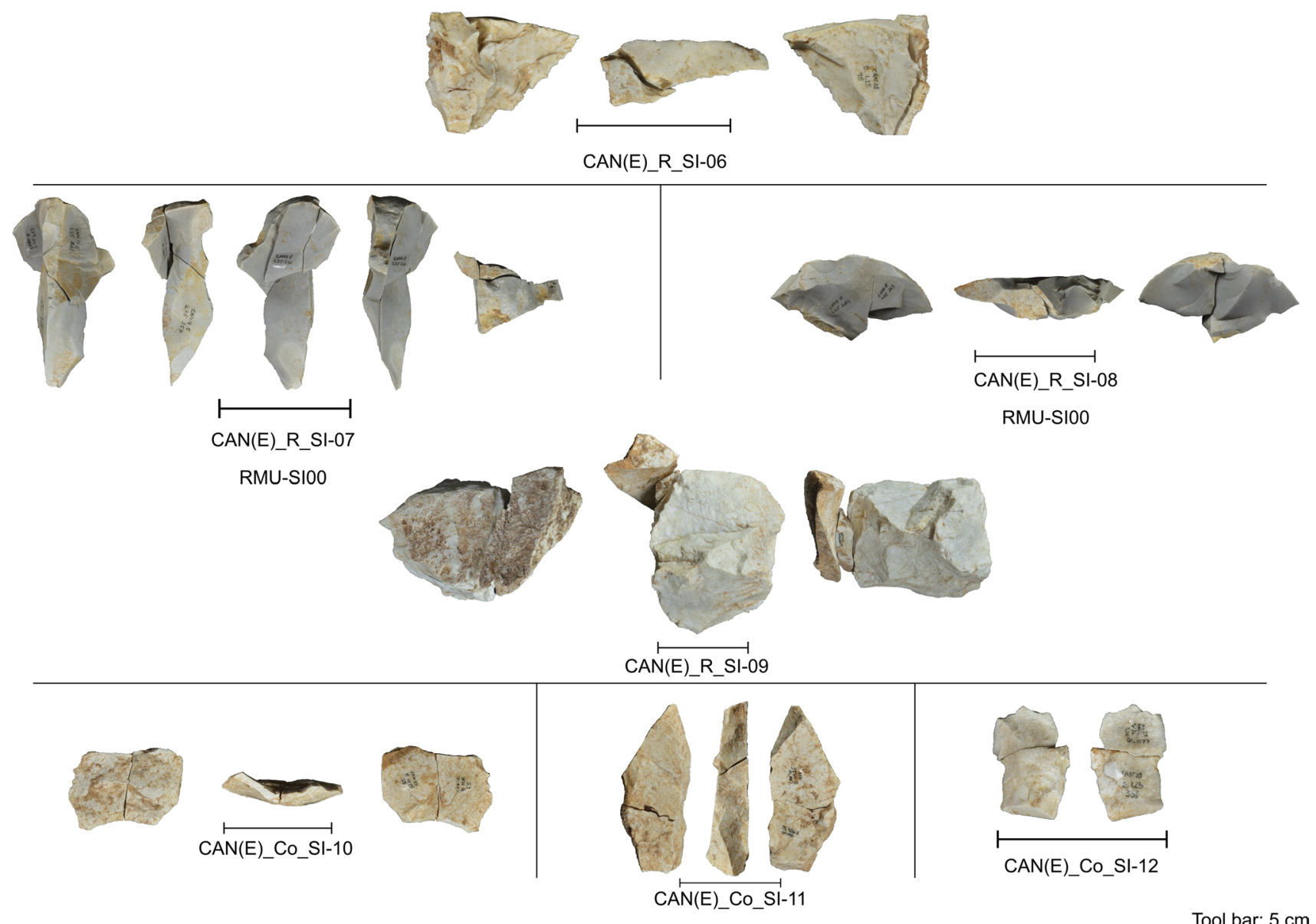

Fig. 7 Chert connections of level E (2)

quartzite had very fine structure and red color. The elements of quartz showed coarse structure and white color. Most of the chert and schist did not allow for the categorization into the RMU due to the altered surfaces. However, categorized chert into RMU represented gray color, yellow color, and fine structure. Regarding schist, the pieces represented black color and coarse structure (Table 4).

\section{Level J}

There were fifteen RMUs generated for both quartzite $(N=11)$ and chert $(N=4)$. Fifty-five percent $(N=61)$ of the entire quartzite elements $(N=111)$ was categorized into the RMU. Connected elements represented $28 \%(N=31)$ of the whole quartzite. Regarding chert $(N=2708), 3 \%(N=70)$ of them was categorized into RMU. The pieces in the connections represented $2 \%$ $(N=54)$ of the whole chert. Concerning schist $(N=189$, $6 \%)$ and quartz $(N=115,4 \%)$, no RMU was analyzed. Total connected elements were calculated $(N=91,3 \%)$.
When considering only larger elements than $20 \mathrm{~mm}$ $(N=881)$, this ratio increased up to $10 \%$. Macroscopically, quartzite was the best identified raw material. Most of the elements had medium-fine inner structure and redgray color. In terms of chert, medium-fine inner structure was also observed and most of them were white. The other types of materials represented very minimal values (Table 5).

\section{Refits and conjoins}

\section{Level E}

There were 95 elements and 78 connections analyzed. Most of the joining type corresponded to the refit category (74\%), being the remaining conjoin (23\%) and computable nonexistent connection (3\%). Raw material distribution of the connections was quartzite (42\%), chert (35\%), quartz (12\%), and schist (12\%). Most of the connections were between more than two elements. The distances 

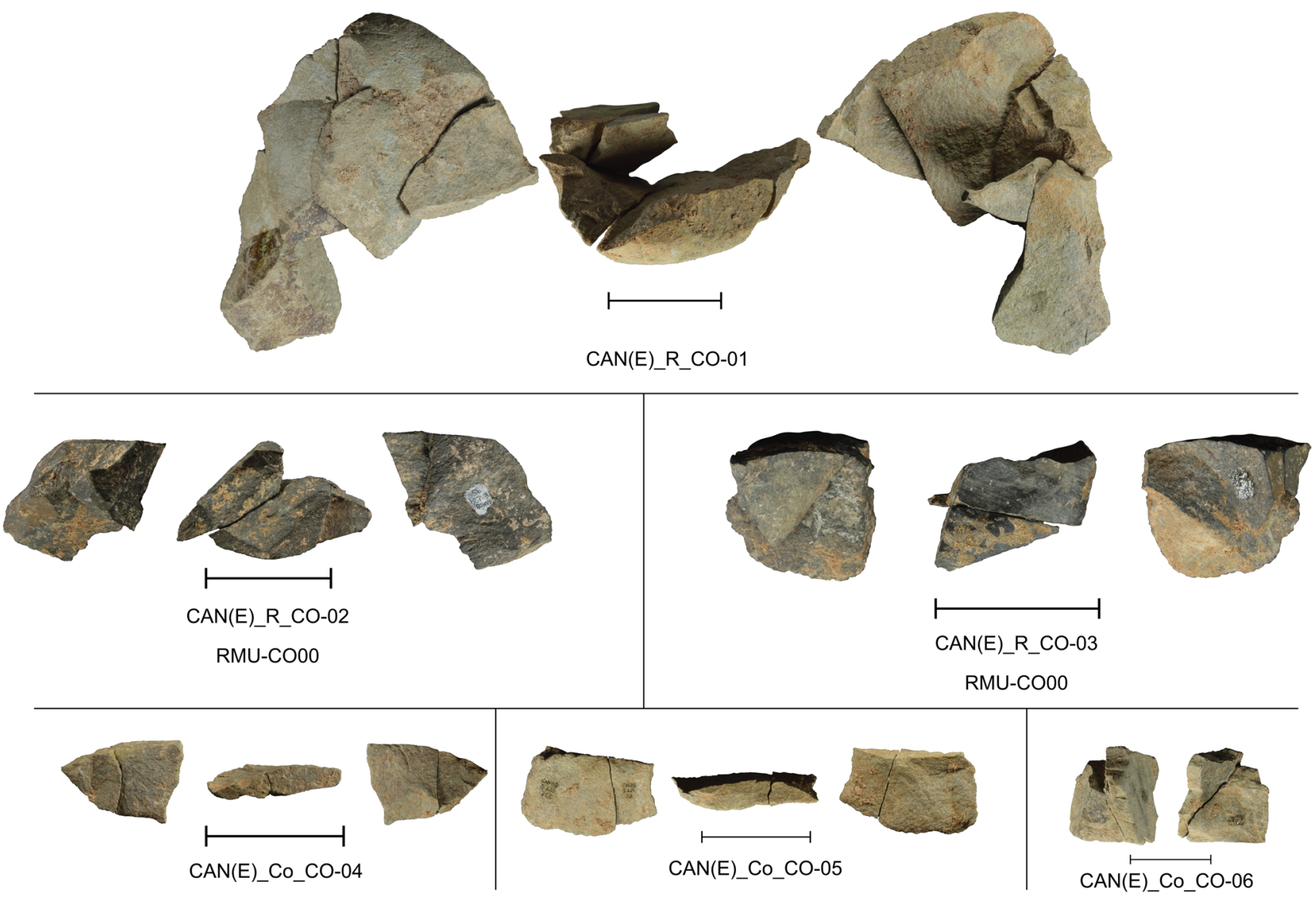

Tool bar: $5 \mathrm{~cm}$

Fig. 8 Schist connections of level E

between the elements were categorized as $<100 \mathrm{~cm}(74 \%)$ and $>100 \mathrm{~cm}(26 \%)$. The orientation of the connection lines showed east-west and northeast-southwest tendencies. The connections longer than $100 \mathrm{~cm}$ had the same result (Table 6, Online Resource 2).

\section{Level J}

There were 91 lithic elements and 75 connections analyzed. Majority of the joining type corresponded to the refit (69\%) more than conjoin (29\%) and computable nonexistent connection (1\%). In terms of raw material distribution of the connections, chert (53\%), quartzite (43\%), and schist and quartz (4\%) were sorted. Most of the connections were between two lithic elements. The distances between the elements were grouped as $<100 \mathrm{~cm}(74 \%)$ and $>100 \mathrm{~cm}(26 \%)$. Regarding the orientation of the connection lines, east-west and northeast-southwest were the most common. In addition, the connections longer than
$100 \mathrm{~cm}$ had the same result, regarding the orientation of the connection lines (Table 6, Online Resource 2).

\section{Clusters}

\section{Level E}

Four lithic clusters were generated. The clusters involved $(N=700) 42 \%$ of the assemblage. In terms of the locations of the cluster, they were detected in the eastern part (cluster E2), western part (cluster E4), and central part (clusters E1-E3). The highest concentration was in the central part (cluster E1). This was exactly located between squares L/ M22. Most of the lithic elements were flakes (31\%) and flake fragments $(35 \%)$. The dimensions of the flakes were mostly very small (59\%), and large flake representation was very low. Regarding the dorsal face corticality, noncortical was dominant (59\%). The elements of the connections mainly recovered from out of clusters (57\%), and 

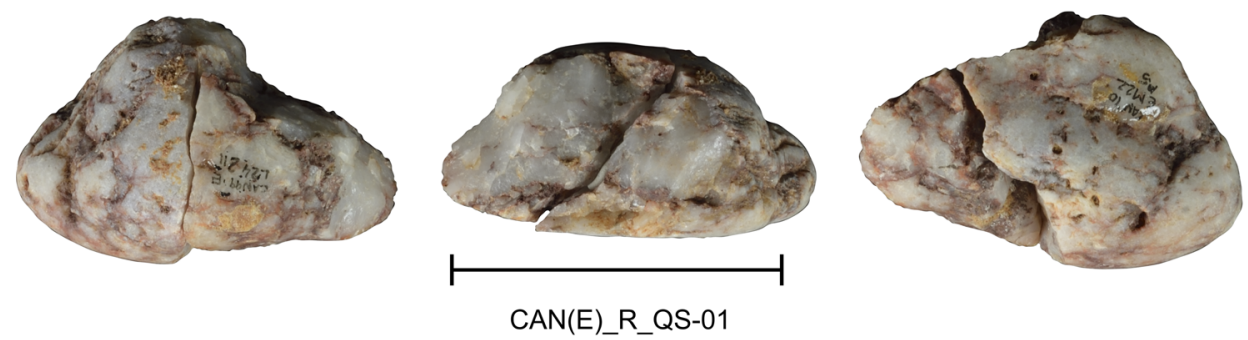

RMU-QS00
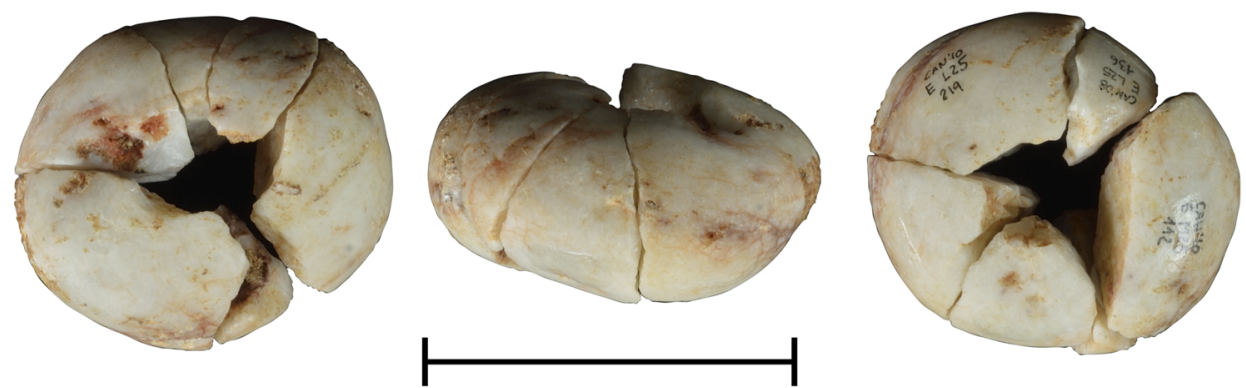

CAN(E)_R_QS-02

RMU-QS01

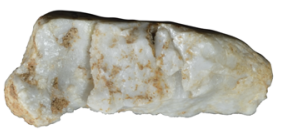

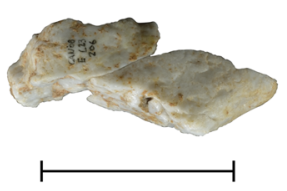

CAN(E)_R_QS-03

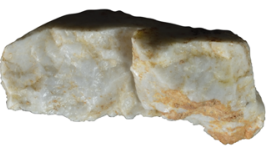

Tool bar: $5 \mathrm{~cm}$

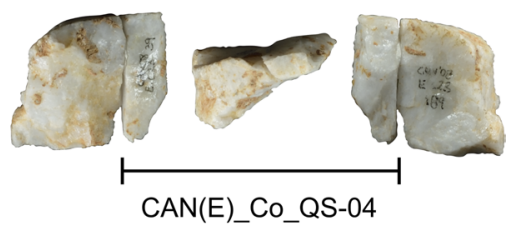

CAN(E)_Co_QS-04

Fig.9 Quartz connections of level E

cluster E1 had the highest value (21\%) (Fig. 4, Table 7, Online Resource 3).

\section{Level J}

There were seven lithic clusters. The clusters involved $(N=2392) 76 \%$ of the assemblage. Those clusters were in well-separated three areas: eastern part (clusters J1-J5), western part (cluster J7), and north central part (cluster J6). Regarding the highest density, the square K25 involves J1-J2 while M25 involves J3. These were the most concentrated clusters (hotspots). The general distribution of the lithic elements was mainly flakes (47\%) and flake fragments $(27 \%)$. In terms of the flake dimension, most of the flakes were very small $(79 \%)$ and almost no large flake was found. Noncortical dorsal face corticality was the common (60\%). In terms of the connected elements, J4 represented the highest value (21\%) in the clusters and the other clusters represented minimal values. However, most of the connected elements (42\%) were recovered from out of the clusters (Fig. 4, Table 8, Online Resource 3).

\section{Sets of level E}

Twenty-seven sets were generated (Online Resources 4-5). They distributed such as quartzite $(N=5,19 \%$; Fig. 5$)$, chert $(N=12,44 \%$; Figs. 6 and 7$)$, schist $(N=6,22 \%$; Fig. 8$)$, and quartz $(N=4,15 \%$; Fig. 9$)$.

\section{Quartzite}

$C A N(E) \_R \_Q T A-01$ had five lithic elements. This set represented a flaking sequence. The core had two different flaking surfaces, which were flaked alternately by freehand direct percussion. Some of the flakes covered with a cortex. The elements were recovered from the cluster E1.

$C A N(E) \_R \_Q T A-02$ included five lithic elements. This was a flaking sequence. The core of the set was reduced by freehand and bipolar technique on an anvil (Vergès and Ollé 

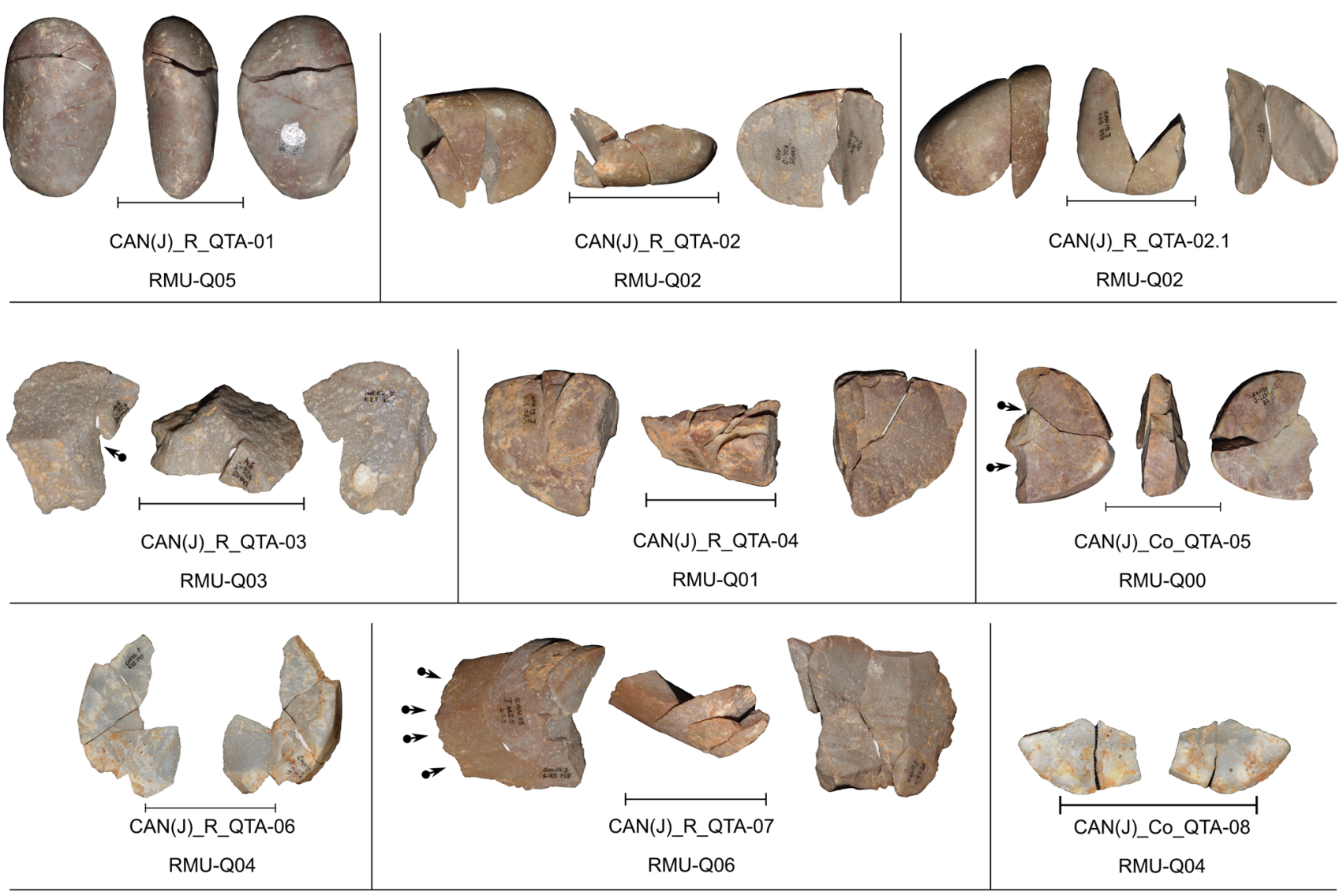

Tool bar: $5 \mathrm{~cm}$

Fig. 10 Quartzite connections of level J

2011). One of those flakes had several impact points, and the other one had transversal fragment. The elements were found in the clusters E1-E4.

$C A N(E) \_R \_Q T A-03$ comprised three elements. This set represented dorso-ventral and transversal connections. The pieces represented the characteristics of direct percussion. These elements were found in the cluster E1. Even though this set had the same RMU with the set before, no connections were detected among them.

$C A N(E) \_C o \_Q T A-04$ had two elements and presented a Siret connection. It was recovered from the cluster E1, side by side. In terms of the RMU, they were the same with the set CAN(E)_R_QTA-01; however, no connection was found.

$C A N(E) \_R \_Q T A-05$ had sixteen elements and was an almost complete set. The cobble was reduced by a singleplatform method along its length by freehand direct percussion. There is a technological gap before the final step of the reduction. Most of the flakes were small and mediumsized and partially covered with the cortex. The core had two flaking surfaces. The elements of this set concentrated in the cluster E2. Additionally, two elements of the Siret connection were recovered from the clusters E2-E4. This connection represented the longest distance of the level $\mathrm{E}$, $276.52 \mathrm{~cm}$.

\section{Chert}

$C A N(E) \_R \_S I-01$ comprised five lithic elements. This connection set represented a flaking sequence. The elements were obtained by freehand direct percussion. Four elements of the set were recovered from the cluster E1; however, the flake was found in the cluster E2, $254.84 \mathrm{~cm}$ away.

$C A N(E) \_R \_S I-02$ had seven elements. This set represented a flaking sequence. The flakes were removed by freehand direct percussion. The core was reduced by an orthogonal strategy. The elements were recovered from the cluster E1.

$C A N(E) \_R \_S I-03$ had three objects. This was a flaking sequence. The flakes were obtained from the left-right lateral flaking surfaces of the core. The elements were found in the cluster E1.

$C A N(E) \_R \_S I-04$ included three objects. This connection set had the core-flake and indirect intentional nonconchoidal fragment connections. The flake was removed 

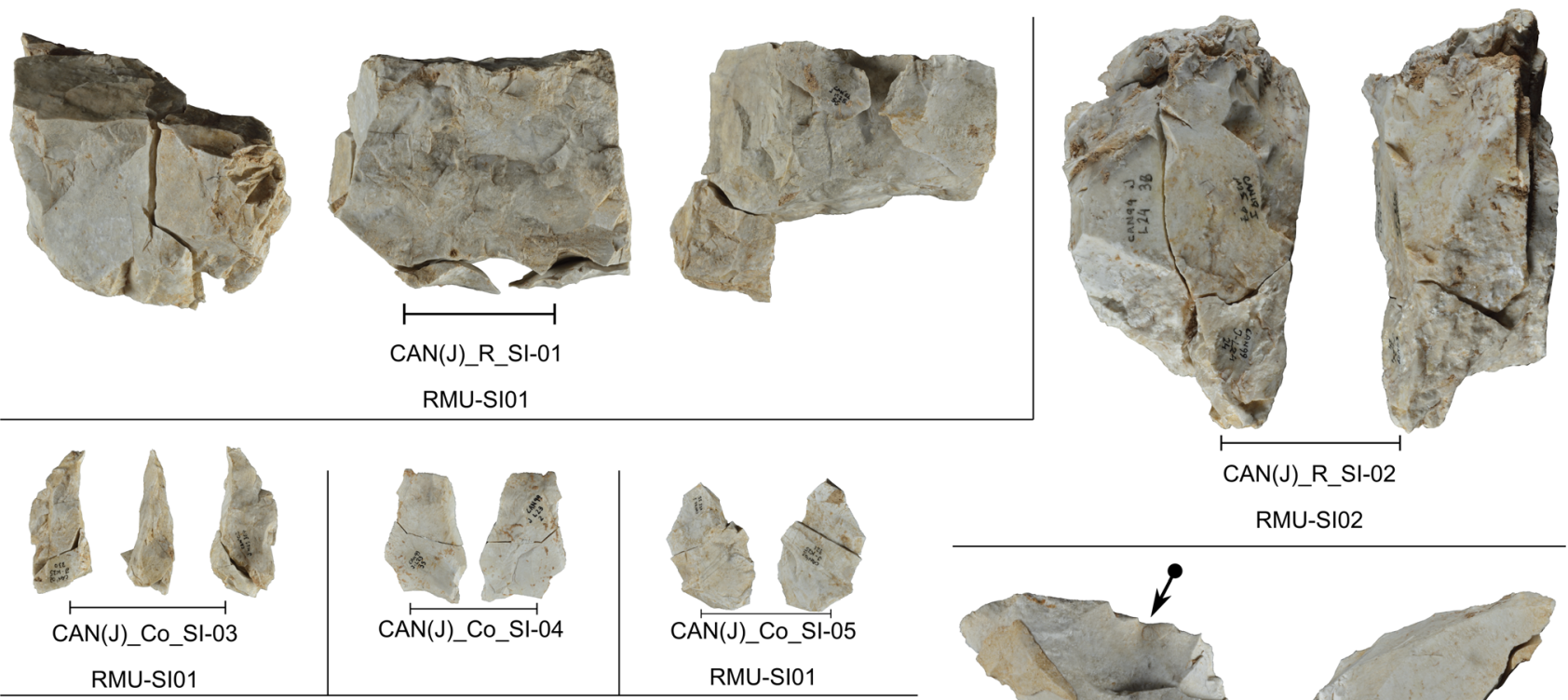

CAN(J)_R_SI-02
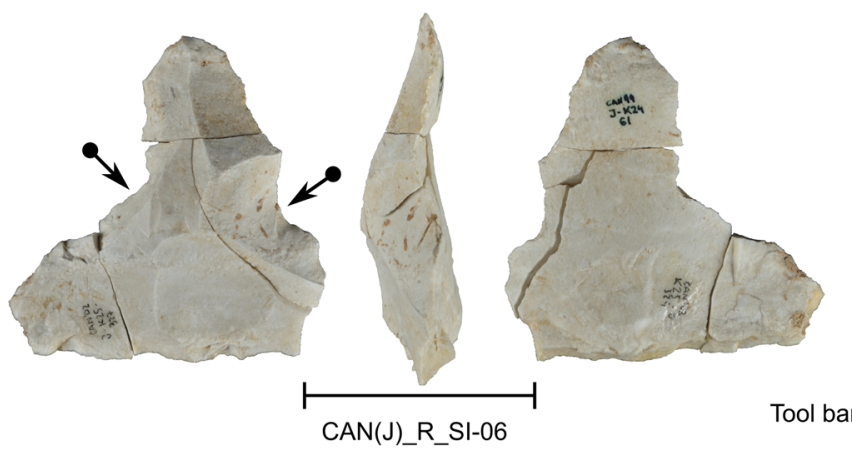

Tool bar: $5 \mathrm{~cm}$
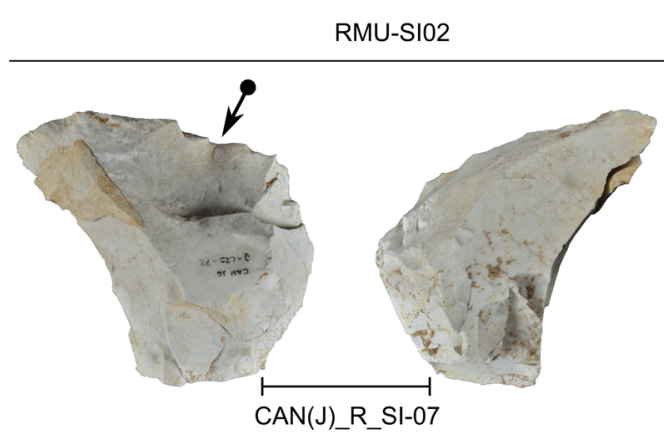

Fig. 11 Chert connections of level J (1)

by freehand direct percussion. One of the elements had deformed striking platform and smashed part due to the bipolar reduction (de Lombera-Hermida et al. 2016). This set was recovered from the cluster E2 and square L25.

CAN $(E) \_C o \_S I-05$ had two elements. This set represented a Siret connection. They were the same RMU with the previous set; however, no connection was found. The pieces were found in the square L25.

$C A N(E) \_R \_S I-06$ represented two elements. This was a dorso-ventral connection. The elements were recovered from the square L25.

$C A N(E) \_R \_S I-07$ had four pieces. This set represented a flaking sequence. All of them were found in the square L25.

$C A N(E) \_R \_S I-08$ comprised two elements. This was a dorso-ventral connection. Regarding RMU, they were the same with the set one before; however, no connection was found. The pieces were recovered from the square L25.

$C A N(E) \_R \_S I-09$ included three elements. This connection set represented a flaking sequence. The core of this set was reduced by multifacial strategy. The elements of the set were found in the clusters E1-E4.

CAN $(E) \_C o \_S I-10$ had two pieces. This set was a Siret connection. It was recovered from the cluster E2, almost side by side.

CAN(E)_Co_SI-11 had two elements. This was a nonconchoidal fragment connection. It was found in the cluster E2, almost side by side.

CAN(E)_Co_SI-12 included two elements. This was a transversal connection. The objects were recovered from the cluster E1, side by side.

\section{Schist}

$C A N(E) \_R \_C O-01$ had five elements. This set represented successive dorso-ventral flake removals. The flakes were partially cortical. The reduction was generated by freehand direct percussion. The pieces of the elements were recovered from the cluster E1.

$C A N(E) \_R_{-} C O-02$ had two elements. This was a dorso-ventral connection. Flaking was done by freehand 


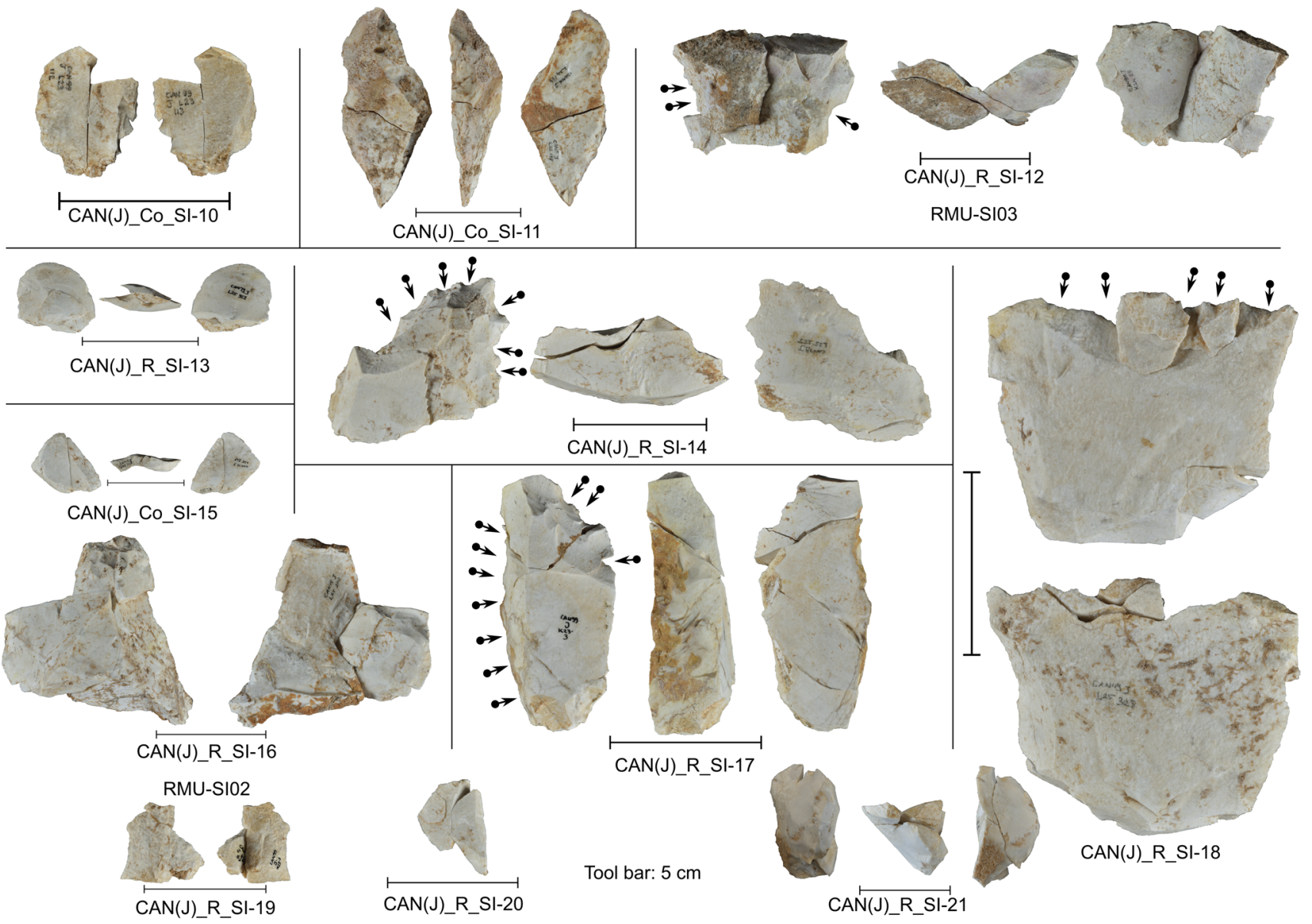

Fig. 12 Chert connections of level J (2)

direct percussion. This connection set recovered from the cluster E1.

$C A N(E) \_R \_C O-03$ had two elements. This set represented dorso-ventral connection. These were detached by freehand direct percussion. Concerning RMU, they were the same with the previous set; however, no connection was detected. The elements were found in the cluster E4.

$C A N(E) \_C o \_C O-04$ included two elements. This was a Siret connection. This set was recovered from the cluster E3, side by side.

CAN $(E)$ CO_CO-O5 included two objects. This connection was a Siret. The objects were found in the cluster E1, side by side.

$C A N(E) \_C o \_C O-06$ had two elements. This was a nonconchoidal fragment connection. The pieces were recovered from the square L25.

\section{Quartz}

$C A N(E) \_R \_Q S$-01 comprised two elements. This was a complete set and core-flake connection. The pebble was flaked by bipolar technique on an anvil (de la Peña 2015; Vergès and Ollé 2011). There were several impact points on the flake. The core was recovered from the cluster E4. However, the flake of the set was found in the square L24. This distance was $229.92 \mathrm{~cm}$.

$C A N(E) \_R \_Q S-02$ had six elements. This was a flaking sequence and an almost complete connection set. The pebble was flaked by bipolar technique on an anvil. There was a technological gap in the central part of the connections. One of the elements has the percussion marks. One of the pieces was found in the cluster E3 and the others in the cluster E2.

$C A N(E) \_R_{-} Q S-03$ included two elements. This was a dorso-ventral connection. The elements of the set were recovered from the cluster E1 and the square L25.

$C A N(E) \_C o \_Q S-04$ had two elements. This connection presented a Siret. The pieces were recovered from the cluster E1, almost side by side.

\section{Sets of level J}

Thirty-two sets were generated (Online Resources 6-7). Quartzite $(N=9,28 \%$; Fig. 10$)$ and chert $(N=21,64 \%$; Figs. 11 and 12) were the highly represented raw materials. 

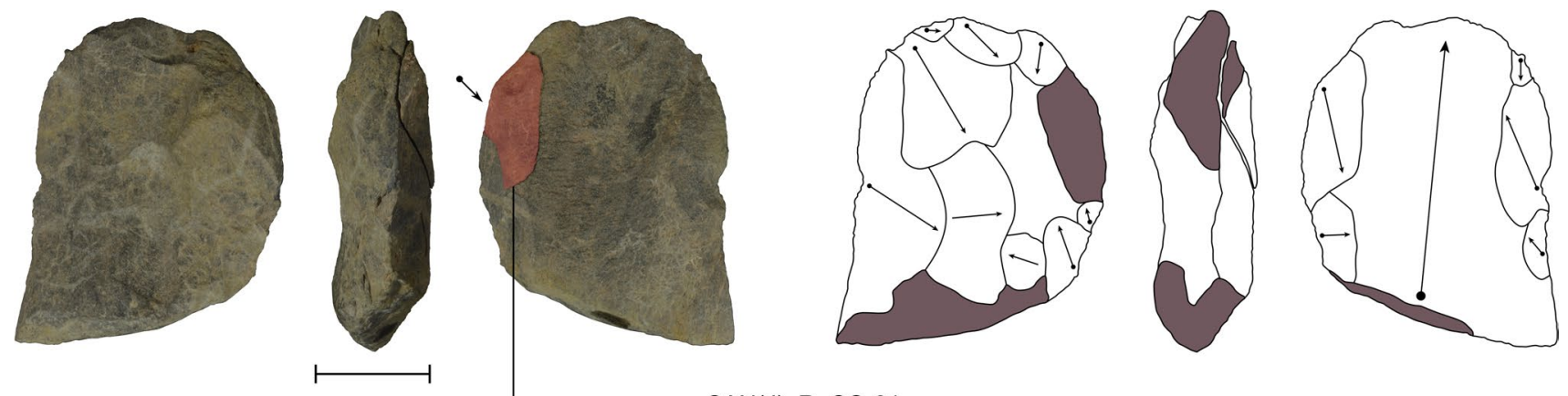

CAN(J)_R_CO-01

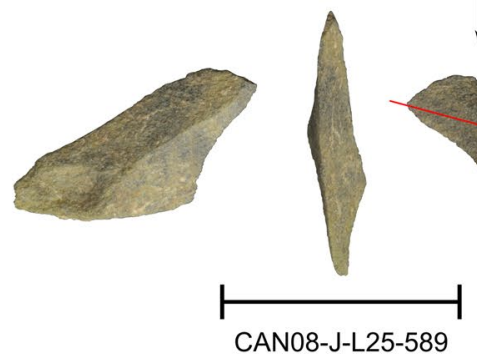

Tool bar: $5 \mathrm{~cm}$
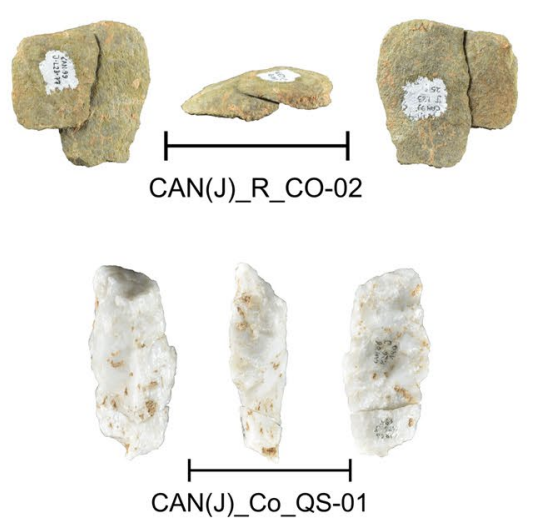

Fig. 13 Schist and quartz connections of level J

Only three sets were generated for schist $(N=2,6 \%)$ and quartz $(N=1,3 \%)$ (Fig. 13$)$.

\section{Quartzite}

$C A N(J) \_R \_Q T A-01$ comprised three elements. This set represented indirect intentional nonconchoidal fragment connections. These were the elements of a pebble with percussion marks. The pebble had several impact damages in the upper, lower, and left-right lateral edges. The pieces were found in the square L23 and almost side by side.

$C A N(J) \_R \_Q T A-02$ included four elements. These were successive dorso-ventral flake removals by freehand direct percussion. The final flake was retouched. The elements of set were recovered from the cluster J5, side by side.

$C A N(J) \_R \_Q T A-02.1$ comprised two elements and was a dorso-ventral connection. This set belonged to the same RMU with the previous set; however, no connection was found. Flaking was generated by freehand direct percussion. Regarding the dimension, the elements of this set were larger than former. Both elements of the set were cortical flakes. One of those elements was recorded in the cluster J5 and the other moved to $\mathrm{J} 4$.
$C A N(J) \_R \_Q T A-03$ had two elements and was a retouch connection. The tool was retouched from the right lateral edge. This was a second retouch because retouch removal had a previous modification removal on it. This connection set was recorded side by side in the cluster $\mathrm{J} 5$.

$C A N(J) \_R \_Q T A-04$ comprised six elements. This set represented dorso-ventral connection of successive cortical flakes. Flaking was done by freehand direct percussion. The flakes in the set were entirely cortical and cortical dominant. The scatter of this set showed random pattern. Even though those were not recorded side by side, the distances of them were close.

$C A N(J) \_C o \_Q T A-05$ represented two elements. This was a transversal connection. The set was a retouch tool on an entirely cortical eroded pebble. It had only two retouch removals side by side. One of the elements of the set was recorded from the cluster J6 and the other from the square L23.

$C A N(J) \_R \_Q T A-06$ included four elements. It had transversal, Siret, and dorso-ventral connections. Regarding the technological observation, it had no characteristic information. In terms of scattering, it had a random pattern.

$C A N(J) \_R \_Q T A-07$ included six elements. This was a flaking sequence by freehand direct percussion. Those 


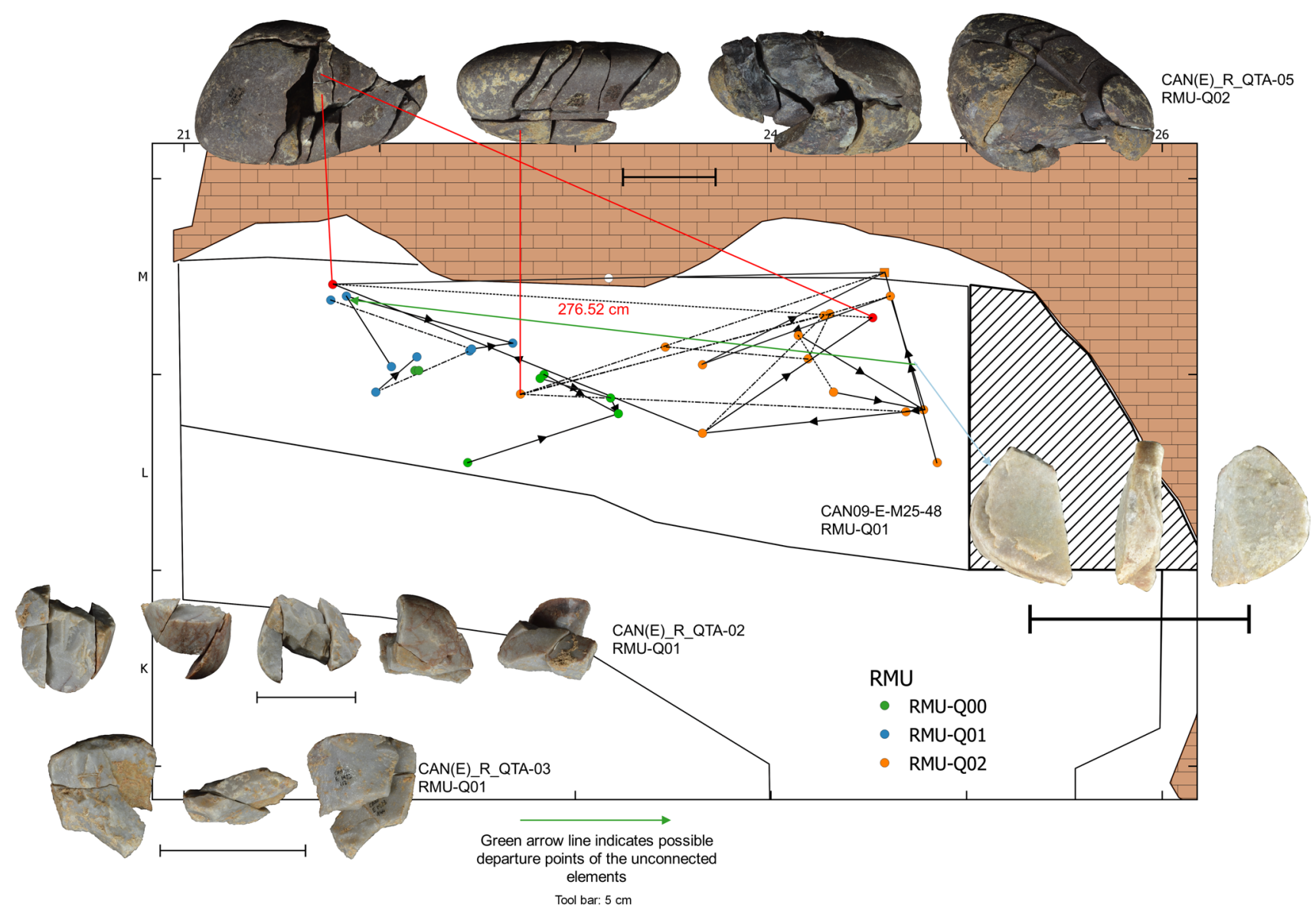

Fig. 14 Important spatial patterns of quartzite (level E)

elements had cortical dominant dorsal faces. The final piece was a retouch tool. This set included the longest distances. First, one of the cortical flakes was recovered from the cluster J3 and two pieces that connected with this flake were moved $351 \mathrm{~cm}$ away from the flaking area to the cluster J7. Second, one of the other elements of the set (CAN99J-L24-50) was recovered with a retouch connection in the square L23 side by side, $178 \mathrm{~cm}$ away from the cluster $\mathrm{J} 3$.

CAN $(J) \_C o \_Q T A-08$ comprised two elements. This was a transversal connection. This was the same RMU with CAN(J)_R_QTA-06; however, no connection was found. The set was recovered side by side from the cluster J6.

\section{Chert}

CAN $(J) \_R \_S I-01$ comprised four elements. This set represented a flaking sequence by freehand direct percussion. The core was flaked from two flaking surfaces. The flakes were small sized. The flaking surfaces were used as unipolar. This set was located in the cluster J1. The elements were recovered almost side by side. The elements of out of the connection of RMU-SI01 also concentrated in this cluster.
$C A N(J) \_R \_S I-02$ included four elements. This set represented flaking sequence by freehand direct percussion. The connected pieces were hard to identify because of the intense geode formation. The core and two angular fragments of this set were recovered from the square L24; however, the flake of this set was located in the cluster J3. Additionally, unconnected elements of the RMU-SI02 concentrated around the cluster J3. Only three pieces were recovered from where the core located. Those were two flakes and a retouch tool.

CAN $(J) \_C o \_S I-03$ had two elements and represented transversal connection. This set belonged to the same RMU with CAN(J)_R_SI-01; however, no connection was found among them. This set was recovered from the cluster J1.

CAN $(J) \_C o \_S I-04$ included two elements. This was a transversal connection. It was recovered from the square L23, almost side by side.

CAN $(J) \_C o \_S I-05$ had two elements. This was a transversal connection. This set was the same RMU-SI01 and found in the cluster J1. However, no connection was found between CAN $(J) \_R \_S I-01$ and CAN $(J) \_C o \_S I-03$.

$C A N(J) \_R \_S I-06$ comprised five elements. This set was one of the best examples that related to successive retouch 


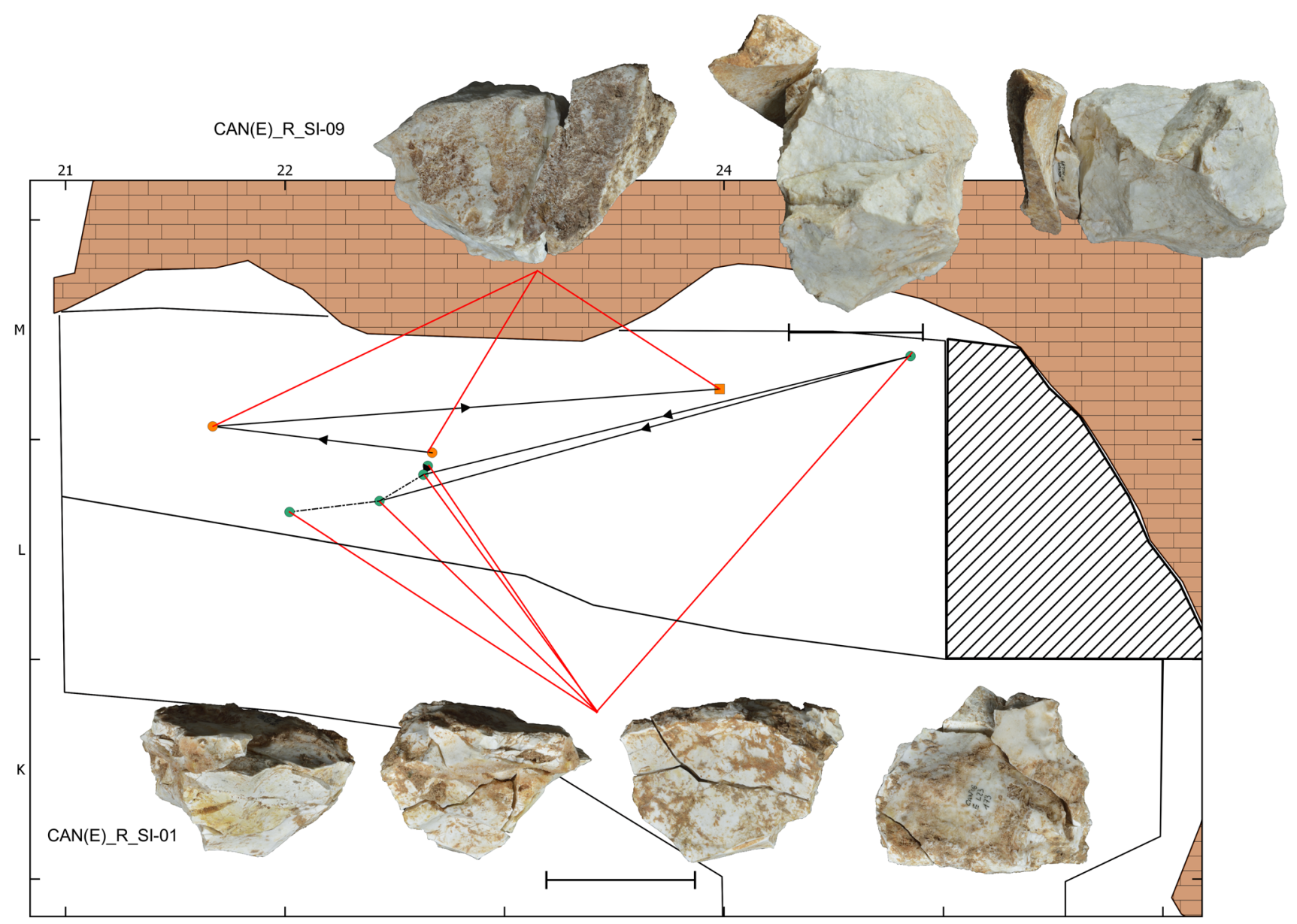

Tool bar: $5 \mathrm{~cm}$

Fig. 15 Important spatial patterns of chert (level E)

removals by freehand direct percussion. Morphologically, it was a notch that was made on a flake. Right lateral edge of the element was retouched thrice. However, only two of them were recorded. The elements of the set were found in the cluster J1. They were recovered with minimal displacements.

$C A N(J) \_R \_S I-07$ included two elements. This was a retouch connection. The retouch tool was made on a large flake and had large platform with several smashing scars. It had two notches in the two lateral edges. Only one of them had a connection. These pieces were found in the cluster J4.

CAN $(J) \_C o \_S I-08$ comprised two elements. It represented a Siret connection. This set was found in the cluster $\mathrm{J} 7$, side by side.

CAN $(J) \_C o \_S I-09$ included two elements and was a Siret connection. These were recovered from the square L24, almost side by side.
CAN $(J) \_C o \_S I-10$ consisted two elements and was a Siret connection. These were found in the square L23 with no displacement.

CAN $(J) \_C o \_S I-11$ had two elements and was a transversal connection. These pieces were recovered $201 \mathrm{~cm}$ far away from each other. One of them was found in the cluster J7 and the other was very close to the cluster J6. The unconnected elements of the same RMU scattered randomly. Two of them were in the cluster J7, and the other three elements were found in the clusters $\mathrm{J} 1-\mathrm{J} 3$ and the square $\mathrm{L} 24$.

$C A N(J) \_R \_S I-12$ comprised three elements. This was one of the significant dorso-ventral connections by freehand direct percussion. The first and third elements of the connection set were the retouch tools. Morphologically, the third element was more characteristic than the first one. This element presented with a very deep notch and a convergent point. Unluckily, no retouch connection was recorded. Regarding the scatters, two elements of this set were found 


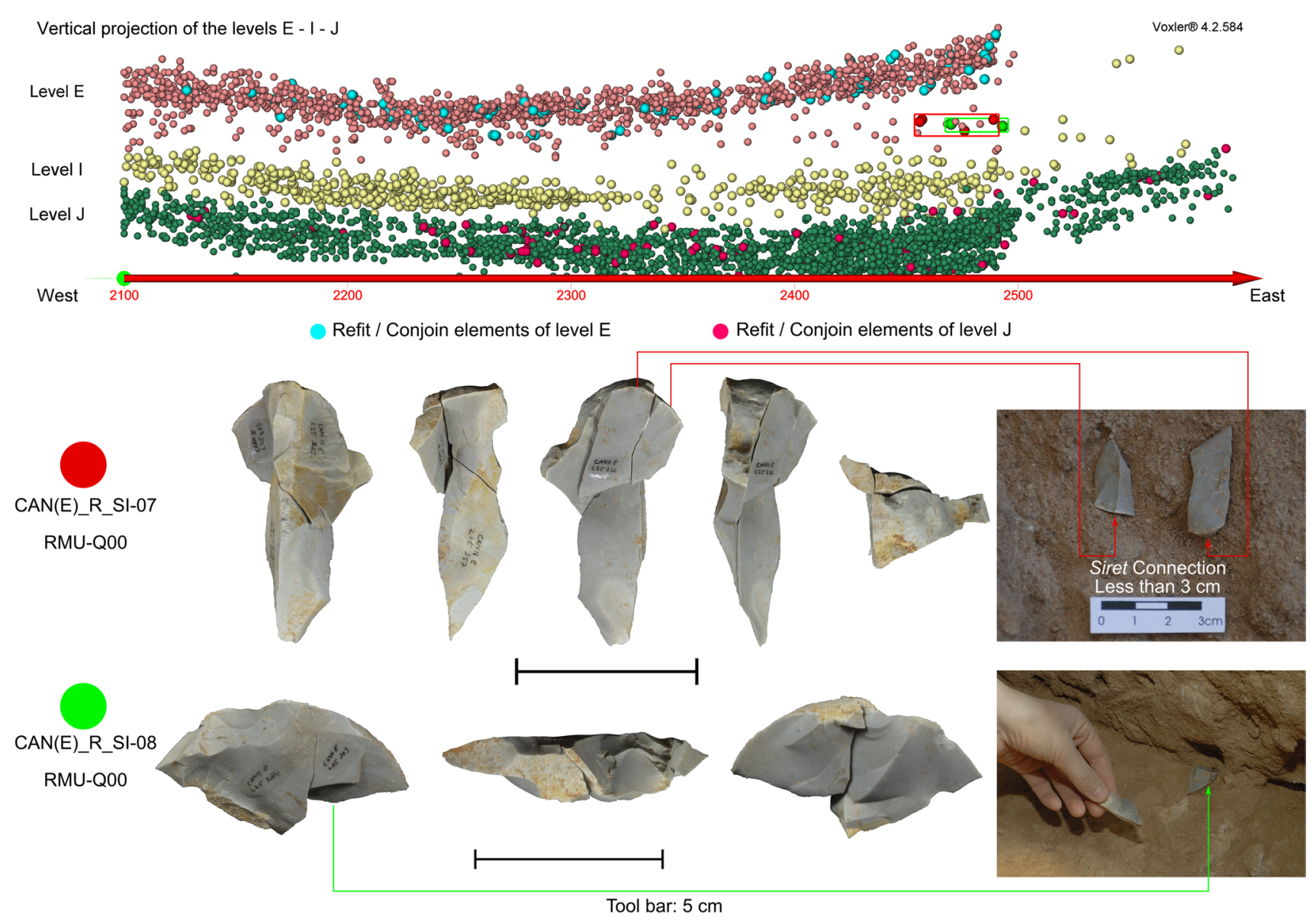

Fig. 16 Vertical projection of the levels E-J and the sets CAN(E)_R_SI-07 and CAN(E)_R_SI-08

with very small displacement in the cluster $\mathrm{J} 7$ and the third element (CAN99-J-K24-28) moved to the square K24. The most of the unconnected elements of RMU-SI03 concentrated in the cluster J7, and one of them (CAN02-J-K25-332) was located in the cluster $\mathrm{J} 1$.

$C A N(J) \_R \_S I-13$ included two elements and was a dorsoventral connection by freehand direct percussion. One of the elements of this set was recovered from the cluster J4, and the other came from the square L24.

$C A N(J) \_R \_S I-14$ consisted two elements. The connection between elements was a dorso-ventral by freehand direct percussion. The retouch tool had very large platform and carinated morphology. Unluckily, no retouch connection was recorded. The retouch tool of the set was found in the cluster J4, and the flake came from the square L23.

CAN $(J)$ CO_SSI-15 had two elements. This was a Siret connection. These pieces were found in the cluster J4 with almost no displacement.

$C A N(J) \_R-S I-16$ comprised two objects. This set was the same RMU with CAN(J)_R_SI-02; however, no connection was found between two sets. These flakes were removed by bipolar orthogonal strategy. These pieces were recorded in the cluster J4 with a small displacement.

$C A N(J) \_R \_S I-17$ consisted two elements. The retouch tool was made on a carinated flake, and the retouched edge was very steep. Unfortunately, these objects had very patinated and fragile structure. Because of this, the dimension of this tool should have been bigger than the current size. Additionally, the flake that was moved due to the retouch had continuous denticulate. This probably was removed from the distal part of the tool. One of the pieces came from the square L23 and the other from the square K23. There was a small displacement between them.

$C A N(J) \_R \_S I-18$ comprised five elements. This was the second important connection related to successive retouch connection by freehand direct percussion. The tool was a transversal denticulate scraper. Four subsequent smallsized flakes were recorded. This connection set came from the cluster J4. The displacements between the pieces were very small.

$C A N(J) \_R \_S I-19$ included two elements and was a dorso-ventral connection by freehand direct percussion. 

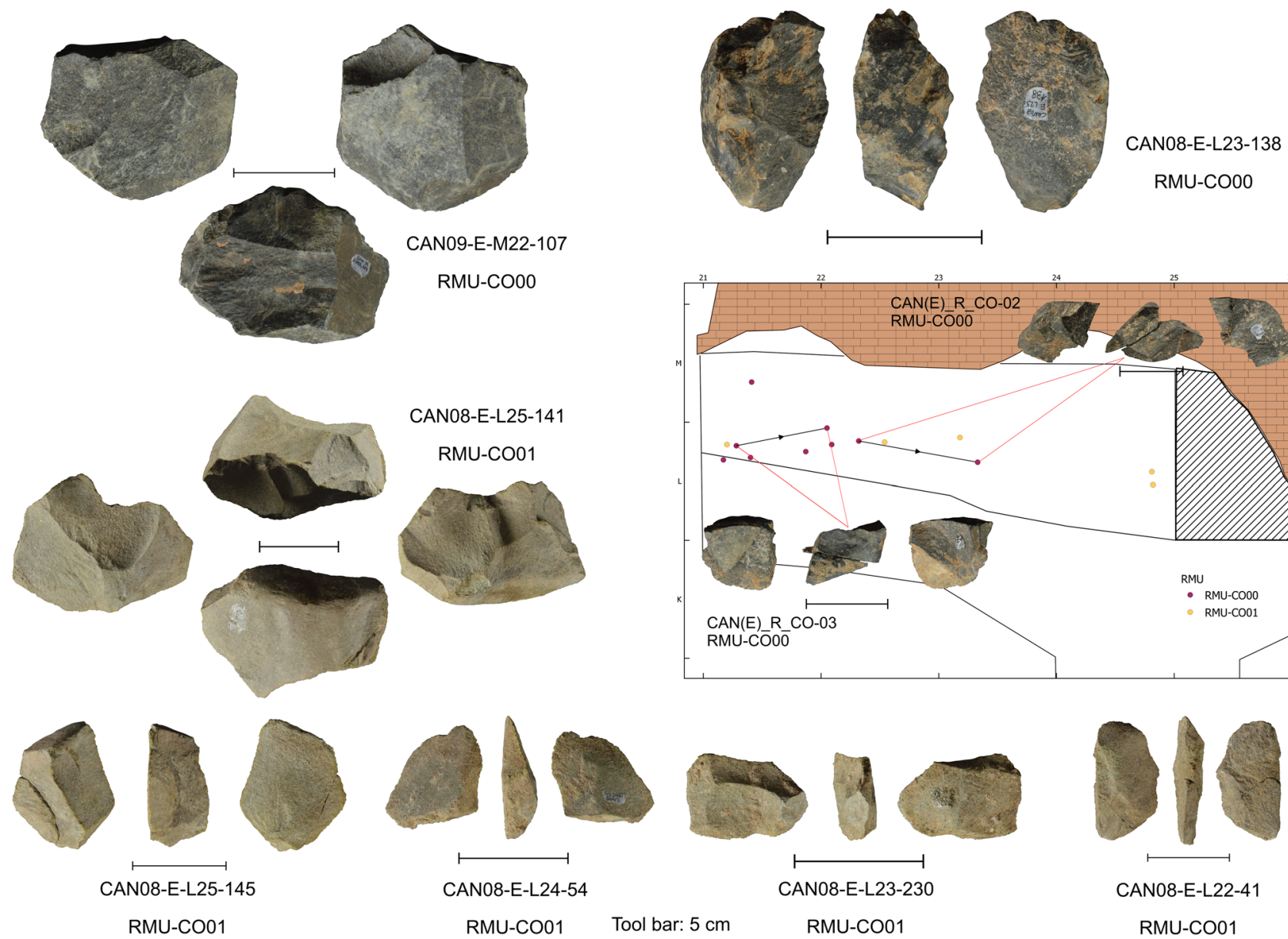

Fig. 17 Important spatial patterns of schist and the distributions of RMU-CO00 and RMU-CO01 (level E)

The pieces of the set came from the squares K23-K24 with a small displacement.

$C A N(J) \_R \_S I-20$ comprised two elements and was a dorso-ventral connection. The pieces were recovered from the clusters J1-J2.

$C A N(J) \_R \_S I-21$ involved three elements. This was a dorso-ventral connection by freehand direct percussion. The elements had intense patina. All pieces recovered from the squares K24-L24.

\section{Schist}

$C A N(J) \_R \_C O-01$ comprised two elements. The retouch tool was a biface (cleaver) on a large schist flake. The tool had partially cortex. The left and right lateral edges of the tool were shaped, and the distal part was an unretouched cutting edge. One of the shaped edges had a dorso-ventral connection with a flake that probably was removed for shaping. Regarding the spatial location, the cleaver was recovered from the cluster J5 and the shaping flake of the edge was found in the cluster J4 (very close to the cluster J1).
$C A N(J) \_R \_C O-02$ included two elements and was a dorso-ventral connection. The pieces were recovered from the square L23, side by side.

\section{Quartz}

CAN $(J) \_C o \_Q S-01$ had two elements. It was a transversal connection. The elements were found in the cluster J5 with no displacement.

\section{Discussion}

\section{Interpretation of some important refit/conjoin sets}

\section{Level $\mathrm{E}$}

The most intense concentration of level $\mathrm{E}$ was detected in the central part. Additionally, also three small clusters were detected. The cluster E1 showed overrepresentation of the flake and flake fragment categories. Additionally, all the 


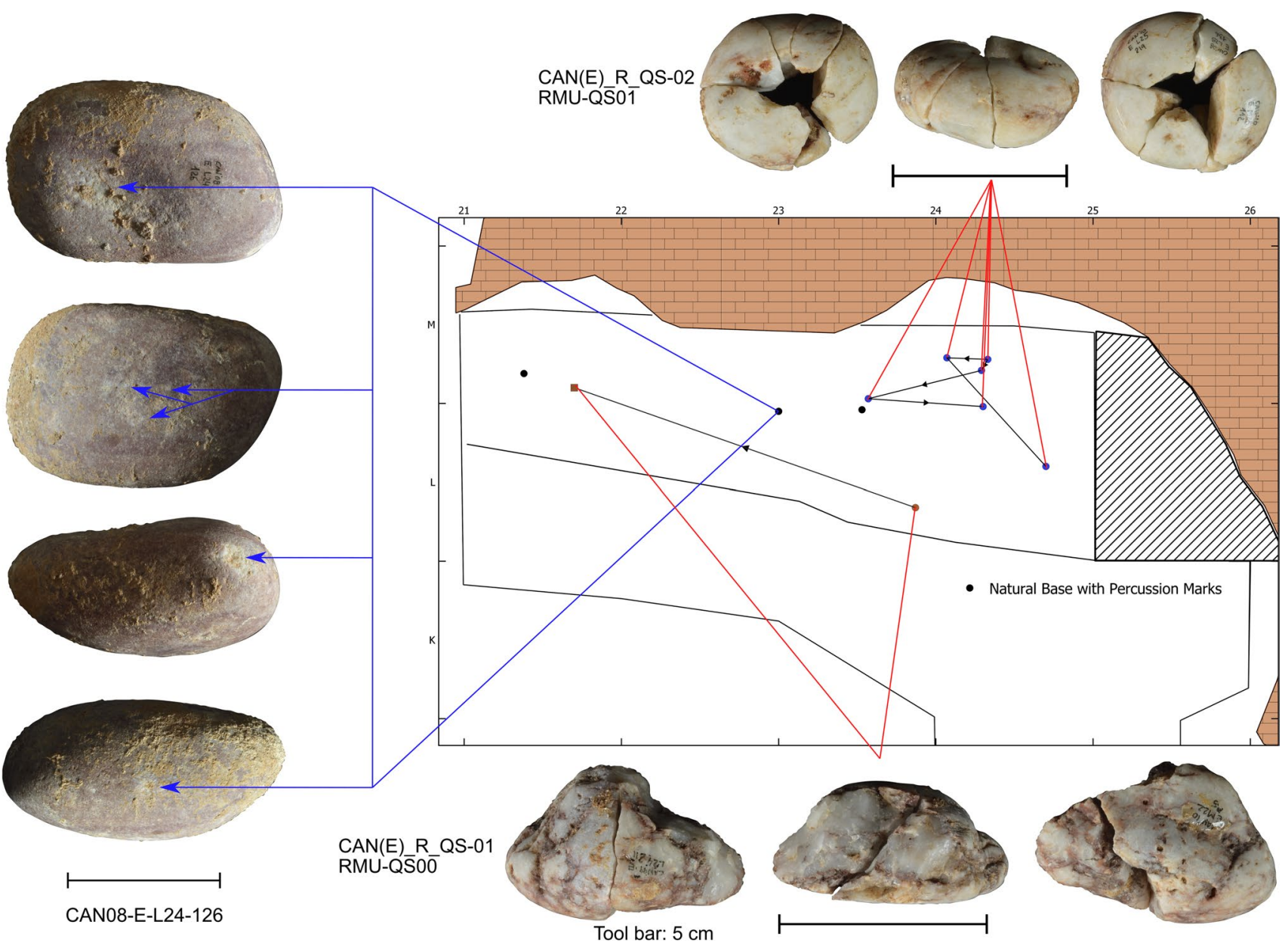

Fig. 18 Important spatial patterns of quartz and the impact scars of the percussion material (level E)

clusters had a high ratio of very small and noncortical flake. In terms of the spatial pattern, each type of raw material had interesting exceptional cases that should be discussed. The high representation of the dorso-ventral (32\%) and core-flake (27\%) connections showed the reduction of the elements was carried out in the site. This is also approved by the dimensions and dorsal face corticality of flakes.

Quartzite had two interesting results. First, the longest distance of the level $\mathrm{E}$ was documented in the set CAN(E)_R_QTA-05. Most of the elements were recovered from the cluster E2. However, one of the Siret fractures (CAN09-E-M22-113) was found $276.52 \mathrm{~cm}$ away from where the main concentration was found. Additionally, one of the angular fragments (CAN08-E-L23-214) moved to the cluster E1. This is exactly where the set CAN(E)_R_QTA-01 was recovered. Second, one of the flake fragments (CAN09E-M25-48) of the RMU-Q01 was recovered from the square M25. Most of the unconnected and connected elements of this RMU were located between the clusters E1 and E4. Even though there was no physical connection between the flake fragment and RMU-Q01, this could be a movement proof to the east part of the level E (Fig. 14).

Chert also had a great importance, in terms of horizontal and vertical projections. First, one of the important connections was documented in the set CAN(E)_R_SI-01. Even though the elements of this sequence were recovered from the cluster E1, the flake of this sequence was located in the cluster E2. The reduction of this set was carried out in the central part, and the flake (CAN10-E-M25-69) moved to the east part of the level E. Second, the set CAN(E)_R_SI-09 presented opposite direction to the previous set. The core (CAN09-E-M24-38) was recovered from the cluster E2 while the flake and flake fragments were found in the clusters E1 and E4 (Fig. 15).

The third one is directly related to the vertical projection of RMU-SI00, CAN(E)_R_SI-07, and CAN(E)_R_SI-08. The type of chert was highly qualified than the other types. These samples represented altered rounded cortex, about 1-2 mm wide (10YR $8 / 2$, very pale orange), that demonstrate regular morphologies of the geological blanks. Macroscopic comparisons with the reference lithic collection at IPHES indicate 


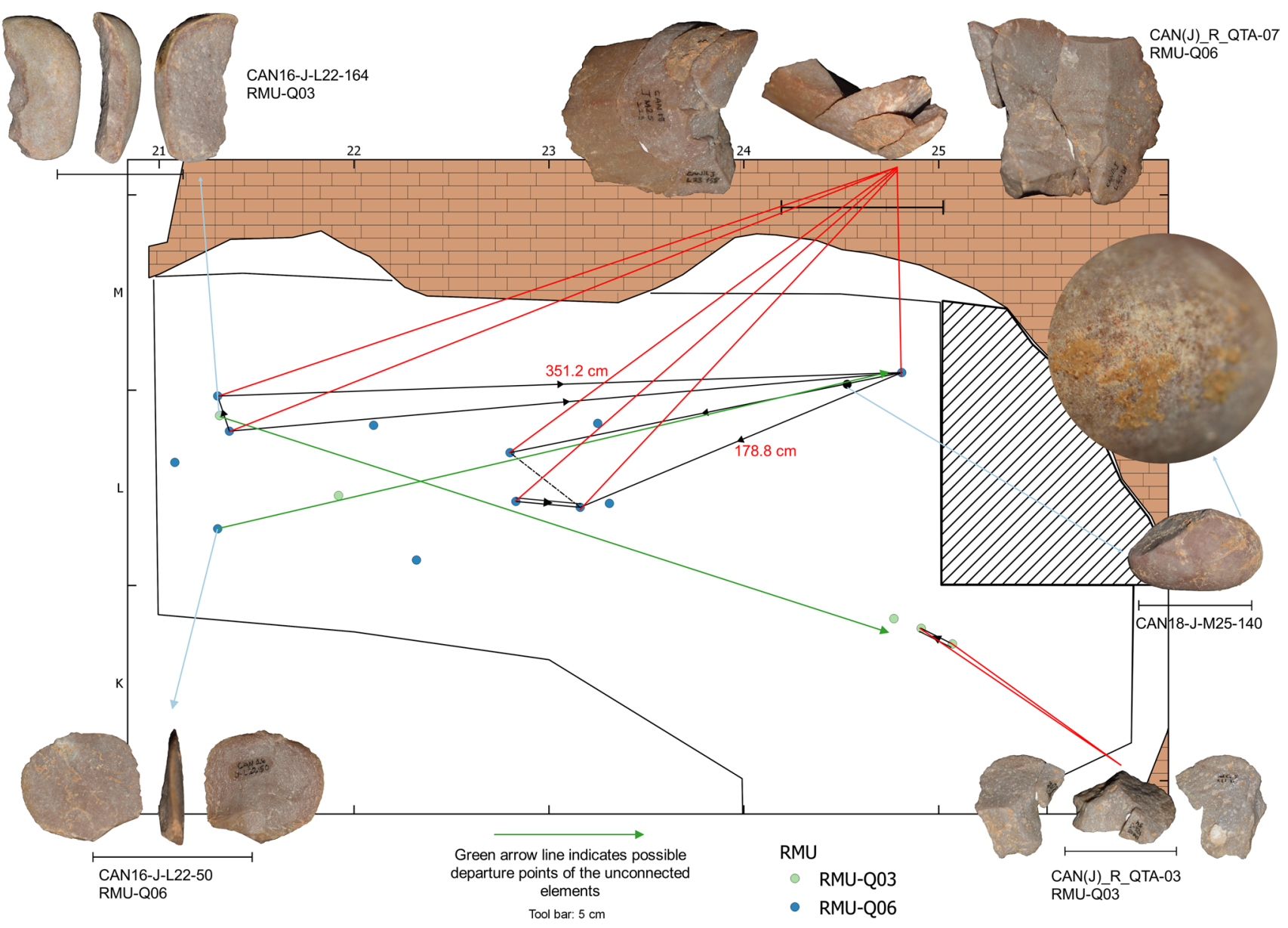

Fig. 19 Important spatial patterns of quartzite (level J)

compatibility with Upper Muschelkalk chert, which can be located very close to La Riba town and continuously along the Triassic series of the pre-littoral range (Soto et al. 2014, 2018). Both sets were recovered between the levels $E$ and I and showed almost no displacement and even could have detached from the same nodule. If we think about the distances and types of the connection, the pieces were flaked in the site. When we concentrate on the vertical projection of the refit/conjoins, they do not present any vertical displacement between the levels. This result is very important about the absence of post-depositional disturbance and excellent preservation of the archaeological levels (Ashton 2004; Hofman 1986; Villa 1982; Villa and Courtin 1983). Vertical projections of the RMU-SI00 and its connections point out a different occupation between two levels (Fig. 16).

Connections of the schist mainly concentrated in the cluster E1 and square L22. First, RMU-CO00 and its connection sets were located around L22; however, there was no connection detected between the sets, core (CAN09-EM22-107), and single elements. Second, two elements of RMU-CO01 were found in the square L25 and the others have scattered random. This RMU included remarkable cortical flakes and a core. However, no connection was found between those pieces. The core (CAN08-E-L25-141) had two flaking surfaces and was reduced by the alternate platform method (Ashton 2016; Mcnabb 2007, p. 322). Unfortunately, interpretation of this spatial pattern is impossible due to the lack of physical connection and limited concentration. If we think about the situation of RMU-CO00, their connection sets presented flaking sequence. So, RMU-CO00 has strong evidence about the reduction of it was done in the site, though there are limited connections. However, RMU-CO01 could have been flaked away from the site and only selected pieces were imported (Fig. 17).

Quartz had two different spatial patterns. The set CAN(E)_R_QS-01 showed the movement between the cluster E4 and square L24, exactly where the flaking was carried out is impossible; however, the set CAN(E)_R_QS-02 concentrated around the cluster E2. Additionally, bipolar reduction is the common point of these sets (de la Peña 2015; de Lombera-Hermida et al. 2016; Vergès and Ollé 2011). If we interpret this case according to the general view of the refit/ 


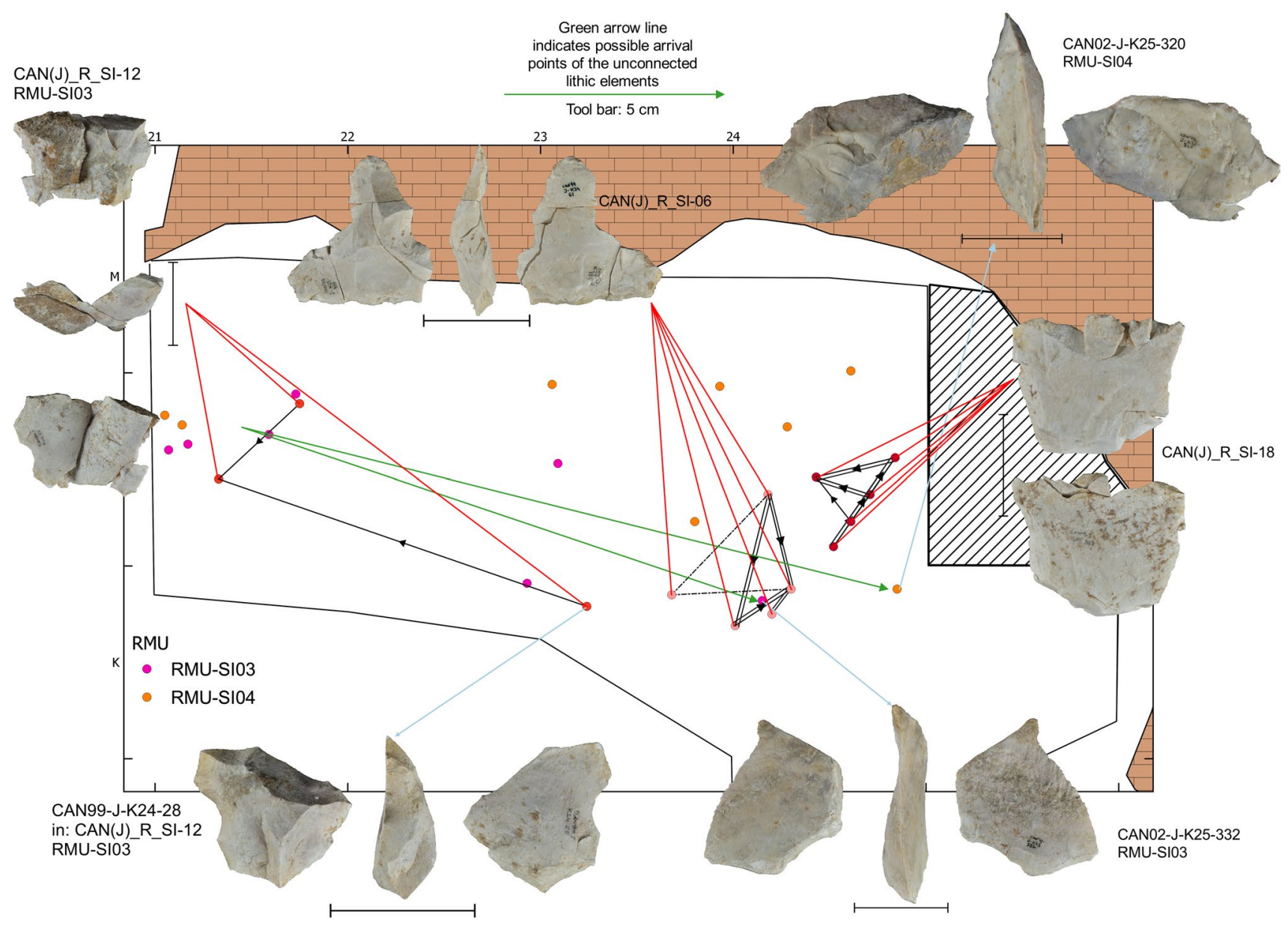

Fig. 20 Important spatial patterns of chert (level J)

conjoins, the east part of the excavation can be flaking points of these sets. Unluckily, they are almost complete sets and no RMU was found out of connections. However, one of the percussion materials was found in the cluster E1 (CAN08-EL24-126). This sample was a red ellipsoidal quartzite cobble and has very deep percussion damage in the horizontal and corner parts. This can be related to bipolar reduction. Maybe those pieces were flaked in the cluster E1 then moved (Fig. 18).

\section{Level J}

Level J showed multiple clusters regarding spatial density analysis. The most intense areas were located in the east part of the excavation. Flake dimension and dorsal face cortex ratio of the high-density clusters (J1 and J3) showed overrepresentation of very small flakes and noncortical dorsal faces. However, even though these clusters represented high-percentage flake ratio, the cluster J3 had extremely higher flake fragment percentage than J1. This was the main technological differences between two important clusters. In terms of the scattering, the results of the experimental analyses have already shown that most of the debris has concentrated within a 1-m area (Kvamme 1997; Newcomer and Sieveking 1980). Additionally, recent studies that are supported by modern quantitative techniques investigate the scatter patterns. The handedness of the knappers plays a very important role in the scatters of lithic elements. The veracity of this hypothesis was documented by an experimental protocol. The results of this study demonstrated the lithic elements scattered by the right-handed knappers group concentrated to the right where the knappers were working. On the other hand, the flaked pieces by the left-handed knappers showed a concentration to the left (Bargalló et al. 2018). Of course, these are not enough for the interpretation of the clusters. Flaking area also must have rest of the technological indicators inside of this concentration such as cortical flakes, flakes, and flake fragments. The clusters J1 and J3 showed similar scatter patterns as in the results of the experimental cases. However, the difference of flake fragment ratio makes the technological evaluation of these 


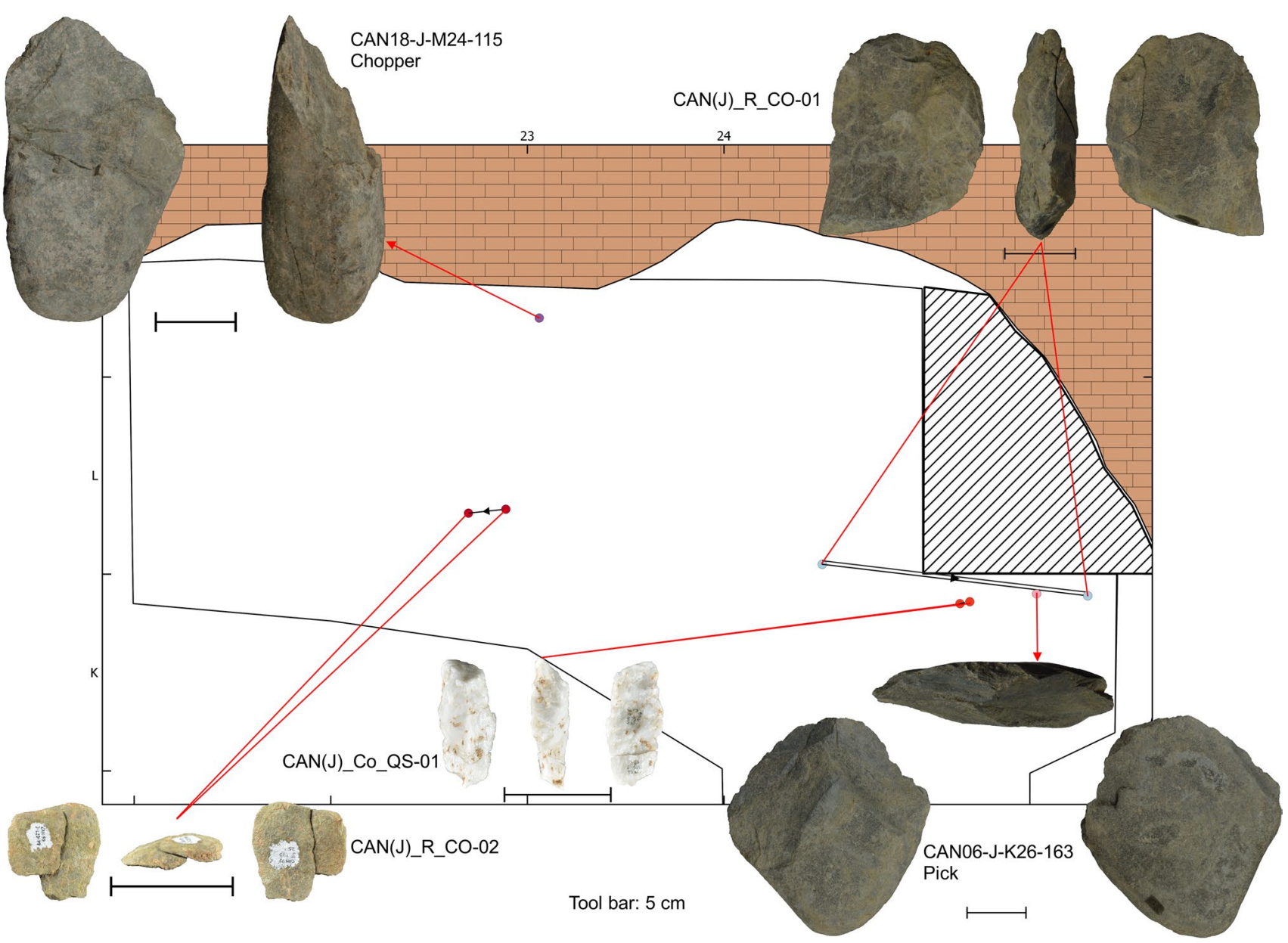

Fig. 21 Horizontal projection of the sets of schist and quartz and large cutting tools (level J)

clusters difficult. This complicated issue will be discussed in the comparison sub-section of levels E and J. The high representation of the dorso-ventral (37\%) and also successive retouch $(17 \%)$ connections had important ratio. They showed that the flaking was done in the settlement. This can be also approved by the dorsal face cortex ratio and the flake dimensions. Both major indicators showed progressively increasing values.

In terms of the spatial patterns, the connection lines and their relation with the clusters are some of the important cases that should be debated. The inter-cluster connections were very limited. Almost, each element of the connection set was found in the same cluster with minimal displacement. However, there are some more different results than level E, regarding exceptional cases that should be mentioned.

Quartzite had two different scenarios regarding the cluster relation. First, the connection set CAN(J)_R_QTA-07 was recovered from three parts of the excavation (west, center, and east). There were a broken flake and a flake fragment moved to cluster J7; however, the main cortical flake of this set was located in the cluster J3. In addition, the retouched element of the set (CAN99-J-L24-50) was recovered from the square L24 with a retouch connection. The distance of this connection was $33.1 \mathrm{~cm}$, and probably, modification should have been done in the square L24. One of the cortical flakes (CAN16-J-L22-50) was found in the cluster J7. Although this flake had no physical connection with this set, they were the same RMU. Probably, this flake also moved to the cluster J7 from J3. Second, the connection set CAN $(\mathrm{J})$ _R_QTA-03 was found in J5. This set comprised a retouch tool with a retouch connection, side by side. However, one of the single retouched tools (CAN16J-L22-164) was recovered from J7. The single retouch tool and the set were the same RMU. No physical connection was found between them. Probably, this tool moved to the cluster J7. Additionally, a pebble with a percussion mark (a hammerstone) was recovered from the cluster J3. This was very strong evidence that the flaking was done in the east. The one of the important issues is that no core was found in quartzite. The dorsal face corticality of the quartzite represented the abundance of entirely cortical flakes. If the 

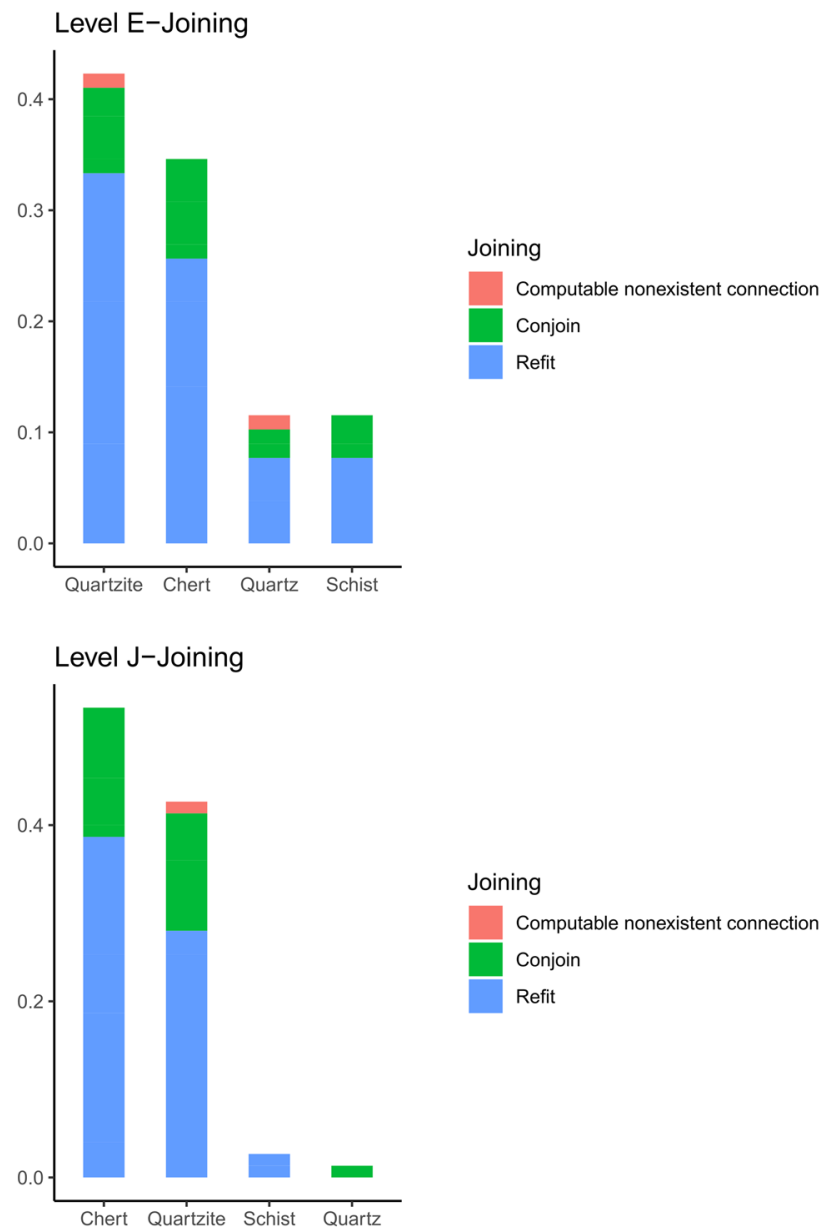

Fig. 22 Bar plots of joining and connection types (levels E and J)

general view of the quartzite is evaluated, the east side of the excavation area is the departure part of the both refitted and unconnected possibly moved elements (Fig. 19).

Chert had three similar scenarios as in the quartzite. The first scenario was related to be one of the best identified connection sets, CAN(J)_R_SI-12. This successive dorsoventral connection set demonstrated the first removal of this set was identified in the cluster $\mathbf{J} 7$ with a small displacement. However, the final element of this set moved to the square K24. Regarding the technological category, this was a retouch tool (CAN99-J-K24-28). According to the spatial view of this connection set, the reduction might have been done in the J7. Moreover, when we pay attention to unconnected elements of the RMU-SI03, most of them concentrated in this cluster. So, this same RMU concentration can explain the elements of the connection set belonged to $\mathrm{J} 7$ even though with no physical connection. This is a very good example in identifying that the RMU can be very useful and good indicator in terms of unconnected lithic elements and limited connections (López-Ortega et al. 2011; Machado et al. 2013; Romagnoli and Vaquero 2019). The
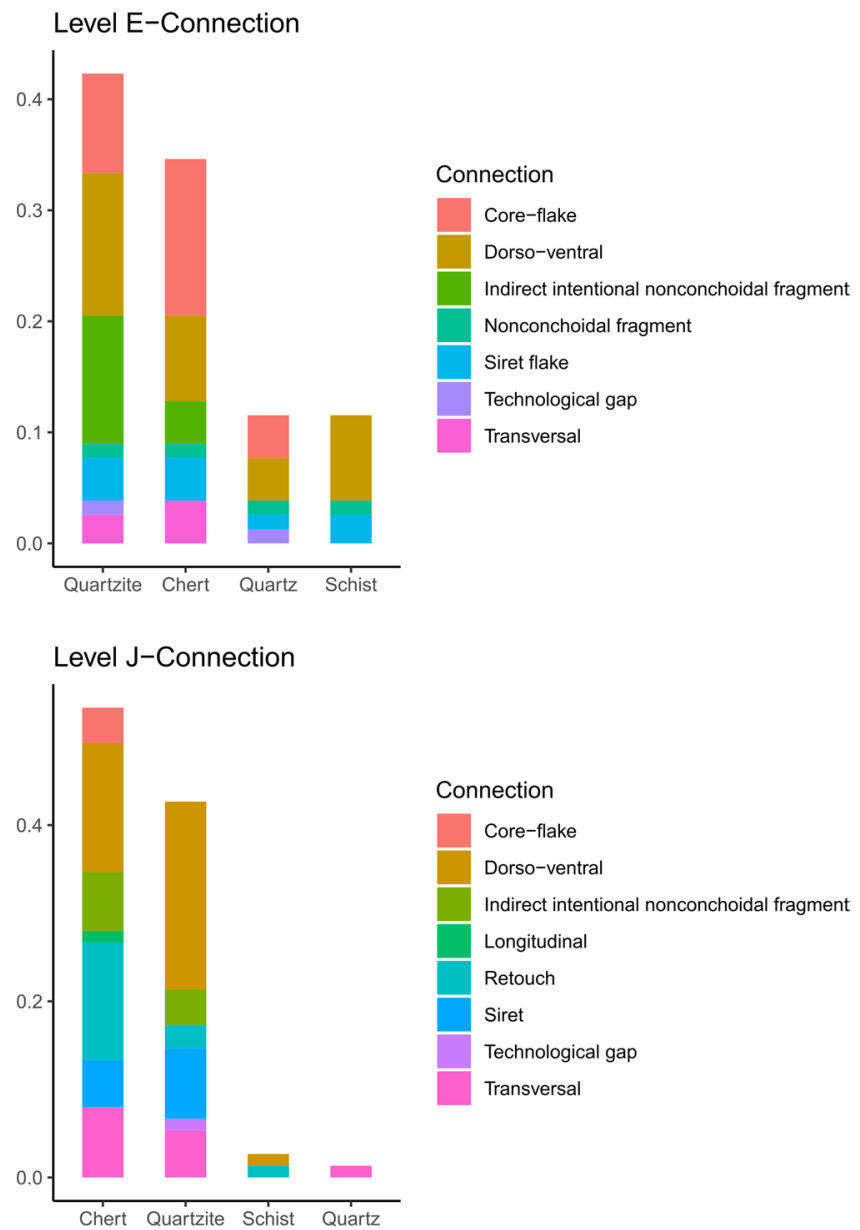

second scenario was related to an entirely cortical flake with a cutting edge (CANO2-J-K25-332). This was also RMUSI03 as the set that we mentioned in the first scenario of the chert. This flake was located in the cluster J1; however, the departure area of this flake might be the cluster $\mathrm{J} 7$ due to the reason of the first scenario. The third scenario was almost the same as the second scenario. The entirely cortical flake (CAN02-J-K25-320) that belonged to RMU-SI04 was located away from the concentration of this RMU. The issue that should be paid attention in this scenario is RMU-SI04 shows mainly random scatter than RMU-SI03 and has no physical connection. Only two elements of it located side by side in the cluster J7. Even though the element (CAN02J-K25-320) was recovered away from those two pieces, the rest of the pieces of RMU-SI04 scattered random. In terms of successive retouch connections of chert, the sets CAN(J)_R_SI-06 and CAN(J)_R_SI-18 had no relation with any clusters (Fig. 20). They were recovered from where they were modified.

As an important interpretation, the previous study of the La Cansaladeta has shown cut marks on an unidentifiable 

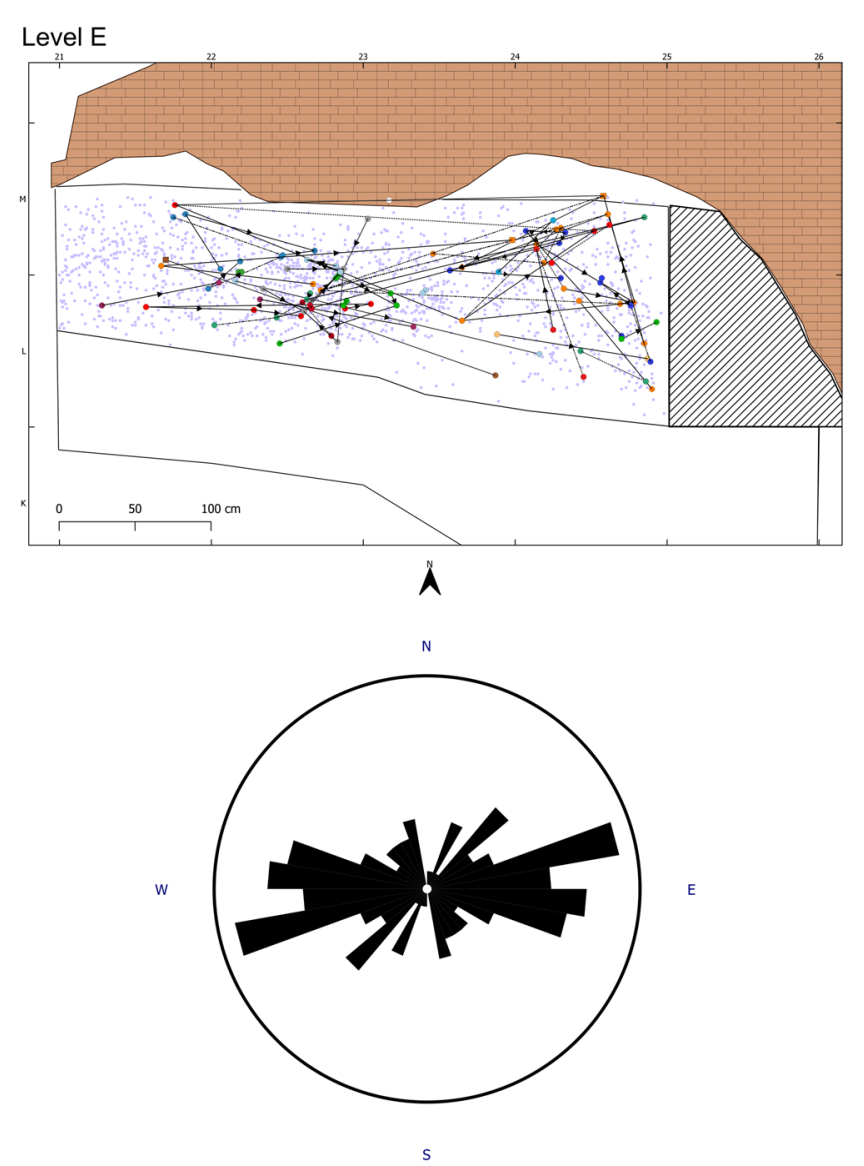
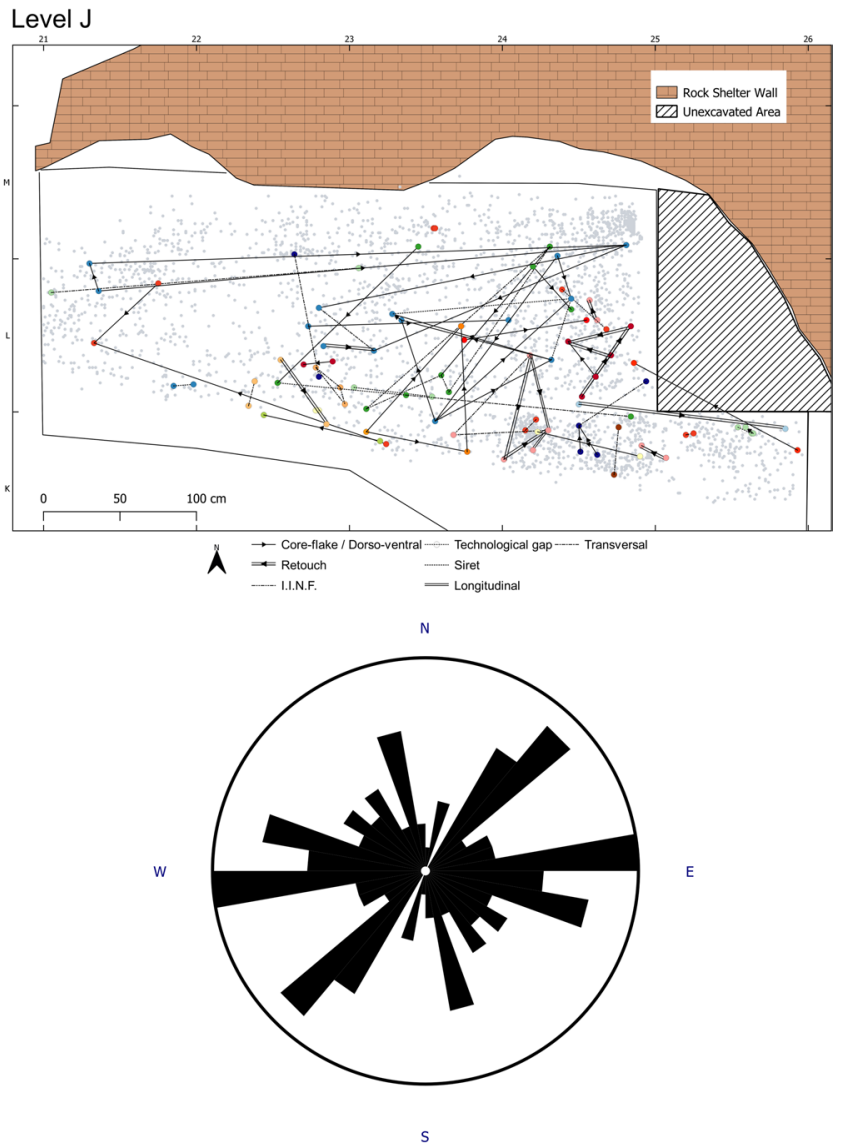

Fig. 23 Connection maps and the rose plots of directions of refit and conjoin lines (levels E and J)

long bone and one flat bone in levels $\mathrm{J}$ and $\mathrm{K}$. One of those samples (CAN02-J-K25-2) was recovered from the square $\mathrm{K} 25$, in the level $\mathrm{J}$. This is where the cluster $\mathrm{J} 1$ is located. The presence of the single flake (CAN02-J-K25-332) and set CAN $(J)$ _R_SI-06 could be the strong evidence of defleshing activity that could have been carried out in this concentration (Ollé et al. 2016).

Regarding schist, only two connection sets were identified. Those connections do not allow to interpret a spatial scenario due to the less connection percentage. First, $\mathrm{CAN}(\mathrm{J}) \_\mathrm{R} \_\mathrm{CO}-01$ represented bifacial shaping retouch and the cleaver of this set was found almost side by side with a pick (CAN06-J-K26-163) in the cluster J5. Additionally, an elongated chopper (CAN18-J-M24-115) was found in J6. Second, CAN(J)_R_CO-02 dorso-ventral connection was recorded in the square L23. In terms of macroscopic features, color, texture, and patterns of surface showed a great similarity with the cortical part of the cleaver. The flakes of this dorso-ventral connection might have been taken for the shaping. Regarding the spatial evaluation, maybe some of the shaping phases of this cleaver were done in the square L23. Then, it moved to the cluster J5. However, this is an open-ended inference with no exact proof. Unluckily, no physical connection was found among them. So, only we can indicate macroscopically common characteristics of those two connection sets (Fig. 21).

Regarding quartz, only one connection set was generated. Those pieces recovered from the cluster J5. Most of the quartz elements were found in the cluster J4. However, neither the cluster nor inter-cluster connections were found. Quartz material had no characteristics in terms of macroscopic observation. Additionally, most of the quartz elements $(61 \%)$ are less than or equal to $20 \mathrm{~mm}$. So, the elements were studied in the refitting practice only $39 \%$ of the entire quartz. However, no other connection was found even inside of this percentage.

\section{Level E vs. level J}

The results of these two levels had remarkable differences regarding connections, clusters, spatial patterns, and technology. In terms of refitting, both levels represented abundance of dorso-ventral connection (Fig. 22). This is very strong evidence that flaking was done in the settlement in both levels. In addition, level E had core-flake connection 


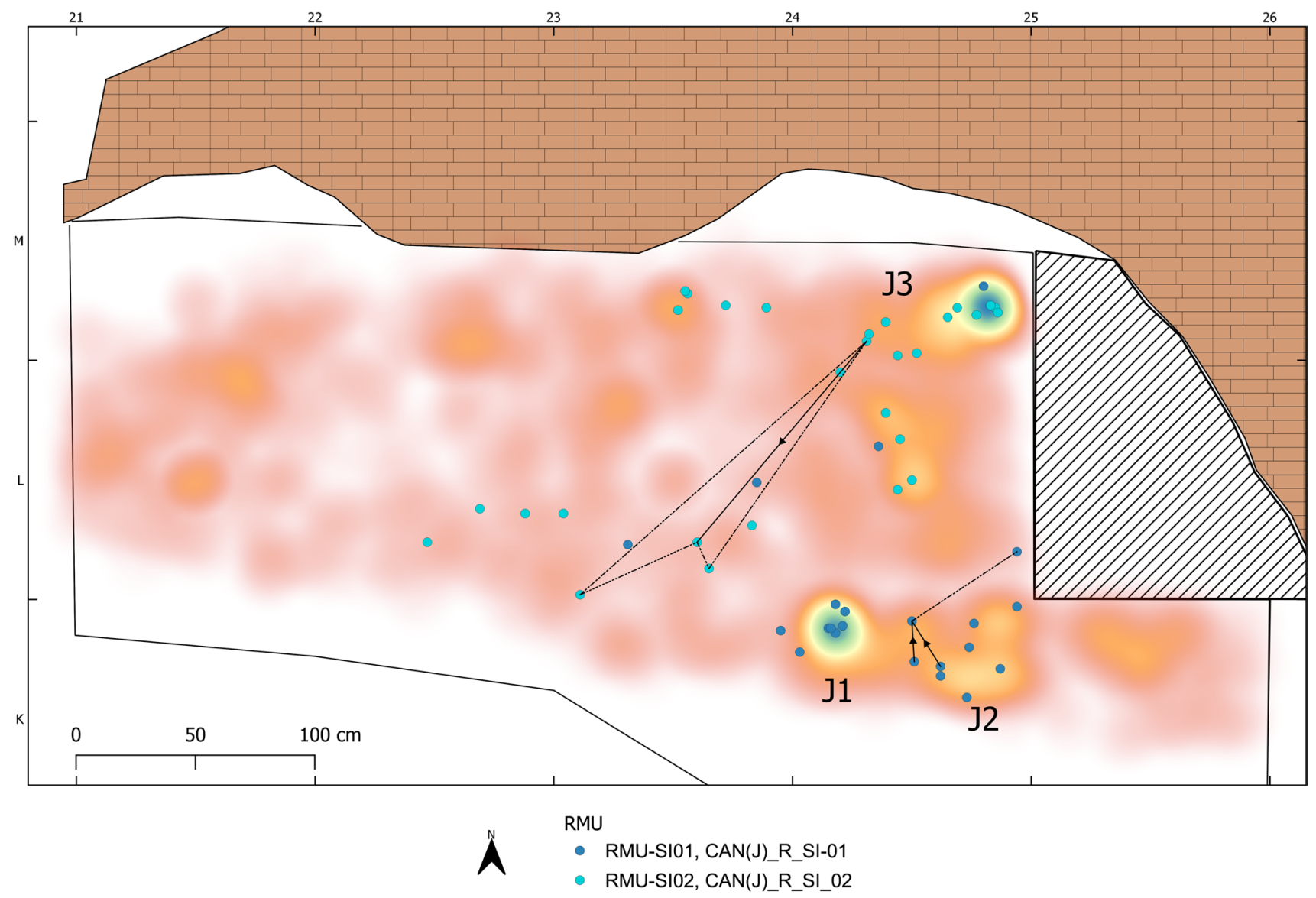

Fig. 24 Distribution of the core-flake connections and RMU-SI01 and RMU-SI02 (level J)

(27\%) and its ratio was almost equal to dorso-ventral (32\%). Almost complete flaking sequences of the quartzite and quartz industries were one of the major representations of level E. However, level J had no connection set with a complete reduction sequence. Moreover, quartzite industry represented with no cores and abundance of entirely cortical flake ratio as we mentioned up. This case indicated very well that level $\mathrm{J}$ was used for primary phases of the flaking, regarding quartzite. One of the important connection types of level $\mathrm{J}$ was retouch connection of the modified tools. Chert was very intense regarding successive retouching activity in level J. This was one of the main absences of level E. Even though there were retouch elements, they had no proof for the modification activity. Additionally, the presence of the $L C T$ was the main issues of the level $\mathrm{J}$ and one of the connection sets represented edge shaping of cleaver. This was also very significant result that showed the shaping phase of the bifacial industries was done in level J (Online Resource 8).

Clusters and spatial patterns between the levels E and $\mathrm{J}$ had very interesting results. Concerning the clusters of level E, it had no multiple lithic accumulations as level J as had. The central area of the excavation was the most intense zone (E1), and there were also three small clusters (E2-E4). Unluckily, neither level J nor level E had bidirectional connections regarding inter-clusters; however, the presence of intense preferential orientation was one of the main spatial patterns of level $\mathrm{E}$. This issue was a very significant difference between two levels regarding comparative spatial pattern analysis. Contemporaneity hypothesis is almost impossible for both levels, although there were seven well-separated clusters in level $\mathbf{J}$ due to the absence of bidirectional connection between the clusters and lack of faunal remains (Romagnoli and Vaquero 2019; Vaquero et al. 2019). Additionally technological analysis also did not show remarkable similarities regarding the clusters. So, the elements of clusters $\mathrm{J} 1-\mathrm{J} 3$ should be the remains of different temporal activities. Although level E had more scarcity cluster results than level $\mathrm{J}$, the preferential orientation of the connection line is one of the interesting results that should be investigated deeper in the future studies. Commonly, preferential tendencies of refit/conjoin lines and archaeological artifacts are related to the water disturbance (Ashton et al. 2005; Benito-Calvo and de la Torre 2011; de la Torre and 
Fig. 25 Connected moved and unconnected possibly moved elements of level E
Connected Moved Elements

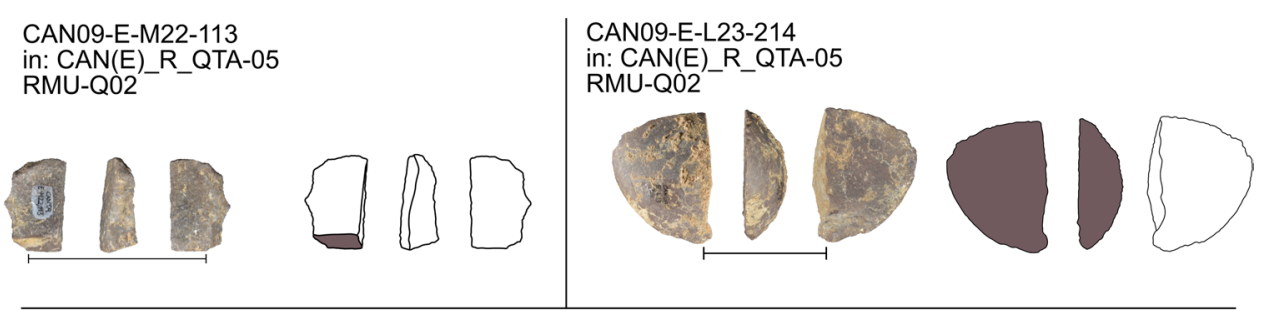

CAN10-E-M25-69 in: CAN(E)_R_SI-01

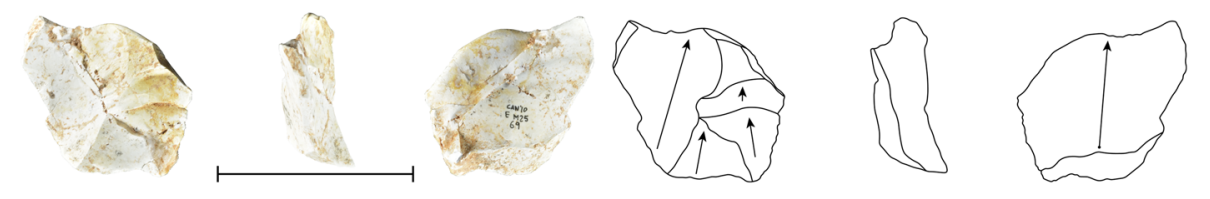

CAN99-E-L24-211 in: CAN(E) R_QS-01 RMU-QSOD
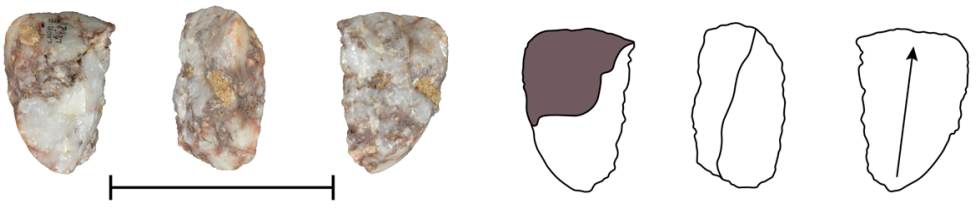

CAN09-E-M24-38 in: CAN(E) R SI-09
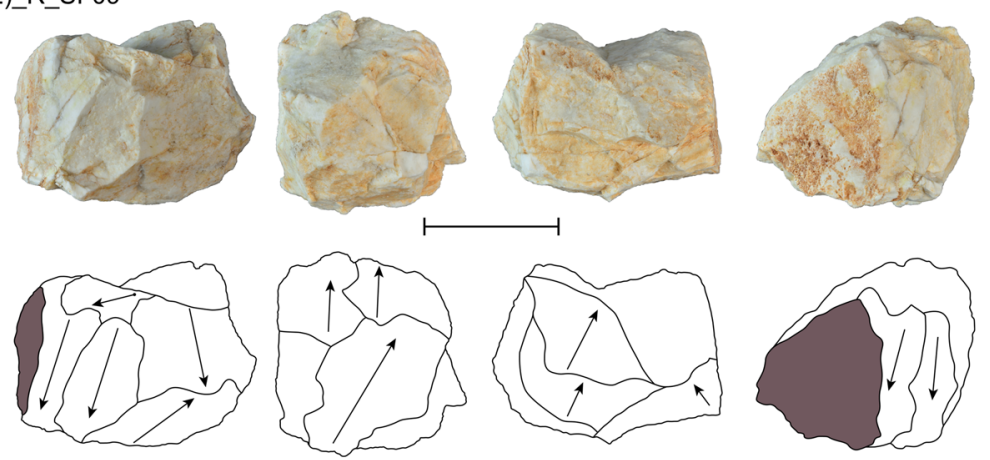

CAN09-E-M25-48 (Quartzite) RMU-Q01

Unconnected Possibly Moved Element
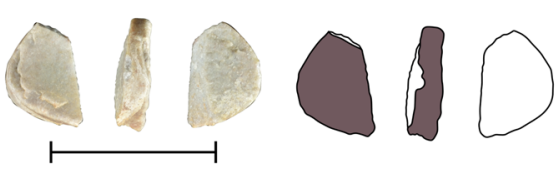

Tool bar: $5 \mathrm{~cm}$
Benito-Calvo 2013; Pope et al. 2020, p. 45; Roberts and Parfitt 1999, p. 321; Sánchez-Romero et al. 2016; Sisk and Shea 2008). However, recent analysis was generated by de la Torre et al. (2019) reported that bipolar flaking can show serious preferred orientations in an undisturbed experiment condition. Additionally, this result will play a very important role not only for the investigation of natural process and site formation but also for the analysis of cultural-behavioral agents (Sisk and Shea 2008) (Fig. 23). The situation of level
$\mathrm{J}$ is very spectacular. Even though there were very close hotspots that represented flakes and flake fragments, no connection was found between them. Moreover, most of the cores were located around the clusters $\mathrm{J} 1$ and J3. According to experimental data if small pieces can scatter $4 \mathrm{~m}$ away from their original area, these two close intense clusters should have had connection lines (Kvamme 1997; Newcomer and Sieveking 1980). However, clusters J1 and J3 had connections with cluster $\mathrm{J} 7$ although the distance was over $3 \mathrm{~m}$. 
CAN99-J-L24-50 in: CAN(J) R QTA-07 RMU-Q06

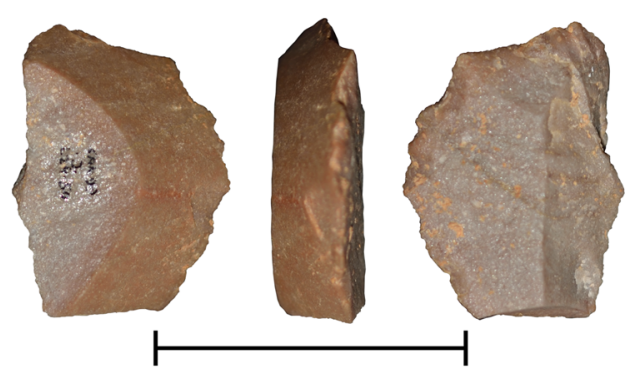

Connected Moved Elements
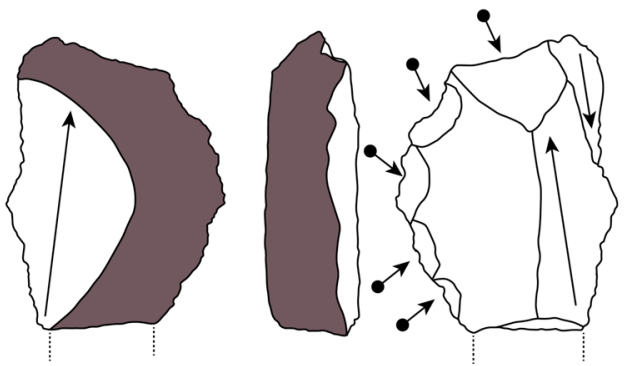

CAN16-J-L22-186 in: CAN(J)_R_QTA-07 RMU-Q06

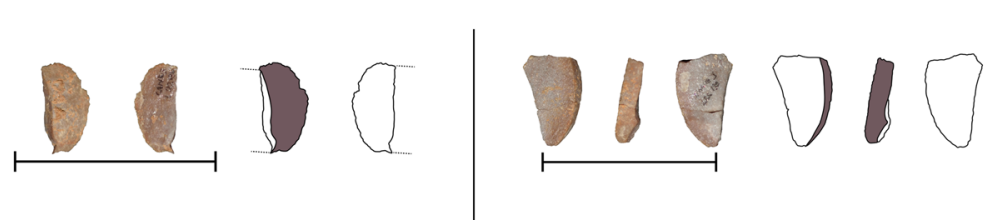

CAN16-J-L22-139 in: CAN $(J)$ R_QTA-07 RMU-Q06
CAN99-J-K24-28 in: CAN(J)_R_SI-12 RMU-SIO3
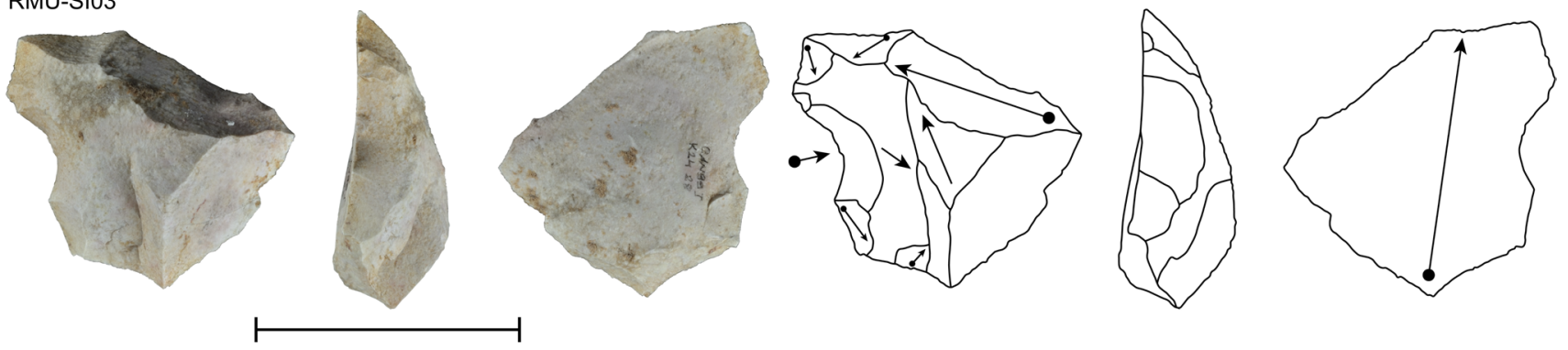

Tool bar: $5 \mathrm{~cm}$

Fig. 26 Connected moved elements of level J

Technological accumulation of $\mathrm{J} 1$ and $\mathrm{J} 3$ is complicated due to the flake and flake fragment ratio. However, one of the core-flake connection sets was found directly in the cluster J1 and J2. So, these clusters can be described as flaking area. Additionally, J3 had unconnected lithic elements of RMU-SI02. The connection set of this RMU was a coreflake connection that was found very near to J3. This issue can show that the cluster J3 was also a flaking area (Fig. 24). The moved artifacts and unconnected possibly moved artifacts of level E indicated no specific characteristics (Fig. 25). Level J also had no important pieces, regarding connected moved artifacts (Fig. 26). However, unconnected possibly moved artifacts of level $\mathbf{J}$ were mostly cortical flakes and located exactly opposite direction of their RMU concentrations (Fig. 27) (Tables 9, 10, 11, and 12). When technological results of the clusters of the two levels are compared, they indicated more or less the same technological results.

As we mentioned above, the connection sets $\mathrm{CAN}(\mathrm{E}) \_\mathrm{R}$ SI-07 and CAN(E)_R_SI-08 present a different short occupation between the levels $\mathrm{E}$ and I. This is the very important proof, regarding the absence of post-depositional disturbance. The elements of the connection sets did not indicate any displacements between the levels, in terms of vertical movement. The vertical movement of the lithic elements is one of the great indicators of disturbance and has been investigated by several researchers (Driscoll et al. 2016; Eren et al. 2010; Hofman 1986; Marwick et al. 2017; Villa 1982; Villa and Courtin 1983). Vertical displacement can be the result of different cases. In terms of horizontal movement, the lithic elements can be explained by human and animal activities (Schoville 2019). Especially, the effect of the carnivores plays a very significant role in the hearthrelated areas. According to the results of the experimental analysis of Camarós et al. (2013), Ursus arctos (bear), Crocuta crocuta (hyenas), Panthera leo (lions), and Canis lupus (wolves) modified the experiment area. Moreover, one of the male Ursus arctos in the area dug a hole with a 50-cm radius. However, neither carnivores nor hearth were identified in the site (Ollé et al. 2016).

Statistically, the numerical ages of La Cansaladeta among levels D and J can be indistinguishable (Ollé et al. 2016). This issue is very important. Rock shelters have represented 
Unconnected Possibly Moved Elements

CAN16-J-L22-50 (Quarzite) RMU-Q06

CAN16-J-L22-164 (Quartzite)
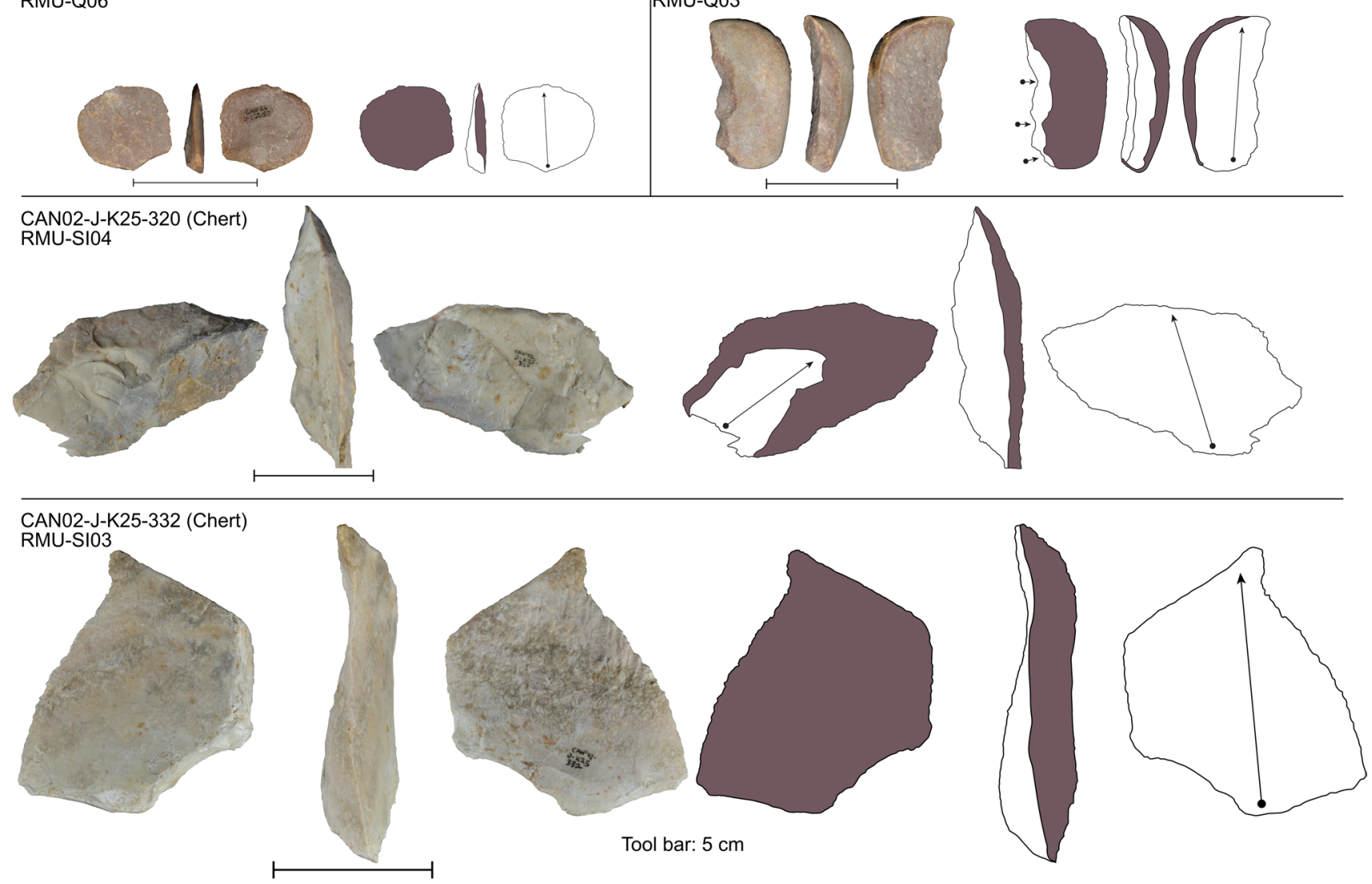

Fig. 27 Selected unconnected possibly moved elements of level J

several technological occupations, and faunal remains successively occurred due to using recurrently of the area and low rate sedimentation (Bailey and Galanidou 2009; Sánchez-Romero et al. 2016; Sañudo et al. 2016). However, well preservation of the archaeological levels makes this issue of La Cansaladeta more different than the general view of the rock shelters. As a result of this, occupation levels can be analyzed with a high resolution. The importance of well-preserved archaeological contexts on the spatial density analysis was also shown by one of the recent studies of Qesem cave (Gopher et al. 2016).

\section{Duration of the occupations}

The abundance of short distance and unidirectional connection lines due to the small dimension of the site can be an important indicator that is related to the short-term occupation hypothesis (Bargalló et al. 2020). In addition, very low tool diversity and thin archaeological deposits are the second ones. Those criteria show compatibility with the current results of La Cansaladeta. However, occasionally, the size of the site and the universal criteria cannot be enough to elucidate the site function (Bicho and Cascalheira 2020). Also, a very low percentage of the faunal remains restraints to make broad inferences. If we could see the presence of nonlocal raw materials in the site, this could have been used as a strong indicator of mobility of the human groups (Moncel and Rivals 2011). However, Francolí basin offers a broad diversity of the knappable raw materials (Mosquera et al. 2016; Soto et al. 2018). Of course, the view of two levels shows the Cansaladeta involved reduction of the local raw materials. At least, the results of levels $\mathrm{E}$ and $\mathrm{J}$ point out this inference. Almost complete connection sets, successive flake, and retouch connections are the base of it. Although the results point that $\mathrm{La}$ Cansaladeta would fit more with a base camp than with shortterm settlements, being conclusive on the function of the site would need to finalize the refitting program for the whole archaeological sequence. The final view of each occupation level will play a very big role, regarding the exact function of the site. Additionally, the connection sets were recovered from the base of level $\mathrm{E}$ which seem to be documenting really short occupation, clearly separated from the two main occupation 


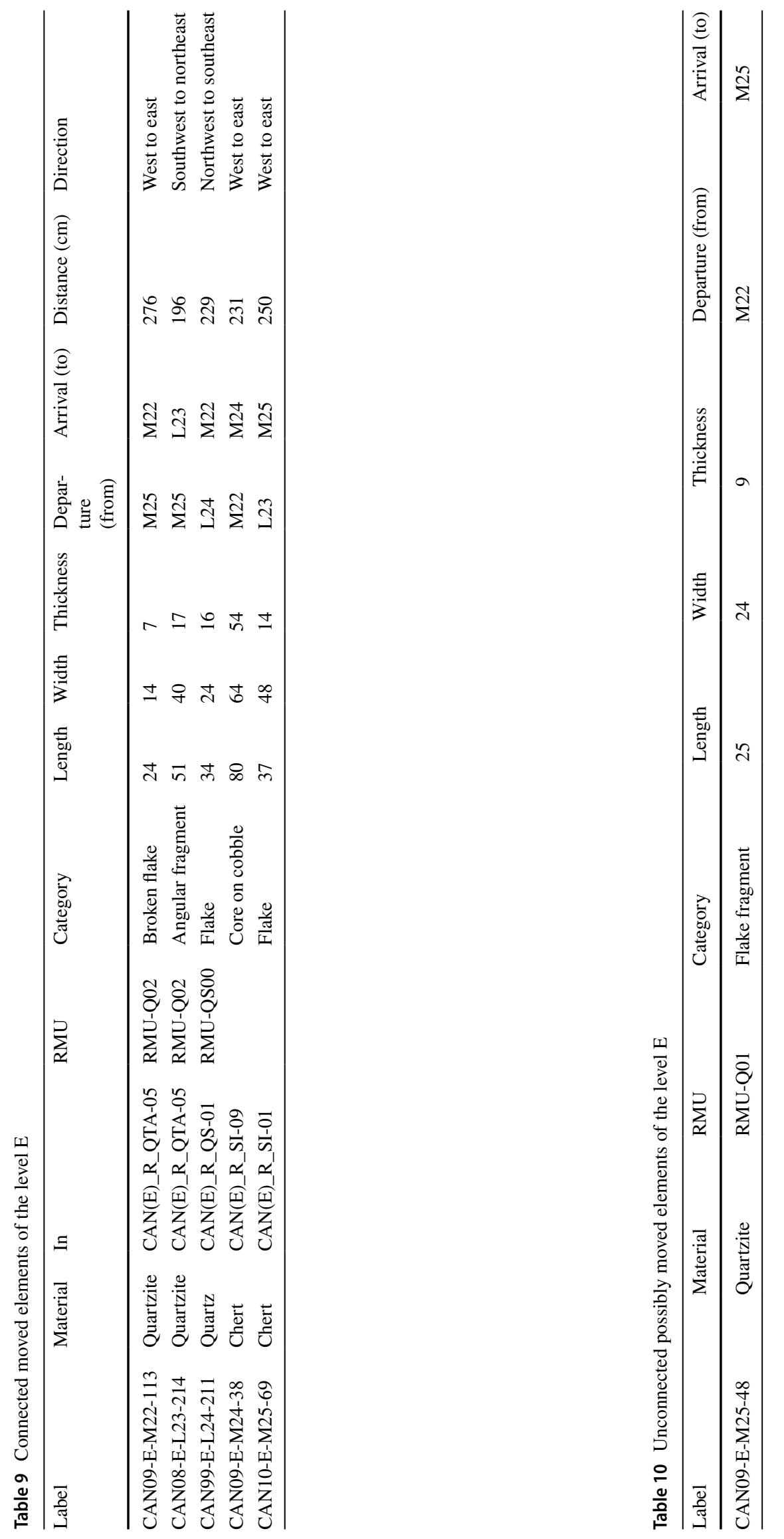


levels, that is, a real snapshot. La Cansaladeta is a site, alternance of structured occupations with more sporadic snapshots.

\section{Final points about the connection success}

The refit ratio is a significant issue that should be clarified. Refitting practice is a very time-consuming method although it is very effective (Cahen et al. 1979). The refit success is related to different variables such as the experience or ability of the person, types of reduction, and the considered dimension of the elements in the refitting program (Laughlin and Kelly 2010, p. 429). Raw material structure is one of the greatest factors that affect the final refitting ratio of the studies. If the major indicator of the materials macroscopically cannot be observed clearly, this issue makes the practice difficult in terms of sorting the raw materials according to color, texture, and pattern on the surface (Roebroeks 1988). As we explained in the "Results" section, the quartzite had more intense ratio than chert due to the raw material quality and the number of samples. The highly patinated chert industry was one of the major negative reasons in our refitting practice. Additionally, the negativity of the patina was discussed and confirmed by one of the recent studies which is related to systematic color reference analysis of the lithic refitting study of Gran Dolina TD10.1 (López-Ortega et al. 2020). In terms of schist, those have very fragile and powdered structure. Even some of the medium- and large-sized flakes cannot be identified regarding the dorsal face and platform corticalities. However, the refitting results of $\mathrm{La}$ Cansaladeta do not represent a low percentage. Additionally, there are still unexcavated areas on the site. Indeed, recovering the archaeological remains from these unexcavated areas is one of the future field responsibilities. The question that must be asked is "Does this limited refit ratio help to answer our research question?" If the answer is "it does," refitting ratio should not be a competitive issue. As we reported in this paper, our refit ratio played a very important role, in terms of interpretation of the spatial analysis and the comparison between two levels. Consequently, the refit ratio of levels $\mathrm{E}$ and $\mathrm{J}$ can be accepted successfully.

\section{Conclusion}

In this study, we tried to find an answer to our research question: "Is a spatial investigation possible without longdistance refit/conjoin connection?" To do it, we analyzed the lithic remains recovered from the levels $E$ and $J$ of La Cansaladeta. The distribution of the lithic elements of each level was studied strongly based on the cluster/density analysis. GIS application was one of the significant study processes for the cluster analysis to see the densities. When the clusters were detected, they have been studied 
Table. 12 Unconnected possibly moved elements of the level J

\begin{tabular}{|c|c|c|c|c|c|c|c|c|}
\hline Label & Material & RMU & Category & Length & Width & Thickness & $\begin{array}{l}\text { Departure } \\
\text { (from) }\end{array}$ & Arrival (to) \\
\hline CAN16-J-L22-164 & Quartzite & RMU-Q03 & Retouch tool & 57 & 26 & 16 & K25 & L22 \\
\hline CAN16-J-L22-50 & Quartzite & RMU-Q06 & Flake & 34 & 37 & 6 & M25 & L22 \\
\hline CAN02-J-K25-332 & Chert & RMU-SI03 & Flake & 78 & 66 & 19 & L22 & $\mathrm{K} 25$ \\
\hline CAN02-J-K25-320 & Chert & RMU-SI04 & Flake & 55 & 107 & 20 & L22 & K25 \\
\hline CAN18-J-M25-97 & Chert & RMU-SI02 & Flake & 69 & 34 & 17 & M25 & $\mathrm{L} 23$ \\
\hline CAN99-J-L24-43 & Chert & RMU-SI02 & Retouch tool & 41 & 33 & 11 & M25 & $\mathrm{L} 24$ \\
\hline CAN99-J-L23-105 & Chert & RMU-SI02 & Flake & 45 & 21 & 13 & M25 & $\mathrm{L} 23$ \\
\hline
\end{tabular}

technologically to understand the relation between the lithic accumulations regarding similarities, contemporaneity, etc. Thus, this method reinforced our study in terms of a lack of long-distance connections which is related to the dimension of the site. The comparison between two levels showed very remarkable differences, in terms of refitting, spatial patterns, and technology. The abundance of successive retouch connections, multiple lithic accumulations, almost no intercluster connection, and the presence of bifacial shaping are the determinative characteristics of J. On the other hand, the presence of single and alternate platform method, bipolar technique on an anvil, and no bifacial elements are the major indicators of E. In addition, the preferential orientations between the two areas show one of the main differences, regarding the spatial patterns in level E. The scarcity and poor preservation of the bone remains limited to a certain extent of behavioral interpretation. However, the identified defleshing cut marks on an unidentifiable flat bone in the previous study are one of the important interpretation sources. In the lights of these results, our research question can be answered positively. Spatial analysis without longdistance refit/conjoin is definitely possible. However, the major case that should be always remembered is the very well preservation of the archaeological levels which is a great opportunity for the Middle Pleistocene rock shelter. The refitting program of La Cansaladeta continues intensively for the other archaeological levels. We propose to apply systematical refitting analysis and to reinforce with the auxiliary methods to the materials of each archaeological level. Particularly, well preservation of the levels, high refit/conjoin success, an identified different short occupation snapshot between the levels E and I, and connection line orientation of the refit/conjoins pushes us to concentrate on an archaeostratigraphy and site formation studies as a further responsibility about La Cansaladeta.

Supplementary Information The online version contains supplementary material available at https://doi.org/10.1007/s12520-021-01384-3.
Acknowledgements We would like to thank all the researchers, students, and participators who studied and worked in La Cansaladeta since the first year of the excavation. Special appreciation goes to Ph.D. Lucía López-Polín for the conservation and restoration of the recovered material, Ph.D. Juan Ignacio Morales for helping and teaching the steps of spatial statistical analysis, Ph.D. Manuel Vaquero for his ideas that related to spatial analysis and refitting, Ph.D. Ester López Ortega for her valuable guidance regarding the lithic connections and spatial analysis, PhD. María Soto for the microscopic description of some of the chert elements, Ph.D. Lena Asryan, Ph.D. students Andión Arteaga, and Diego Lombao Vázquez. La Cansaladeta fieldwork was founded by the Culture Department of Generalitat de Catalunya (Ref. CLT009/18/00024) project. This research has been carried out in the framework of the AGAUR (Ref. 2017SGR1040), the MICINN/ FEDER (Ref. PGC2018-093925-B-C32), and the URV (Ref. 2019PFRURV-91) projects.

Funding Open Access funding provided thanks to the CRUE-CSIC agreement with Springer Nature. The Institut Català de Paleoecologia Humana i Evolució Social (IPHES-CERCA) has received financial support from the Spanish Ministry of Science and Innovation through the "María de Maeztu" program for Units of Excellence (CEX2019-000945-M).

Open Access This article is licensed under a Creative Commons Attribution 4.0 International License, which permits use, sharing, adaptation, distribution and reproduction in any medium or format, as long as you give appropriate credit to the original author(s) and the source, provide a link to the Creative Commons licence, and indicate if changes were made. The images or other third party material in this article are included in the article's Creative Commons licence, unless indicated otherwise in a credit line to the material. If material is not included in the article's Creative Commons licence and your intended use is not permitted by statutory regulation or exceeds the permitted use, you will need to obtain permission directly from the copyright holder. To view a copy of this licence, visit http://creativecommons.org/licenses/by/4.0/.

\section{References}

Abel RL, Parfitt SA, Ashton N et al (2011) Digital preservation and dissemination of ancient lithic technology with modern microCT. Comput Graph 35:878-884

Alperson-Afil N, Goren-Inbar N (2010) The Acheulean site of Gesher Benot Ya'aqov volume II: ancient flames and controlled used of fire, 1st edn. Springer Netherlands 
Alperson-Afil N, Richter D, Goren-Inbar N (2017) Evaluating the intensity of fire at the Acheulian site of Gesher Benot Ya'aqov-Spatial and thermoluminescence analyses. PLoS One 12:e0188091

Alperson-Afil N, Sharon G, Kislev M et al (2009) Spatial organization of hominin activities at Gesher Benot Ya'aqov, Israel. Science 326:1677-1680

Angelucci DE, Cáceres I, Lozano M et al (2004) El jaciment de la Cansaladeta (La Riba, Alt Camp) en el marc del Plistocè mitjà català. Cypsela 15:151-170

Ashton N (2004) The role of refitting in the British Lower Palaeolithic: a time for reflection. In: Walker A, Wenban-Smith F (eds) Lithics in action. Lithic Studies Society Occasional Paper 8. Oxbow Books, Oxford, pp 57-64

Ashton N (2016) The human occupation of Britain during the Hoxnian Interglacial. Quat Int 409:41-53. https://doi.org/10.1016/J. QUAINT.2015.11.055

Ashton N, Lewis S, Parfitt S et al (2005) Excavations at the Lower Palaeolithic site at Elveden, Suffolk, UK. Proc Prehist Soc 71:1-61

Audouze F (1988) Les activités de boucherie à Verberie (Oise). In: Tixier J (ed) Technologie Préhistorique Notes et Monographies Techniques, No. 25, CNRS. Paris, pp 97-111

Audouze F, Cahen D, Keeley LH, Schmider B (1981) Le site magdalénien du Buisson campin à Verberie (Oise). Gallia Préhistoire 24:99-143

Audouze F, Enloe JG (1997) High resolution archaeology at Verberie: limits and interpretations. World Archaeol 29:195-207

Baddeley A, Rubak E, Turner R (2015) Spatial point pattern methodology and application with R. CRC Press

Baddeley A, Turner R (2005) spatstat: an R package for analyzing spatial point patterns. J Stat Softw 12:1-42

Bailey G, Galanidou N (2009) Caves, palimpsests and dwelling spaces: examples from the Upper Palaeolithic of South-East Europe. World Archaeol 41:215-241

Bargalló A, Gabucio MJ, Gómez de Soler B, et al (2020) Rebuilding the daily scenario of Neanderthal settlement. J Archaeol Sci Reports 29:102139

Bargalló A, Gabucio MJ, Rivals F (2016) Puzzling out a palimpsest: testing an interdisciplinary study in level O of Abric Romaní. Quat Int 417:51-65

Bargalló A, Mosquera M, Lorenzo C (2018) Identify the handedness at knapping; an analysis of the scatter pattern of lithic remains. Archaeol Anthropol Sci 587-598

Baxter MJ, Beardah CC, Wright RVS (1997) Some archaeological applications of kernel density estimates. J Archaeol Sci 24:347-354

Benito-Calvo A, de la Torre I (2011) Analysis of orientation patterns in Olduvai Bed I assemblage using GIS techniques: implications for site formation processes. J Hum Evol 61:50-60

Bergman CA, Roberts MB (1988) Flaking technology at the Acheulean site of Boxgrove (West Sussex, England). Rev Archéologique Picardie 1-2:105-113

Bicho N, Cascalheira J (2020) Use of lithic assemblages for the definition of short-term occupations in hunter-gatherer prehistory. In: Cascalheira J, Picin A (eds) Short-term occupations in Paleolithic archaeology definition and interpretation. Springer, pp 19-38

Binford LR (1978) Dimensional analysis of behavior and site structure: learning from an Eskimo hunting stand. Am Antiq 43:330-361

Bodu P (1996) Les chasseurs magdaléniens de Pincevent: quelques aspects de leurs comportements. Lithic Technol 21:48-70

Bradbury AP, Carr PJ (1995) Flake typologies and alternative approaches: an experimental assessment. Lithic Technol 20:100-115

Cahen D, Keeley LH, Van Noten FL (1979) Stone tools, toolkits and human behavior in prehistory. Curr Anthropol 20:661-683
Camarós E, Cueto M, Teira LC et al (2013) Large carnivores as taphonomic agents of space modification: and experimental approach with archaeological implications. J Archaeol Sci 40:1361-1368

Carbonell E, Dolores M, Garcí-Antón, et al (1999) The TD6 level lithic industry from Gran Dolina, Atapuerca (Burgos, Spain): production and use. J Hum Evol 37:653-693

Caron-Laviolette E, Bignon-Lau O, Olive M (2018) (Re)occupation: following a Magdalenian group through three successive occupations at Étiolles. Quat Int 498:12-29

Cerasoni JN (2021) Vectorial application for the illustration of archaeological lithic artefacts using the "Stone Tools Illustrations with Vector Art" (STIVA) Method. PLoS One 16:e0251466

Chacón MG, Bargalló A, Gabucio MJ, et al (2015) Neanderthal behaviors from a spatio-temporal perspective: an interdisciplinary approach to interpret archaeological assemblages. In: Conard NJ, Delagnes A (eds) Settlement dynamics of the Middle Paleolithic and Middle Stone Age. pp 253-294

Clark AE (2016) Time and space in the Middle Paleolithic: spatial structure and occupation dynamics of seven open-air sites. Evol Anthr 25:153-163

Clark AE (2017) From activity areas to occupational histories: new methods to document the formation of spatial structure in hunter-gatherer sites. J Archaeol Method Theory 24:1300-1325

Clark AE (2019) Using spatial context to identify lithic selection behaviors. J Archaeol Sci Reports 24:1014-1022

Close AE (2000) Reconstructing movement in prehistory. J Archaeol Method Theory 7:49-77

Cooper JR, Qiu F (2006) Expediting and standardizing stone artifact refitting using a computerized suitability model. J Archaeol Sci 33:987-998

Connet N, Soriano S, Bertran P, et al (2020) A 400,000 years old milestone of the Acheulian technocomplex in Central-Western France at Londigny (Charente). J Archaeol Sci Reports 30:102225

Cziesla E (1990) On refitting of stone artefacts. In: Cziesla E, Eickhoff S, Arts N, Winter D (eds) The big puzzle: international symposium on refitting stone artefacts. pp 9-44

Cziesla E, Eickhoff S, Arts N, Winter D (eds) (1990) The big puzzle: international symposium on refitting stone artefacts. Studies in Modern Archaeology 1. Holos, Bonn

de la Peña P (2015) The interpretation of bipolar knapping in African stone age studies. Curr Anthropol 56:911-923. https://doi.org/ $10.1086 / 684071$

de la Torre I, Benito-Calvo A (2013) Application of GIS methods to retrieve orientation patterns from imagery; a case study from beds I and II, Olduvai Gorge (Tanzania). J Archaeol Sci 40:2446-2457

de la Torre I, Mora R, Arroyo A, Benito-Calvo A (2014) Acheaulean technological behaviour in the Middle Pleistocene landscape of Mieso (East-Central Ethiopia). J Hum Evol 76:1-25

de la Torre I, Vanwezer N, Benito-Calvo A et al (2019) Spatial and orientation patterns of experimental stone tool refits. Archaeol Anthropol Sci 11:4569-4584

de la Torre I, Wehr K (2018) Site formation processes of the early Acheulean assemblage at EF-HR (Olduvai Gorge, Tanzania). J Hum Evol 120:298-328

de Lombera-Hermida A, Rodríguez-Álvarez XP, Peña L et al (2016) The lithic assemblage from Pont-de-Lavaud (Indre, France) and the role of the bipolar-on-anvil technique in the Lower and Early Middle Pleistocene technology. J Anthropol Archaeol 41:159184. https://doi.org/10.1016/j.jaa.2015.12.002

Delpiano D, Cocilova A, Zangrossi F, Peresani M (2019) Potentialities of the virtual analysis of lithic refitting: case studies from the Middle and Upper Paleolithic. Archaeol Anthropol Sci 11:4467-4489 
Delpiano D, Peresani M, Pastoors A (2017) The contribution of 3D visual technology to the study of Palaeolithic knapped stones based on refitting. Digit Appl Archaeol Cult Herit 4:28-38. https://doi. org/10.1016/j.daach.2017.02.002

Deschamps M, Zilhão J (2018) Assessing the site formation and assemblage integrity through stone refitting at Gruta da Oliveira (Almando karst system, Torres Novas, Portugal): A Middle Paleolithic case study. PLoS One 13:e192423

Dibble HL, Schurmans UA, Iovita RP, McLaughlin MV (2005) The measurement and interpretation of cortex in lithic assemblages. Am Antiq 70:545-560

Domínguez-Rodrigo M, Cobo-Sánchez L (2017) The spatial patterning of the social organization of modern foraging Homo sapiens: a methodological approach for understanding social organization in prehistoric foragers. Palaeogeogr Palaeoclimatol Palaeoecol 488:113-125

Driscoll K, Alcaina J, Égüez N et al (2016) Trampled underfoot: a quartz and chert human trampling experiment at the Cova del Padro rock shelter, Spain. Quat Int 424:130-142

Enloe JG (2010) Refitting bones: negative evidence, site structure and social organization. Lithic Technol 35:63-71

Enloe JG, David F (1992) Food sharing in the Paleolithic: carcass refitting at Pincevent. In: Hofman JL, Enloe J (eds) Piecing together the past: the application of refitting studies in archaeology. BAR International Series 578, Archaeopress, Oxford, pp 296-315

Eren MI, Durant A, Neudorf C et al (2010) Experimental examination of animal trampling effects on artifact movement in dry and water saturated substrates: a test case from South India. J Archaeol Sci 37:3010-3021. https://doi.org/10.1016/j.jas.2010.06.024

Fernández-Laso MC, Rosell J, Blasco R, Vaquero M (2020) Refitting bones: spatial relationships between activity areas at the Abrci Romaní level M (Barcelona, Spain). J Archaeol Sci Reports 29:102188

Gallotti R, Lembo G, Peretto C (2012) Mapping three-dimensional density patterns for analyzing artefact (re)distribution in Palaeolithic sites. Adv Anthropol 2:39-48

Gopher A, Parush Y, Barkai R (2016) Spatial aspects as seen from a density analysis of lithics at Middle Pleistocene Qesem cave: preliminary results and observations. Quat Int 398:103-117

Hammond G, Hammond N (1981) Child's play: a distorting factor in archaeological distribution. Am Antiq 46:634-636

Herzog I, Yépez A (2013) Least-cost kernel density estimation and interpolation-based density analysis applied to survey data. In: Contreras F, Farjas M, Melero FJ (eds) CAA 2010: fusion of cultures: proceedings of the 38th annual conference on computer application and quantitative methods in archaeology, Granada, Spain, April 2010. BAR International Series 2494, Archaeopress, Oxford, pp 367-374

Hofman JL (1986) Vertical movement of artifacts in alluvial and stratified deposits. Curr Anthropol 27:163-171

Hofman JL, Enloe JG (eds) (1992) Piecing together the past: application of refitting studies in archaeology. BAR International Series 578, Archaeopress, Oxford

Karlin C, Julien M (2019) An autumn at Pincevent (Seine-et-Marne, France): refitting for an ethnographic approach of a Magdalenian settlement. Archaeol Anthropol Sci 11:4437-4465. https://doi.org/10.1007/s12520-019-00860-1

Kvamme KL (1997) Patterns and models of debitage dispersal in percussion flaking. Lithic Technol 22:122-138

Lancelotti C, Pérez Negre J, Alcaina-Mateos J, Carrer F (2017) Intrasite spatial analysis in ethnoarchaeology. Environ Archaeol 22:354-364

Langley MC (2020) Space to play: identifying children's sites in the Pleistocene archaeological record. Evol Hum Sci 2:e41

Larson ML, Ingbar EE (1992) Perspectives on refitting: critique and a complementary approach. In: Hofman JL, Enloe JG (eds)
Piecing together the past: the application of refitting studies in archaeology. BAR International Series 578, Archaeopress, Oxford, pp 151-162

Laughlin JP, Kelly RL (2010) Experimental analysis of the practical limits of lithic refitting. J Archaeol Sci 37:427-433. https://doi. org/10.1016/j.jas.2009.10.007

Leroi-Gourhan A, Brézillon MN (1966) L'habitation magdalénienne $\mathrm{n}^{\circ} 1$ de Pincevent près Monterau (Seine-et-Marne). Gall Préhistoire 9:263-385. https://doi.org/10.3406/galip.1966.1264

López-Ortega E, Rodríguez XP, Vaquero M (2011) Lithic refitting and movement connections: the NW area of level TD10-1 at the Gran Dolina site (Sierra de Atapuerca, Burgos, Spain). J Archaeol Sci 38:3112-3121. https://doi.org/10.1016/j.jas. 2011.07.011

López-Ortega E, Bargalló A, de Lombera-Hermida A et al (2017) Quartz and quartzite refits at Gran Dolina (Sierra de Atapuerca, Burgos): connecting lithic artefacts in the Middle Pleistocene unit of TD10.1. Quat Int 433:85-108

López-Ortega E, Rodríguez-Álvarez XP, Ollé A, Lozano S (2019) Lithic refits as a tool to reinforce postdepositional analysis. Archaeol Anthropol Sci 11:4555-4568. https://doi.org/10. 1007/s12520-019-00808-5

López-Ortega E, Morales JI, Ollé A, Rodríguez-Álvarez XP (2020) Avoiding the blue and black/white and gold argument: an automated colour reference system applied to lithic refit processes. J Archaeol Method Theory 27:245-270

Machado J, Hernández CM, Mallol C, Galván B (2013) Lithic production, site formation and Middle Paleolithic palimpsest analysis: in search of human occupation at Abric del Pastor stratigraphic unit IV (Alicante, Spain). J Archaeol Sicence 40:2254-2273

Marean CW, Kim SY (1998) Mousterian large-mammal remains from Kobeh Cave behavioral implications for Neanderthals and early modern humans. Curr Anthropol 39:79-113

Marwick B, Hayes E, Clarkson C, Fullagar R (2017) Movement of lithics by trampling: an experiment in the Madjedbebe sediments, northern Australia. J Archaeol Sci 79:73-85

Mauldin R, Amick DS (1989) Investigating patterning in debitage from experimental bifacial core reduction. In: Amick DS, Mauldin R (eds) Experiments in lithic technology. BAR International Series, vol 528. Oxford, pp 67-88

Mcnabb J (2007) The British Lower Palaeolithic stones in contention. Routledge, Abingdon \& New York

McPherron SJP (2005) Artifact orientations and site formation processes from total station proveniences. J Archaeol Sci $1003-1014$

Moncel MH, Rivals F (2011) On the question of short-term Neanderthal site occupations: Payre, France (MIS 7-8), Taubach/ Weimar, Germany (MIS 5). J Anthropol Res 67:47-75

Moncel MH, Ashton N, Lamotte A et al (2015) The Early Acheulian of north-western Europe. J Anthropol Archaeol 40:302-331. https://doi.org/10.1016/j.jaa.2015.09.005

Moncel MH, Chacón MG, Vettese D et al (2021) Late Neanderthal short-term and specialized occupations at the Abri du Maras (South-East France, level 4.1, MIS 3). Archaeol Anthropol Sci 13:45

Moon K-W (2016) Learn ggplot2 using shiny app, 1st edn. Springer International Publishing

Morrow TM (1996) Lithic refitting and archaeological site formation processes. A case study from the Twin Ditch Site, Greene County, Illinois. In: Odell GH (ed) Stone tools theoretical insights into human prehistory. Plenum Press, New York, pp 345-373

Mosquera M, Ollé A, Saladie P et al (2016) The Early Acheulean technology of Barranc de la Boella (Catalonia, Spain). Quat International 393:95-111 
Mouhoubi Y (2012) Stratigraphie géomorphologie fluviale du site de Cansaladeta, La Riba, Alt Camp, Catalogne, Espagne. Master thesis. Department d'Història i Història de l'Art. Universitat Rovira i Virgili

Newcomer MH, de Sieveking G, G, (1980) Experimental flake scatter-patterns: a new interpretative technique. J F Archaeol $7: 345-352$

Nielsen AE (1991) Trampling the archaeological record: an experimental study. Am Antiq 56:483-503. https://doi.org/10.2307/280897

O'Brien M (2015) Evaluating the contemporaneity of households at the Eden-Farson site. Int J Osteoarchaeol 25:653-664

O'Connell JF, Hawkes K, Jones NB (1991) Distribution of refuseproducing activities at Hadza residential base camps. Implications for analyses of archaeological site structure. In: Kroll EM, Price TD (eds) The interpretation of archaeological spatial patterning. Plenum, New York, pp 61-76

Olive M (1988) Une habitation magdalénienne d'Étiolles: 1'Unité P 15. Société préhistorique française (Mémoires $n^{\circ} 20$ ), Paris

Ollé A, Mosquera M, Rodríguez XP et al (2013) The Early and Middle Pleistocene technological record from Sierra de Atapuerca (Burgos, Spain). Quat Int 295:138-167. https://doi.org/ 10.1016/J.QUAINT.2011.11.009

Ollé A, Vergès JM, Rodríguez-Álvarez XP et al (2016) The Middle Pleistocene site of La Cansaladeta (Tarragona, Spain): stratigraphic and archaeological succession. Quat Int 393:137-157. https://doi.org/10.1016/j.quaint.2015.08.053

Olive M, Pigeot N, Bignon-Lau O (2019) Un campement magdalénien à Étiolles (Essonne) Des activités à la microsociologie d'un habitat. Gall Préhistoire 59:47-108

Pigeot N (1987) Magdaléniens d'Étiolles. Économie de Débitage et organisation sociale (l'unite d'habitation U5). Éditions du CNRS XXVe supplément à Gallia Préhistoire, Paris

Pope M, Parfitt S, Roberts M (2020) The Horse Butchery Site: a high resolution record of Lower Palaeolithic hominin behaviour at Boxgrove. SpoilHeap Publications, UK

Pope M, Roberts M (2005) Observations on the relationship between Palaeolithic individuals and artefact scatters at the Middle Pleistocene site of Boxgrove, UK. In: Gamble C, Porr M (eds) The hominid individual in context archaeological investigations of Lower and Middle Palaeolithic landscapes, locales and artefacts. Taylor \& Francis, pp 81-97

Rapson DJ, Todd LC (1992) Conjoins, contemporaneity, and site structure: distributional analyses of the Burgas-Holding site. In: Piecing together the past: the application of refitting studies in archaeology. BAR International Series 578, Archaeopress, Oxford, pp 238-263

Roberts MB, Parfitt SA (1999) Boxgrove: a Middle Pleistocene hominid site at Eartham Quarry, Boxgrove, West Sussex. English Heritage, London

Roebroeks W (1988) From find scatters to early hominid behaviour: a study of Middle Palaeolithic riverside settlements at MaastrichtBelvédère (the Netherlands). In: Analecta Praehistorica Leidensia, vol 21. University of Leiden, Leiden

Romagnoli F, Vaquero M (2019) The challenges of applying refitting analysis in the Palaeolithic archaeology of the twentyfirst century: an actualised overview and future perspectives. Archaeol Anthropol Sci 11:4387-4396. https://doi.org/10.1007/ s12520-019-00888-3

Rosell J, Modesto-Mata M, Fernández-Laso MC et al (2019) Refitting bones to reconstruct the diversity in Middle Palaeolithic human occupations: the case of the Abric Romaní (Capellades, Barcelona, Spain). Archaeol Anthropol Sci 11:4601-4619

Sánchez-Romero L, Benito-Calvo A, Marín-Arroyo AB et al (2020) New insights for understanding spatial patterning and formation processes of the Neanderthal occupation in the Amalda I cave (Gipuzkoa, Spain). Sci Rep 10:8733
Sánchez-Romero L, Benito-Calvo A, Pérez-González A, Santonja M (2016) Assessment of accumulation processes at the Middle Pleistocene site of Ambrona (Soria, Spain). Density and orientation patterns in spatial datasets derived from excavations conducted from the 1960s to the present. PLoS One 11:e0167595

Sánchez-Romero L, Benito-Calvo A, Rios-Garaizar J (2021) Defining and characterising clusters in Paleolithic sites: a review of methods and constraints. J Archaeol Method Theory

Sañudo P, Blasco R, Fernández Peris J (2016) Site formation dynamics and human occupations at Bolomor Cave (Valencia, Spain): an archaeostratigraphic analysis of levels I to XII (100-200 ka). Quat Int 417:94-104. https://doi.org/10.1016/j.quaint.2015.09. 044

Schiffer MB (1972) Archaeological context and systemic context. Am Antiq 37:156-165

Schoville BJ (2019) Experimental lithic tool displacement due to longterm animal disturbance. Archaeol Anthropol Sci 11:5879-5891

Schurmans UA (2007) Refitting in the old and new worlds. In: Schurmans UA, De Bie M (eds) Fitting rocks: lithic refitting examined. BAR International Series 1596, Archaeopress, Oxford, pp 7-23

Siret L (1933) Le Coup de burin moustérien. Bull La Société Préhistorique Française 30-2:120-127. https://doi.org/10.3406/bspf. 1933.12126

Sisk ML, Shea JJ (2008) Intrasite spatial variation of the Omo Kibish Middle Stone Age assemblages: artifact refitting and distribution patterns. J Hum Evol 55:486-500

Smith WG (1894) Man, the primeval savage. Edward Stanford, London

Soto M, Gómez de Soler B, Vallverdú J, Vaquero M (2014) Potential siliceous sources during prehistory: results of prospecting in the East margin of the Ebro basin (NE Iberian Peninsula). J Lithic Stud 1:293-318

Soto M, Gómez de Soler B, Vallverdú J (2018) The chert abundance ratio (CAR): a new parameter for interpreting Palaeolithic raw material procurement. Archaeol Anthropol Sci 10:2027-2046

Spurrell FCJ (1880) On implements and chips from the floor of a Palæolithic workshop. Archaeol J 37:294-299. https://doi.org/ 10.1080/00665983.1880.10851939

Stackelbeck KL (2010) Maximizing the research potential of refit analysis without replicating Pincevent: a case study from the Big Eddy Site in Southwest Missouri. Lithic Technol 35:37-62. https://doi.org/10.1080/01977261.2010.11721082

Stevenson MG (1991) Beyond the formation of hearth-associated artifact assemblages. In: Kroll EM, Price TD (eds) The interpretation of archaeological spatial patterning. Plenum, New York, pp 269-299

Takakura J (2018) Lithic refitting and its implication for the integrity and duration of site occupation: the case of the Late Upper Paleolithic site of Kiusu-5 in Hokkaido, Northern Japan. Quat Int 474:156-167

Theunissen R, Balme J, Beck W (1998) Headroom and human trampling: cave ceiling-height determines the spatial patterning of stone artefacts at Petzkes Cave, northern New South Wales. Antiquity 72:80-89

Vandendriessche H, Crombé P (2020) Formalized reduction sequences from the site of Kerkhove, Belgium - new perspectives on Early Mesolithic flint knapping. Lithic Technol 45:110-124

Vaquero M (2008) The history of stones: behavioural inferences and temporal resolution of an archaeological assemblage from the Middle Paleolithic. J Archaeol Sci 35:3178-3185

Vaquero M (2011) New perspectives on recycling of the lithic resources using refitting and spatial data. Neue Nachweismöglichkeiten der Wiederverwendung von lithischem Rohmaterial mittels Zusammensetzungen und räumlicher Verteilung. Quartär 58:113-130

Vaquero M, Chacón MG, Cuartero F, et al (2012) The lithic assemblage of level J. In: Carbonell i Roura E (ed) High resolution 
archaeology and Neanderthal behavior time and space in level J of Abric Romaní (Capellades, Spain). Springer, pp 189-311

Vaquero M, Fernández-Laso MC, Chacón MG et al (2017) Moving things: comparing lithic and bone refits from a Middle Paleolithic site. J Anthropol Archaeol 48:262-280. https://doi.org/10.1016/j. jaa.2017.09.001

Vaquero M, Romagnoli F, Bargalló A et al (2019) Lithic refitting and intrasite artifact transport: a view from the Middle Paleolithic. Archaeol Anthropol Sci 11:4491-4513

Vergès JM, Ollé A (2011) Technical microwear and residues in identifying bipolar knapping on an anvil: experimental data. J Archaeol Sci 38:1016-1025. https://doi.org/10.1016/j.jas.2010.11.016

Villa P (1982) Conjoinable pieces and site formation processes. Am Antiq 47:276-290. https://doi.org/10.2307/279901
Villa P, Courtin J (1983) The interpretation of stratified sites: a view from underground. J Archaeol Sci 10:267-281. https://doi.org/ 10.1016/0305-4403(83)90011-0

Waguespack NM (2002) Caribou sharing and storage: refitting the Palangana site. J Anthropol Archaeol 21:396-417

Wickham H (2009) ggplot2-elegant graphics for data analysis, 1st edn. Springer-Verlag, New York

Wilson DC (1994) Identification and assessment of secondary refuse aggregates. J Archaeol Method Theory 1:41-68

Publisher's note Springer Nature remains neutral with regard to jurisdictional claims in published maps and institutional affiliations. 